IVAN PARREIRAS DE CARVALHO JUNIOR

\title{
ESTUDO DA UTILIZAÇÃO DE ENERGIA DE MICROONDAS NA REDUÇÃO DE MINÉRIO DE FERRO POR CARBONO NA FORMA DE PELOTAS AUTO-REDUTORAS
}

Dissertação apresentada à Escola Politécnica da Universidade de São Paulo para obtenção do título de Mestre em Engenharia. 


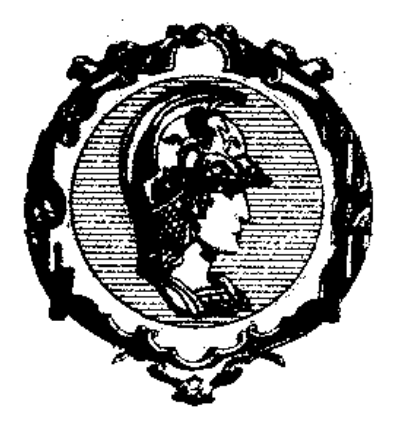

Dissertação apresentada à Escola Politécnica da Universidade de São Paulo para obtenção do título de Mestre em Engenharia.

Área de Concentração:

Engenharia Metalúrgica

Orientador:

Prof. Dr. Marcelo Breda Mourão 
Dedicado a :

Meu pai, Ivan Parreiras de Carvalho Minha mãe, Maria José Gonçalves Minha avó, Anna Parreira de Carvalho 


\section{$\underline{\text { Agradecimentos }}$}

À minha família, pelo apoio e carinho durante toda minha vida.

Ao Prof. Dr. Marcelo Breda Mourão pela orientação e incentivo na execução deste trabalho.

Ao Engenheiro Metalurgista Dener Martins dos Santos, ao Prof. Dr. Cyro Takano e ao Dr. Ramiro C. Nascimento pela ajuda cotidiana e pelas discussões sobre o tema envolvido nesta pesquisa.

À CAPES - Coordenação de Aperfeiçoamento de Pessoal de Nível Superior - por financiar minha formação teórica.

À FAPESP - Fundação de Amparo à Pesquisa do Estado de São Paulo pelo projeto de auxílio à pesquisa 98/10581-9.

À Escola Politécnica da USP e a todos os professores(as) que desde a graduação fizeram parte de minha formação acadêmica.

Aos funcionários do laboratório Danilo e Márcia pela ajuda experimental.

$\mathrm{E}$, finalmente, a todos que, direta ou indiretamente, colaboraram para a realização deste trabalho . 


\section{SUMÁRIO}

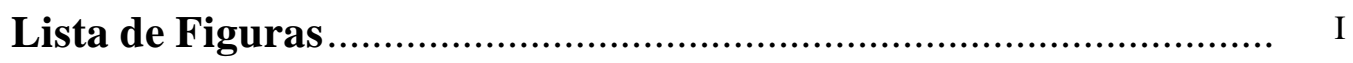

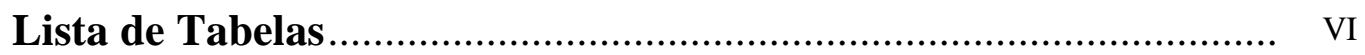

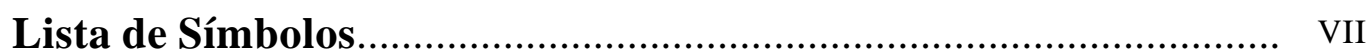

Resumo

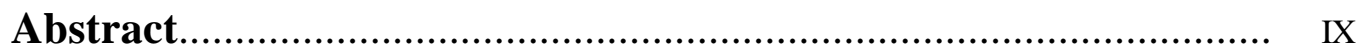

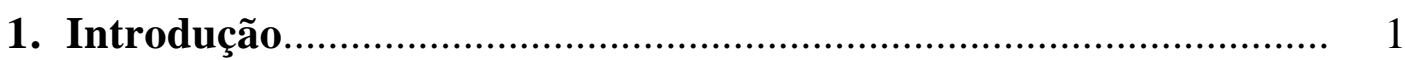

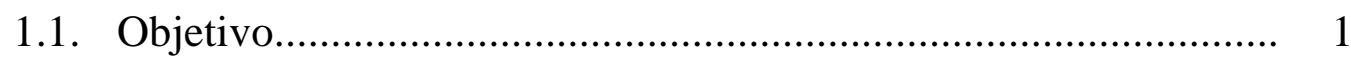

1.2. Justificativa............................................................................. 1

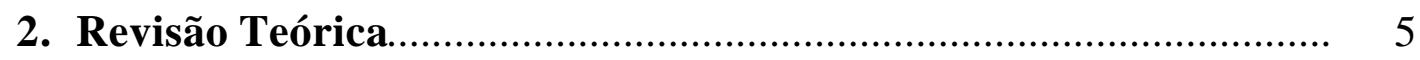

2.1. Redução de Óxido de Ferro por Carbono....................................... 5

2.2. Ondas de Alta Freqüência............................................................ 15

2.2.1. Definições.................................................................. 15

2.2.2. Microondas.................................................................... 17

2.2.2.1. Condução de Energia de Microondas................ 19

2.2.2.2. O Magnetron................................................... 21

2.2.3. Aquecimento por Ondas de Alta Frequiência................... 23

2.2.3.1. Aquecimento Dielétrico.................................... 23

2.2.3.2. Aquecimento por Microondas............................ 26

2.2.4. Parâmetros Dielétricos.................................................... 28

2.2.4.1. Perdas Magnéticas............................................ 31

2.2.4.2. Penetração do Campo Eletromagnético............. 32

2.2.5. Equipamento de Microondas............................................ 34

2.3. Trabalhos com a Utilização da Energia de Microondas................ 36

3. Materiais e Métodos.........................................................................

3.1. Materiais Utilizados.................................................................. 44 


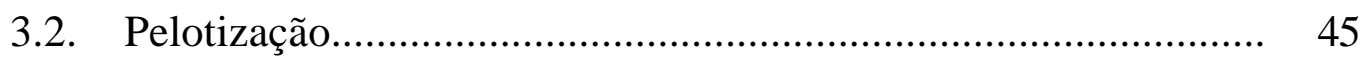

3.3. Composição das Pelotas.............................................................. 46

3.4. Ensaios Termogravimétricos....................................................... 48

4. Resultados e Discussões............................................................. 52

4.1. Termogravimetria em Forno de Resistência................................ 52

4.2. Termogravimetria em Forno de Microondas................................. 54

4.3. Análise das Variáveis de Processo............................................... 60

4.3.1. Influência da Presença de Aglomerante............................ 60

4.3.2. Influência da Quantidade de Agente Redutor.................... 61

4.3.3. Influência da Granulometria do Agente Redutor............... 63

4.3.4. Influência do Tipo de Agente Redutor............................... 65

4.3.5. Influência do Isolamento Térmico da Amostra.................. 66

4.4. Análise Cinética.......................................................................... 68

4.5. Análise Microscópica................................................................... 70

4.6. Análise por Difratometria de Raios-X......................................... 80

4.7. Comparações dos Resultados ...................................................... 84

4.8. Pré-tratamento do Minério de Ferro por Irradiação de Microondas.......................................................................... 92

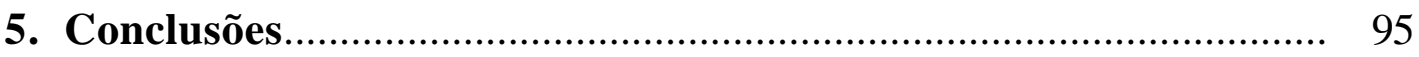

6. Referências Bibliográficas ............................................................ 98 


\section{Lista de Figuras}

Figura 1: Esquema da redução de wustita $(\mathrm{FeO})$ para ferro metálico......... 6

Figura 2: Propagação de uma onda eletromagnética................................ 15

Figura 3: Interação das microondas com diferentes materiais.................. 18

Figura 4: Campo no interior de um duto retangular............................... 19

Figura 5: Esquema de um "magnetron"simples.................................. 21

Figura 6: Padrões de aquecimento em forno convencional e de microondas.

Figura 7: Variação da temperatura $\left({ }^{\circ} \mathrm{C}\right)$ em função do tempo de exposição à irradiação por microondas $(900 \mathrm{~W}-2450 \mathrm{MHz})$

Figura 8: Variação da temperatura em função do tempo de exposição à irradiação por microondas, em dois pontos distintos da cavidade do forno

Figura 9: Fotografia do misturador Turbula utilizado para a homogeneização da mistura a ser pelotizada.

Figura 10: Esquema do forno de microondas utilizado nos ensaios termogravimétricos.

Figura 11: Esquema do forno de resistência utilizado nos ensaios termogravimétricos.

Figura 12: Foto do forno de resistência utilizado nos ensaios termogravimétricos

Figura 13: Porcentagem de reação em função do tempo, a $1150{ }^{\circ} \mathrm{C}$, de várias composições de pelotas (tabela 10), em forno de resistência.

Figura 14: Porcentagem de reação em função do tempo, a $950{ }^{\circ} \mathrm{C}$, de várias composições de pelotas (tabela 10), em forno de resistência. 
Figura 15: Porcentagem de Reação $(\%)$ e Temperatura $\left({ }^{\circ} \mathrm{C}\right)$ em função do Tempo (min) para as pelotas $\mathrm{A}$ (coque; $\mathrm{C} / \mathrm{O}=1,0$; sem cimento).

Figura 16: Porcentagem de Reação (\%) e Temperatura $\left({ }^{\circ} \mathrm{C}\right)$ em função do Tempo (min) para as pelotas B (coque; $\mathrm{C} / \mathrm{O}=1,0$; com cimento)

Figura 17: Porcentagem de Reação $(\%)$ e Temperatura $\left({ }^{\circ} \mathrm{C}\right)$ em função do Tempo (min) para as pelotas $\mathrm{C}$ (coque; $\mathrm{C} / \mathrm{O}=1,33$; com cimento)

Figura 18: Porcentagem de Reação (\%) e Temperatura $\left({ }^{\circ} \mathrm{C}\right)$ em função do Tempo (min) para as pelotas D (coque "grosso"; $\mathrm{C} / \mathrm{O}=1,33$; com cimento) 56

Figura 19: Porcentagem de Reação (\%) e Temperatura $\left({ }^{\circ} \mathrm{C}\right)$ em Função do Tempo (min) para as pelotas D isol. (coque "grosso"; $\mathrm{C} / \mathrm{O}=1,33$; com cimento e isolamento térmico).

Figura 20: Porcentagem de Reação (\%) e Temperatura $\left({ }^{\circ} \mathrm{C}\right)$ em Função do Tempo (min) para as pelotas E (carvão vegetal; $\mathrm{C} / \mathrm{O}=1,0 ;$ com cimento)

Figura 21: Porcentagem de Reação $(\%)$ e Temperatura $\left({ }^{\circ} \mathrm{C}\right)$ em função do Tempo (min) para as pelotas $\mathrm{E}$ isol. (carvão vegetal; $\mathrm{C} / \mathrm{O}=1,0 ;$ com cimento e isolamento térmico).

Figura 22: Porcentagem de Reação $(\%)$ e Temperatura $\left({ }^{\circ} \mathrm{C}\right)$ em função do Tempo (min) para as pelotas F (carvão vegetal;

$\mathrm{C} / \mathrm{O}=1,33$; com cimento)

Figura 23: Porcentagem de Reação $(\%)$ e Temperatura $\left({ }^{\circ} \mathrm{C}\right)$ em função do Tempo (min) para as pelotas $\mathrm{F}$ isol. (carvão vegetal; $\mathrm{C} / \mathrm{O}=1,33$; com cimento e isolamento térmico)

Figura 24: Porcentagem de reação em função do tempo para as pelotas A e B, analisando o efeito da presença do aglomerante, cimento Portland ARI.

Figura 25: Porcentagem de reação em função do tempo para as pelotas $\mathrm{B}$ e $\mathrm{C}$, analisando o efeito da quantidade do agente redutor - moinha de coque.

Figura 26: Porcentagem de reação em função do tempo para as 
pelotas E e F, analisando o efeito da quantidade do agente redutor - carvão vegetal.

Figura 27: Porcentagem de reação em função do tempo para as pelotas $\mathrm{C}$ e $\mathrm{D}$, analisando o efeito da granulometria do agente redutor - moinha de coque.

Figura 28: Porcentagem de reação em função do tempo para as pelotas B e E, analisando o efeito do tipo de agente redutor empregado (moinha de coque $\mathrm{X}$ carvão vegetal).

Figura 29: Porcentagem de reação em função do tempo para as pelotas D e D isol., analisando o efeito do isolamento térmico.

Figura 30: Porcentagem de reação em função do tempo para as pelotas E e E isol., analisando o efeito do isolamento térmico.

Figura 31: Porcentagem de reação em função do tempo para as pelotas $\mathrm{F}$ e $\mathrm{F}$ isol., analisando o efeito do isolamento térmico.

Figura 32: Porcentagem de redução em função da raiz quadrada do tempo de exposição à microondas (modelo parabólico), para as pelotas "C"e"D"

Figura 33: Microscopia eletrônica de varredura de pelota tipo A exposta 30 minutos à irradiação por microondas; $42 \%$ de redução; aumento de $200 \mathrm{X}$

Figura 34: Microscopia eletrônica de varredura de pelota tipo B exposta 30 minutos à irradiação por microondas; 74\% de redução; aumento de $200 \mathrm{X}$.

Figura 35: Microscopia eletrônica de varredura de pelota tipo C exposta 30 minutos à irradiação por microondas; $81 \%$ de redução; aumento de $200 \mathrm{X}$.

Figura 36: Microscopia eletrônica de varredura de pelota tipo D exposta 30 minutos à irradiação por microondas; $84 \%$ de redução; aumento de $200 \mathrm{X}$

Figura 37: Microscopia eletrônica de varredura de pelota tipo E exposta 30 minutos à irradiação por microondas; $90 \%$ de redução;

(A) aumento de $500 \mathrm{X}$, (B) aumento de $200 \mathrm{X}$

Figura 38: Análise EDS realizada na pelota tipo E, na região 
marcada da figura $37(\mathrm{~A})$

Figura 39: Microscopia eletrônica de varredura de pelota tipo D, isolada termicamente, exposta 8 minutos à irradiação por microondas; $61 \%$ de redução; aumento de $200 \mathrm{X}$

Figura 40: Microscopia eletrônica de varredura de pelota tipo E, isolada termicamente, exposta 15 minutos à irradiação por microondas; 92 \% de redução; aumento de $500 \mathrm{X}$

Figura 41: Microscopia eletrônica de varredura de pelota tipo B exposta 15 minutos à irradiação por microondas; 61 \% de redução; aumento de $500 \mathrm{X}$

Figura 42: Análise EDS realizada na pelota tipo B, na região marcada da figura 41

Figura 43: Microscopia eletrônica de varredura de pelota tipo $\mathrm{C}$ exposta 8 minutos à irradiação por microondas; $48 \%$ de redução; aumento de $400 \mathrm{X}$

Figura 44: Análise EDS realizada na pelota tipo C na região marcada da figura 43.

Figura 45: Microscopia eletrônica de varredura de pelota tipo D exposta 8 minutos à irradiação por microondas; $60 \%$ de redução; aumento de $200 \mathrm{X}$

Figura 46: Análise EDS realizada na pelota tipo D, na região marcada da figura 45 .

Figura 47: Difratograma de raios- $X$ de uma pelota $C$ (coque; $\mathrm{C} / \mathrm{O}=1,33$; com cimento) ensaiada em forno de microondas por 8 min., $48 \%$ de redução.

Figura 48: Difratograma de raios-X de uma pelota $\mathrm{E}$ (carvão vegetal; $\mathrm{C} / \mathrm{O}=1,0$; com cimento) ensaiada em forno de microondas por 30 min., $90 \%$ de redução.

Figura 49: Difratograma de raios- $X$ de uma pelota $E$ (carvão vegetal; $\mathrm{C} / \mathrm{O}=1,0$; com cimento) ensaiada em forno de resistência a $1150{ }^{\circ} \mathrm{C}$.

Figura 50: Ensaios termogravimétricos, porcentagem de reação $\mathrm{X}$ tempo ( $\mathrm{min})$, da pelota tipo A, realizado em forno de resistência 
a $1150{ }^{\circ} \mathrm{C}, 950{ }^{\circ} \mathrm{C}$ e em forno de microondas

Figura 51: Ensaios termogravimétricos, porcentagem de reação $\mathrm{X}$ tempo ( $\mathrm{min}$ ), da pelota tipo $\mathrm{B}$, realizado em forno de resistência a $1150{ }^{\circ} \mathrm{C}, 950{ }^{\circ} \mathrm{C}$ e em forno de microondas

Figura 52: Ensaios termogravimétricos, porcentagem de reação $\mathrm{X}$ tempo ( $\mathrm{min}$ ), da pelota tipo $\mathrm{C}$, realizado em forno de resistência a $1150{ }^{\circ} \mathrm{C}, 950{ }^{\circ} \mathrm{C}$ e em forno de microondas.

Figura 53: Ensaios termogravimétricos, porcentagem de reação $\mathrm{X}$ tempo ( $\mathrm{min}$ ), da pelota tipo $\mathrm{D}$, realizado em forno de resistência a $1150{ }^{\circ} \mathrm{C}, 950{ }^{\circ} \mathrm{C}$ e em forno de microondas.

Figura 54: Ensaios termogravimétricos, porcentagem de reação $\mathrm{X}$ tempo ( $\mathrm{min}$ ), da pelota tipo $\mathrm{E}$, realizado em forno de resistência a $1150{ }^{\circ} \mathrm{C}, 950{ }^{\circ} \mathrm{C}$ e em forno de microondas

Figura 55: Ensaios termogravimétricos, porcentagem de reação $\mathrm{X}$ tempo(min), da pelota tipo $\mathrm{F}$, realizado em forno de resistência a $1150{ }^{\circ} \mathrm{C}, 950{ }^{\circ} \mathrm{C}$ e em forno de microondas

Figura 56: Ensaios termogravimétricos, porcentagem de reação $\mathrm{X}$ tempo(min), da pelota tipo $\mathrm{D}$, isolada termicamente, realizado em forno de resistência a $1150{ }^{\circ} \mathrm{C}, 950{ }^{\circ} \mathrm{C}$ e em forno de microondas

Figura 57: Ensaios termogravimétricos, porcentagem de reação $\mathrm{X}$ tempo(min), da pelota tipo $\mathrm{E}$, isolada termicamente, realizado em forno de resistência a $1150{ }^{\circ} \mathrm{C}, 950{ }^{\circ} \mathrm{C}$ e em forno de microondas

Figura 58: Ensaios termogravimétricos, porcentagem de reação $\mathrm{X}$ tempo(min), da pelota tipo $\mathrm{F}$, isolada termicamente, realizado em forno de resistência a $1150{ }^{\circ} \mathrm{C}, 950{ }^{\circ} \mathrm{C}$ e em forno de microondas.........

Figura 59: Ensaios termogravimétricos, porcentagem de reação X tempo (min), de todas as composições de pelota (segundo tabela 10), em forno de microondas.

Figura 60: Ensaios termogravimétricos da mistura tipo A (coque; $\mathrm{C} / \mathrm{O}=1,0$; sem cimento) em forno de resistência $\left(1000{ }^{\circ} \mathrm{C}\right)$ na situação de pré-tratamento do minério de ferro por exposição à microondas e sem tratamento do minério. 


\section{Lista de Tabelas}

Tabela 1: Valores dos coeficientes $p, u, v$ (reação 6)

Tabela 2: Energia de ativação aparente e mecanismo controlador da reação de redução de óxidos de ferro por carbono segundo vários autores

Tabela 3: Classificação das microondas quanto ao seu comprimento de onda $(\lambda)$

Tabela 4: Valores de $\varepsilon_{\mathrm{r}}^{\prime}$ e $\tan \delta$, a $25^{\circ} \mathrm{C}$, em três freqüências

Determinadas

Tabela 5: Valores do Fator de Perdas Dielétricas, $\varepsilon_{\mathrm{r}}$ ", para alguns materiais a $2450 \mathrm{MHz}$ e a $25^{\circ} \mathrm{C}$

Tabela 6: Composição Química (\% em peso)-Min. de Ferro Cauê. 44

Tabela 7: Composição Química (\% em peso)-Moinha de Coque. 44

Tabela 8: Composição Química (\% em peso)-Cimento Portland ARI....... 44

Tabela 9: Análise Imediata dos Agentes Redutores (\%).......................... 44

Tabela 10: Composição da mistura (\% em peso) das Pelotas Auto -Redutoras ensaiadas.

Tabela 11: Granulometria do Agente Redutor utilizado nas

Pelotas Auto-Redutoras

Tabela 12: Distribuição Granulométrica do Minério de Ferro Cauê

Tabela 13: Valores de "k" (constante cinética) segundo

modelo parabólico para todas as amostras estudadas.

Tabela 14: Amostras Analisadas no Microscópio Eletrônico de Varredura - Figura Correspondente. 


\section{Lista de Símbolos}

Unidade

E Campo elétrico

$\mathrm{V} / \mathrm{m}$

H Campo magnético

$\mathrm{A} / \mathrm{m}$

V Velocidade da luz

$\mathrm{m} / \mathrm{s}$

$\lambda$ Comprimento de onda

$\mathrm{m}$

Z Impedância

$\Omega$

F Freqüência do campo elétrico

$\mathrm{Hz}$

$\mathrm{P}_{\mathrm{v}} \quad$ Potência dissipada por unidade de volume

$\mathrm{W} / \mathrm{m}^{3}$

$\varepsilon^{\prime} \quad$ Permissividade ou Constante dielétrica

$\mathrm{F} / \mathrm{m}$

$\varepsilon^{\prime \prime} \quad$ Fator de perdas

$\mathrm{F} / \mathrm{m}$

$\varepsilon_{\mathrm{r}}^{\prime} \quad$ Constante dielétrica relativa

$\varepsilon_{\mathrm{r}}^{\prime \prime} \quad$ Fator de perdas relativas

$\tan \delta \quad$ Tangente de perdas

d Profundidade de penetração

$\mathrm{m}$

$\mu_{\text {eff }} \quad$ Fator de perdas magnéticas

$\alpha \quad$ Constante de atenuação

$\rho \quad$ Densidade específica

$\mathrm{Kg} / \mathrm{m}^{3}$

$\mathrm{c}_{\mathrm{p}} \quad$ Calor específico

$\mathrm{J} / \mathrm{Kg}{ }^{\mathrm{o}} \mathrm{C}$

PR Porcentagem de reação

$\%$

$\mathrm{M}_{\mathrm{i}} \quad$ Peso inicial da amostra g

$\mathrm{M}_{\mathrm{t}} \quad$ Peso no instante $\mathrm{t} g \mathrm{~g}$

M Porcentagem máxima de perda de peso \% 


\section{RESUMO}

A redução carbotérmica do minério de ferro é a mais imp ortante reação na fabricação do ferro, e tem sido obtida principalmente em Alto-Forno. Nos últimos anos, muitos processos novos foram propostos como alternativas e vários tipos de reatores foram testados. O processo mais promissor foi aquele em que a mistura minério de ferro e material carbonáceo eram aquecidos a altas temperaturas, promovendo a reação com formação do ferro metálico. Tornou-se claro que um dos principais obstáculos para a rápida reação é a transferência de calor da região externa para o centro da mistura. Por outro lado, muitos estudos têm mostrado que o aquecimento por microondas é muito efetivo em processos industriais, como secagem e sinterização de cerâmicos. No aquecimento por microondas, o material é aquecido a partir de seu interior, logo evita a obrigação de um aquecimento de fora para dentro do material. Neste trabalho, o aquecimento por microondas foi aplicado para a redução carbotérmica da hematita. Os resultados obtidos mostraram que é possível aquecer a mistura minério de ferro - carbono acima da temperatura de reação e que a taxa de reação é comparável à obtida por aquecimento convencional utilizando-se a mesma mistura. 


\begin{abstract}
The carbothermic reduction of iron ores is the most important reaction in ironmaking, and has been performed mainly in the Blast Furnace. In the last years, several new processes have been proposed as alternatives, and many types of reactors have been tested. The most promising processes are those in which a mixture of iron ore and carbonaceous material is heated at high temperatures, promoting the reaction with formation of metallic iron. It became clear that one of the main obstacles to a fast reaction is heat transfer from the surroundings to the core of the mixture. On the other hand, several studies have shown that microwave heating is very effective in some industrial processes, like drying and sintering of ceramics. In the microwave heating, the material is heated from the inside, thus avoiding the constraints of heat transfer from the surroundings to the inner part of the material. In this work, microwave heating has been applied to the carbothermic reduction of hematite. The obtained results have show that it is possible to heat iron-carbon mixture above the reduction temperature, and the reaction rates have been compared to those obtained employing conventional heating with the same mixtures .
\end{abstract}




\section{Introdução}

\subsection{Objetivo}

Estudar o comportamento cinético da redução do minério de ferro por carbono, na forma de pelotas auto-redutoras, feitas a partir da mistura destes materiais, quando o aquecimento da pelota é feito por energia de microondas.

\subsection{Justificativa}

Pelotas auto-redutoras para redução de minérios de ferro por carbono apresentam como principal atrativo altas velocidades de redução, em conseqüência da presença do redutor internamente à pelota, em mistura íntima com o minério, o que minimiza o efeito do transporte de massa na velocidade global de reação. A reação de redução é muito endotérmica, e os diversos estudos cinéticos apontam para a transferência de calor à carga como um dos determinantes da cinética da redução. Recentemente ${ }^{\mathbf{1 , 2}}$, foi proposto o emprego de energia de microondas como meio de fornecer calor à mistura óxido-carbono; deste modo, a geração interna de calor elimina a necessidade de transporte externo e a reação teria a sua cinética favorecida.

Além disso, vários fatores têm dificultado a implantação de novas usinas siderúrgicas baseadas na utilização de altos-fornos ${ }^{3}$; fatores como a limitada quantidade de carvão coqueificável e sua própria distribuição geográfica além dos custos de instalação de novas plantas. 
Os processos alternativos aos altos-fornos são classificados como processos de redução direta (redução do minério por redutor sólido ou gasoso, sem a fusão do produto, obtendo-se o chamado ferro-esponja).

Uma das formas de se utilizar o carbono sólido como redutor em processos de auto-redução é a sua utilização em pelotas auto-redutoras, constituídas de minério de ferro e carvão (vegetal ou mineral), podendo haver também misturas aglomerantes e/ou fluxantes.

O uso de pelotas auto-redutoras como forma de carga para redução tem alguns atrativos que indicam um alto potencial de utilização desta técnica:

a) possibilidade de utilização de diversas fontes de ferro e de carbono como redutor;

b) devido à fina granulometria se tem o contato íntimo entre as partículas, favorecendo a velocidade das reações de redução;

c) flexibilidade em relação ao equipamento de redução e/ou fusão das pelotas, que podem ser tratadas antes ou depois da redução em equipamentos como alto-forno, fornos cubilô, rotativos, elétricos, etc.

O processo de redução direta para a obtenção de ferro tem se tornado objeto de intensos estudos nos últimos anos, pois os mesmos permitem uma maior flexibilidade tanto de produção quanto ao uso de matérias-primas. Desta forma, o processo de redução direta vem constituindo uma alternativa de menor custo para a produção de ferro. Entre os processos industriais de produção de ferro primário merecem destaque o Tecnored e o Corex, por apresentarem uma 
melhor adequação às novas tendências mercadológicas e ambientais. O processo Tecnored baseia-se no emprego de pelotas auto-redutoras de cura a frio, resultando na obtenção do gusa com custos operacionais e de investimento inferiores aos de processos tradicionais ${ }^{4}$. O processo Corex consiste basicamente na pré-redução em grau elevado de metalização de pelotas de minério de ferro pelos gases provenientes do reator de fusão/gaseificação, num leito fluidizado 5

As potenciais vantagens do aquecimento por microondas em sistemas pirometalúrgicos são ${ }^{\mathbf{6}}$ :

a) O calor é gerado no próprio material, não havendo necessidade de transporte de calor a partir de fonte externa.

b) Apenas o material é aquecido e a temperatura do refratário que o contem é minimizada.

c) A fonte de energia é limpa, de fácil controle e não gera gases de combustão, reduzindo o volume de gases no processo.

d) O aquecimento ocorre em nível molecular, promovendo tanto reações endotérmicas como exotérmicas.

e) Existe potencial considerável para melhoria das condições de trabalho em processos com microondas em comparação aos processos convencionais.

$\mathrm{O}$ aquecimento por energia de microondas tem sido usado em diversos processos industriais, como secagem (alimentos, pigmentos, cerâmica, tecidos, 
químicos), cozimento de alimentos, cura de fibras, reciclagem de asfalto, disposição de resíduos tóxicos, medicamentos, aquecimento de óleo, colas, resíduos radioativos, semi-condutores, borracha, e em pesquisa em geral ${ }^{7}$. Existem fabricantes de equipamentos industriais e de pesquisa. No entanto, fornos de microondas domésticos podem ser adaptados para uso em laboratório ${ }^{8}$, já tendo sido usados, por exemplo, em pesquisa sobre obtenção de carbeto de silício ${ }^{9}$, ou no pré-tratamento de redução do minério de ferro pelo $\mathrm{CO}^{\mathbf{1 0}}$.

Sistemas como pelotas auto-redutoras, que contém óxidos de ferro e material carbonoso, são muito convenientes para processamento por microondas, pois o material carbonoso é facilmente aquecível por microondas. Dentre os óxidos de ferro, a magnetita é a que melhor absorve microondas. Foi relatado que na redução de minério de ferro por carvão o tempo para atingir-se $80 \%$ de redução foi reduzido em três vezes no aquecimento por microondas em relação ao aquecimento convencional, obtendo-se metalização final acima de $90 \%$ e um gás sem poeiras ${ }^{1}$. 


\section{Revisão Teórica}

\subsection{Redução de óxido de ferro por carbono}

Quando um óxido de ferro e carbono sólido são misturados e aquecidos numa temperatura de redução, a reação ocorre segundo o mecanismo: reação gássólido com intermediários gasosos (reações de 2 a 5) e a reação (1) sólido-sólido tem participação desprezível no processo de redução do minério de ferro devido à fatores cinéticos.

$$
\begin{array}{r}
\mathrm{Fe}_{2} \mathrm{O}_{3(\mathrm{~s})}+3 \mathrm{C}_{(\mathrm{s})}==2 \mathrm{Fe}_{(\mathrm{s})}+3 \mathrm{CO}_{(\mathrm{g})} \\
\Delta \mathrm{G}^{\mathrm{o}}(\mathrm{cal})=106700-118,2 \mathrm{~T}
\end{array}
$$

$\underline{\text { Reações gás-sólido com intermediários gasosos: }}$

$$
\begin{gathered}
3 \mathrm{Fe}_{2} \mathrm{O}_{3(\mathrm{~s})}+\mathrm{CO}_{(\mathrm{g})}==2 \mathrm{Fe}_{3} \mathrm{O}_{4(\mathrm{~s})}+\mathrm{CO}_{2(\mathrm{~g})} \\
\Delta \mathrm{G}^{\mathrm{o}}(\mathrm{cal})=-7880-12,87 \mathrm{~T} \\
\mathrm{Fe}_{3} \mathrm{O}_{4(\mathrm{~s})}+\mathrm{CO}_{(\mathrm{g})}=3{ }^{\mathrm{FeO}}{ }_{(\mathrm{s})}+\mathrm{CO}_{2(\mathrm{~g})} \\
\Delta \mathrm{G}^{\mathrm{o}}(\mathrm{cal})=7120-9,15 \mathrm{~T} \\
{ }^{\mathrm{FeO}}{ }_{(\mathrm{s})}+\mathrm{CO}_{(\mathrm{g})}==\mathrm{Fe}(\mathrm{s}) \\
\Delta \mathrm{G}^{\mathrm{o}}(\mathrm{cal})=-5450+5,8 \mathrm{~T} \\
\mathrm{CO}_{2(\mathrm{~g})}+\mathrm{C}_{(\mathrm{s})}==2 \mathrm{CO}{ }_{(\mathrm{g})} \\
\Delta \mathrm{G}^{\mathrm{o}}(\mathrm{cal})=40800-41,7 \mathrm{~T}
\end{gathered}
$$


Como foi demonstrado inicialmente por Baldwin ${ }^{11}$, a redução de óxidos de ferro por carbono ocorre principalmente através de intermediários gasosos, de acordo com as reações de (2) a (5).

$\mathrm{Na}$ figura 1 tem-se o esquema da redução de wustita a ferro (reação(4)), mostrando os fenômenos que ocorrem durante esta redução.

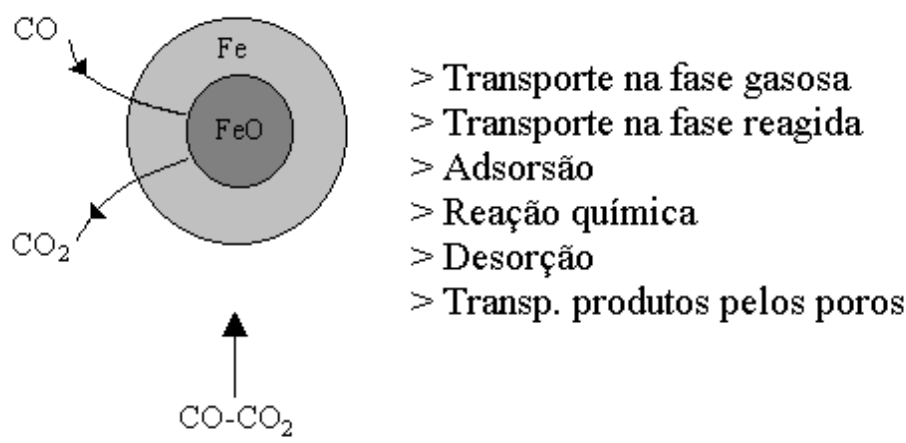

Figura1:Esquema da redução de wustita $(\mathrm{FeO})$ para ferro metálico.

Percebe-se que a reação (1) pode ser obtida através das demais reações (de (2) a (5)), com os devidos acertos nos coeficientes estequimétricos. Porém, Mourão ${ }^{3}$ mostrou que a reação global não possui estequiometria fixa , por depender da velocidade das reações parciais, tanto da redução de cada óxido como da gaseificação do carbono sólido. Desta maneira, representa-se a reação global como sendo:

$$
\mathrm{Fe}_{2} \mathrm{O}_{3(\mathrm{~s})}+p \mathrm{C}_{(\mathrm{s})}==2 \mathrm{Fe}_{(\mathrm{s})}+u \mathrm{CO}_{(\mathrm{g})}+v \mathrm{CO}_{2(\mathrm{~g})}
$$


A maior parte dos estudos sobre o sistema óxido de ferro- carbono, utilizou a técnica de termogravimetria para acompanhar o desenvolvimento do processo. Como a perda de peso deve-se à liberação dos gases $\mathrm{CO}$ e $\mathrm{CO}_{2}$, e como a estequiometria do sistema não é definida, a certeza experimental sobre o estado do sistema em um determinado instante só é possível com a simultânea análise da composição do gás de saída.

A seguir temos a tabela 1 que mostra os valores de $p, u$ e $v$, obtidos ${ }^{3}$ na situação onde a etapa química do processo de redução é controlada pela cinética de gaseificação do carbono pelo $\mathrm{CO}_{2}$ (reação (5)).

Tabela 1: Valores dos coeficientes $p, u, v$ (reação 6)

\begin{tabular}{|c|c|c|c|}
\hline $\mathrm{T}\left({ }^{\circ} \mathrm{C}\right)$ & $p$ & $u$ & $v$ \\
\hline 900 & 2,004 & 1,008 & 0,995 \\
\hline 1000 & 2,044 & 1,080 & 0,955 \\
\hline 1100 & 2,077 & 1,156 & 0,921 \\
\hline
\end{tabular}

Pode-se dividir o processo de auto-redução do minério de ferro por carbono sólido (através do mecanismo reação gás-sólido com intermediários gasosos) em duas etapas: a primeira correspondendo à redução da hematita até wustita (podendo haver a coexistência dos três óxidos- $\mathrm{Fe}_{2} \mathrm{O}_{3}, \mathrm{Fe}_{3} \mathrm{O}_{4}$ e $\mathrm{FeO}$ ), e a segunda etapa seria a transformação da wustita em ferro metálico. As transformações dos óxidos de ferro são acompanhadas de mudanças estruturais importantes (Bogdandy ${ }^{\mathbf{1 2}}$ ), que causam, por exemplo, o inchamento das pelotas. $\mathrm{Na}$ segunda etapa temos que a relação $\mathrm{Pco}_{2}-\mathrm{Pco}$ atinge valores muito próximos 
do equilíbrio $\mathrm{FeO}$ - $\mathrm{Fe}$, assim a reação mais lenta (controladora) é a reação de gaseificação do carbono pelo $\mathrm{CO}_{2}$.

Trushenski et al $^{\mathbf{1 3}}$, estudaram a redução dos óxidos de ferro por $\mathrm{CO}_{(\mathrm{g})}$, determinando a energia de ativação de cada etapa:

$$
\begin{array}{ll}
\mathrm{Fe}_{2} \mathrm{O}_{3} \rightarrow \mathrm{Fe}_{3} \mathrm{O}_{4} & 69,0 \mathrm{~kJ} / \mathrm{mol} \\
\mathrm{Fe}_{3} \mathrm{O}_{4} \rightarrow \text { "FeO" } & 78,2 \mathrm{~kJ} / \mathrm{mol} \\
" \mathrm{FeO} " \rightarrow \mathrm{Fe} & 116,0 \mathrm{~kJ} / \mathrm{mol}
\end{array}
$$

Este estudo envolveu o desenvolvimento de um modelo nãotopoquímico por meio da redução das pelotas de hematita por misturas de $\mathrm{CO} / \mathrm{CO}_{2}$, a temperaturas entre 873 e $1173 \mathrm{~K}$.

Foram levadas em consideração a variação de tamanho, alterações locais de fração de vazios, difusividade efetiva, superfície de reação, possibilidade de ocorrência de reações simultâneas e possibilidade de adaptação para modelo topoquímico ou reação homogênea no caso de, respectivamente, controle por difusão ou reação química.

Os autores concluíram que o caráter topoquímico é característico da redução dos três óxidos de ferro e diminui à medida que se aumenta a temperatura. Além disso, o grau de sinterização do material e a temperatura seriam diretamente proporcionais. O modelo apresentaria um fator de correlação, sendo função da sinterização presente em nível microscópico no interior da pelota.

$$
\text { Rao }{ }^{14} \text {, Fruehan }{ }^{15} \text {, Srinivasan e Lahiri }{ }^{16} \text {, Ajerrsch }{ }^{17} \text {, Mourão }{ }^{3} \text { e }
$$

Nascimento Jr. $^{\mathbf{1 8}}$ (ordem cronológica) concluíram que a reação de Boudouard 
(reação (5)) é a mais lenta dentre as reações sólido-gás, sendo assim, a etapa controladora do processo de redução até a temperatura de $1150{ }^{\circ} \mathrm{C}^{3}$. Esses autores tiveram em comum o fato de utilizarem misturas de minério de ferro e carvão, ainda que de diferentes tipos e temperaturas.

Porém, para outros autores, o controle não seria exercido pela reação de Boudouard. Ghosh e Tiwari ${ }^{19}$ num estudo de redução de pelotas auto-redutoras de minério de ferro e lignita em temperaturas de 1173 a $1373 \mathrm{~K}$, durante intervalos de tempo de 15 a 120 min., concluíram que o processo é controlado pela redução de 'FeO" a Fe pelo $\mathrm{CO}_{(\mathrm{g})}$. Relataram que todas as fases, tanto os óxidos como o ferro reduzido coexistem na pelota. Além disso, a velocidade de redução e o teor de carvão na mistura são diretamente proporcionais.

O principal parâmetro para se determinar o mecanismo controlador do processo de redução corresponde ao valor obtido para a energia de ativação aparente que é medida experimentalmente através da determinação da variação da velocidade de reação com a temperatura, pode variar bastante em função das condições experimentais. Para determinar a energia de ativação do processo, é preciso certificar-se que o transporte de calor e de massa não são etapas limitantes da velocidade de reação. Quando comparamos energias de ativação de alguns autores, percebemos estas diferenças, como é mostrado na tabela 2: 
Tabela 2: Energia de ativação aparente e mecanismo controlador da reação de redução de óxidos de ferro por carbono segundo vários autores.

\begin{tabular}{|c|c|c|c|}
\hline AUTORES & $\begin{array}{c}\text { EA } \\
(\mathrm{kJ} / \mathrm{mol})\end{array}$ & Observação & $\begin{array}{l}\text { Mecanismo } \\
\text { Controlador }\end{array}$ \\
\hline Ghosh e Tiwari ${ }^{19}$ & 78,2 & ---- & Redução de FeO \\
\hline $\mathrm{Rao}^{14}$ & 301,3 & ----- & Reação Boudouard \\
\hline Fruehan $^{15}$ & $293-335$ & $\begin{array}{c}\mathrm{De} \mathrm{Fe}_{2} \mathrm{O}_{3} \mathrm{p} / \mathrm{FeO} \mathrm{e} \\
\mathrm{FeO} \mathrm{p} / \mathrm{Fe}\end{array}$ & Reação Boudouard \\
\hline Seaton $^{30}$ et al & $\begin{array}{l}125,6 \\
238,6\end{array}$ & $\begin{array}{l}\text { Acima de } 1273 \mathrm{~K} \\
\text { Abaixo de } 1273 \mathrm{~K}\end{array}$ & $\begin{array}{l}\text { Reação Boudouard } \\
\text { e/ou transf. de calor }\end{array}$ \\
\hline $\begin{array}{l}\text { Srinivasan e } \\
\text { Lahiri }^{16}\end{array}$ & 414,4 & ---.- & $\begin{array}{l}\text { Reação Boudouard no } \\
\text { começo e Redução de } \\
\text { FeO no final }\end{array}$ \\
\hline $\begin{array}{l}\text { Abraham e } \\
\text { Ghost }^{31}\end{array}$ & $\begin{array}{l}140,0 \\
296,0\end{array}$ & 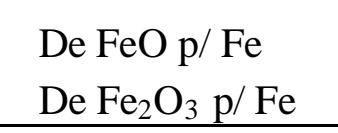 & Reação Boudouard \\
\hline $\begin{array}{l}\text { Mourão e } \\
\text { Capocchi }^{32}\end{array}$ & 226,6 & ---- & Reação Boudouard \\
\hline $\operatorname{Ajersch}^{17}$ & $\begin{array}{l}182,0 \\
647,1\end{array}$ & $\begin{array}{c}\mathrm{De} \mathrm{Fe}_{2} \mathrm{O}_{3} \mathrm{p} / \mathrm{FeO} \\
\mathrm{De} \mathrm{FeO} \mathrm{p} / \mathrm{Fe}\end{array}$ & $\begin{array}{l}\text { Reação Química, } \\
\text { Difusão }\end{array}$ \\
\hline
\end{tabular}

Recentemente $^{\mathbf{2 0}}$ determinou-se a energia de ativação aparente do processo de redução de minério de ferro por carbono em condições nãoisotérmicas (a grande maioria dos trabalhos considera a hipótese de situação isotérmica), obtendo-se o valor de 300,0 kJ/mol em temperaturas acima de 1110 ${ }^{\circ} \mathrm{C}$, mostrando que o controle do processo é exercido pela reação de Boudouard. Rao ${ }^{\mathbf{1 4}}$ estudou o processo de redução através da mistura hematitacarbono em cadinho, ou ainda na forma de briquete, por análise termogravimétrica. As variáveis estudadas de maior interresse no momento estão descritas a seguir, sendo que o autor fez a análise do processo a partir dos resultados na forma de fração reagida em função do tempo: 


\section{Temperatura:}

$\rightarrow$ a $1173 \mathrm{~K}\left(900{ }^{\circ} \mathrm{C}\right)$, após 360 min., não se chegou a $20 \%$ de fração de reação; já a $1260 \mathrm{~K}\left(987{ }^{\circ} \mathrm{C}\right)$ obteve-se fração de reação de aproximadamente de 90\% após 100 min. Assim o aumento da temperatura diminui o tempo necessário do processo e, principalmente, possibilita a continuidade do processo de redução.

Tamanho das partículas de carbono

$\rightarrow$ observou-se que quanto menor a granulometria, menor o tempo para $50 \%$ de fração de reação, mas quanto mais elevada a temperatura, menor o efeito da variação do tamanho da partícula.

3. Relação molar $\mathrm{Fe}_{2} \mathrm{O}_{3} / \mathrm{C}$

$\rightarrow$ em relação a essa variável verificou-se que quanto maior o teor de carbono, menor seria o tempo necessário para se atingir $50 \%$ de fração de reação.

Fruehan ${ }^{15}$ estudou a redução de misturas de $\mathrm{Fe}_{2} \mathrm{O}_{3}$ ou "FeO" com diversos tipos de carvão, tanto na forma de pó (colocado em cadinho) como em briquetes, na faixa de temperaturas de 1173 a $1473 \mathrm{~K}\left(900\right.$ a $\left.1200{ }^{\circ} \mathrm{C}\right)$.

De acordo com os resultados experimentais, a velocidade de redução dependeria do tipo, tamanho e quantidade do carvão utilizado. Isto reforçaria a hipótese de que a velocidade global da reação está diretamente ligada à reação de Boudouard. 
A partir da análise do gás de saída, verificou que na primeira etapa da reação (redução de $\mathrm{Fe}_{2} \mathrm{O}_{3}$ a "FeO"), o produto gasoso era basicamente $\mathrm{CO}_{2}$, indicando estar o processo em equilíbrio, relativo à etapa $\mathrm{Fe}_{2} \mathrm{O}_{3}$ a 'FeO", sendo a velocidade controlada pela reação de Boudouard.

$\mathrm{Na}$ segunda fase do processo ("FeO a $\mathrm{Fe}$ ), ainda com controloe da reação de Boudouard, a relação $\mathrm{CO}_{2} / \mathrm{CO}$ esteve próxima do equilíbrio 'FeO $\mathrm{Fe}$, com o valor diminuindo com o decorrer do processo.

A ocorrência de diminuição na velocidade nos estágios finais de redução de "FeO" foi creditada à penetração do gás inerte na amostra e à formação de "FeO". $\mathrm{SiO}_{2}$. De acordo com o autor, não se verificou o efeito catálítico da formação de Fe na reação de Boudouard.

Mourão ${ }^{3}$ efetuou um estudo cinético da redução de vários tipos de pelotas auto-redutoras por meio de termogravimetria, além de análise dos gases de saída $\left(\mathrm{CO}_{2} / \mathrm{CO}\right)$ e difração de raio-X.

O trabalho envolveu o efeito da variação de temperatura, tipo e quantidade de redutor, uso de adições de diversos materiais, teor e vazão dos gases injetados no equipamento de redução.

Verificou que não existe um único mecanismo controlador, podendo ele mudar com o transcorrer da redução, de acordo com os parâmetros experimentais. Foram testadas diversas expressões cinéticas para ajuste dos resultados experimentais e concluiu-se que na segunda etapa de reação ("FeO" $\rightarrow$ $\mathrm{Fe}$ ), a relação $\mathrm{CO}_{2} / \mathrm{CO}$ é praticamente constante, e a temperatura tende também a um valor constante; a expressão cinética que melhor se ajustou, segundo o autor, 
foi $G(F)=1-(1-F)^{1 / 3}$, onde "F" corresponde à fração de reação, e essa expressão representa reações controladas por cinética química, neste caso então controle pela reação de gaseificação do carbono sólido (ou reação de Boudouard).

Foi comprovado o caráter não isotérmico do processo, com a existência de um gradiente térmico no interior da pelota. Foram obtidas também conclusões sobre a estrutura das pelotas em relação a alterações de volume (inchamento ou contração) em função da composição.

Nascimento Jr. $^{18}$ analisou o processo de redução de pelotas autoredutoras com carvão vegetal não desvolatilizado e aglomeradas a frio com cimento Portland. Foram estudadas pelotas de 9,1mm e de $15,3 \mathrm{~mm}$ a temperaturas entre 1223 a $1423 \mathrm{~K}\left(950\right.$ a $\left.1150{ }^{\circ} \mathrm{C}\right)$. Com relação ao aspecto cinético, concluiu que o processo é controlado por reações químicas, com a ação de intermediários gasosos. $\mathrm{O}$ autor verificou a existência de gradiente térmico no interior da pelota. Quanto a análise microestrutural, discutiu uma série de variáveis envolvendo o inchamento das pelotas durante o processo de redução, em particular quanto ao efeito do material volátil presente na matéria-prima.

Existe uma grande quantidade de informações já acumuladas a respeito de estudos cinéticos sobre a redução de óxidos de ferro por carbono. As principais características da reação que já estão plenamente estabelecidas são mostradas a seguir: 
- a reação global entre óxidos de ferro e material carbonoso ocorre através dos intermediários gasosos $\mathrm{CO}$ e $\mathrm{CO}_{2}$, isto é, a reação global ocorre por meio de duas reações gás-sólido, quais sejam, a redução do óxido por $\mathrm{CO}$ e a gaseificação do carbono por $\mathrm{CO}_{2}$ (reação de Boudouard);

- dentre estas duas reações, a mais lenta é a reação de gaseificação do carbono (até a temperatura de $1150{ }^{\circ} \mathrm{C}$ ); isto implica que as propriedades relativas à reatividade do redutor (tipo, granulometria, teor de impurezas) são importantes na determinação da cinética global;

- ainda como consequência do controle químico ser devido à reação de Boudouard, que tem alta energia de ativação, a velocidade global é muito sensível a variações de temperatura;

- a reação é fortemente endotérmica; transporte de calor para as regiões internas da pelota é um dos fatores determinantes da velocidade do processo. 


\subsection{Ondas de Alta Frequiência}

\subsubsection{Definições ${ }^{21}$}

As ondas eletromagnéticas, que se propagam pelo espaço, são associações de oscilações de campos elétricos e magnéticos. São conhecidas ondas eletromagnéticas sob várias formas, como a luz, os raios-X, o calor radiante, as ondas de rádio, entre outras. $\mathrm{O}$ fundamento das ondas eletromagnéticas é a coexistência desses campos (o elétrico e o magnético), em movimento, um gerando o outro, mantendo-se assim enquanto se deslocam.

A seguir é mostrado na figura 2 um gerador que, por meio de uma antena, gera um campo elétrico $E_{1}$ para o espaço vizinho e que, por sua vez, gera o campo magnético $\mathrm{H}_{1}$ que gera o campo elétrico seguinte, e assim por diante, propagando-se pelo espaço.

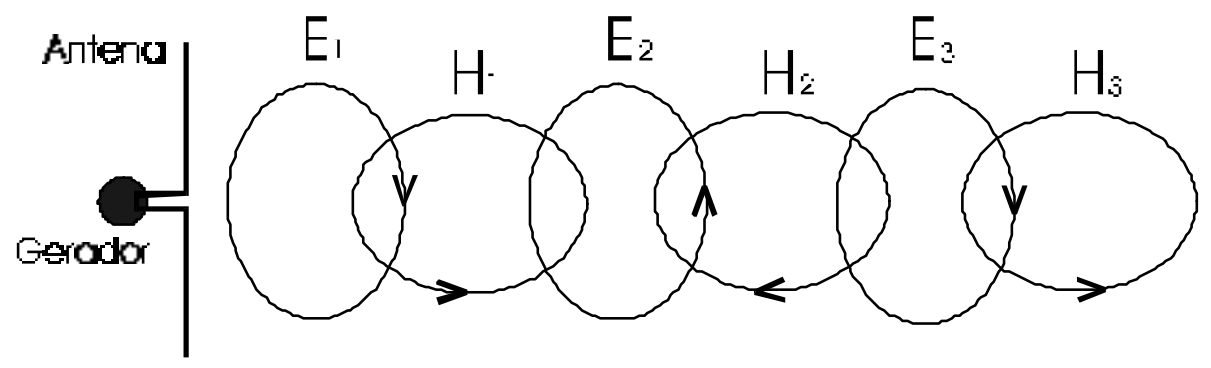

Figura 2: Propagação de uma onda eletromagnética.

A velocidade de propagação de uma onda eletromagnética no vácuo é a mesma da luz, $3 \times 10^{8} \mathrm{~m} / \mathrm{s}$. 
Denomina-se comprimento de onda a distância de um ponto de uma onda ao ponto correspondente da onda seguinte, por exemplo a distância entre dois máximos positivos consecutivos. O comprimento de onda é normalmente representado pela letra grega lambda $(\lambda)$.

Sendo a velocidade da onda eletromagnética de $3 \times 10^{8} \mathrm{~m} / \mathrm{s}$, e tendo-se um emissor contínuo de ondas eletromagnéticas, 1 segundo após emitida uma onda ela estará a $3 \times 10^{8} \mathrm{~m}($ ou $300.000 \mathrm{Km}$ ) do emissor, e entre a onda e o emissor estarão $3 \times 10^{8} / \lambda$ ondas. Esse quociente é denominado frequiência que é o número de ondas, ou ciclos, por segundo. A freqüência é normalmente representada pela letra "f" e medida em Hertz $(\mathrm{Hz})$

A intensidade do campo elétrico (E) é dada em Volts/metro e do campo magnético $(\mathrm{H})$ em Ampéres/metro; comparando-se as intensidades dos dois campos tem-se:

$$
\frac{E(\text { Volts } / \text { metro })}{H(\text { Ampéres / metro })}=\frac{\text { Volts }}{\text { Ampéres }} \quad ; \quad \text { expressão conhecida }
$$

na teoria de circuitos com o nome de impedância (representada pela letra Z), que ficará definida como a relação $\mathrm{E} / \mathrm{H}$, medida em Ohms e representada pela letra grega omega $(\Omega)$.

No vácuo e nos gases, Z é igual $377 \Omega$, nos materiais magnéticos pode ser maior e nos dielétricos e condutores é menor. 


\subsubsection{Microondas ${ }^{21}$}

As microondas são ondas eletromagnéticas com frequências na faixa de $300 \mathrm{MHz}$ a $300 \mathrm{GHz}$, compreendendo inclusive aquelas frequências usadas em telecomunicações. Equipamentos de aquecimento por microondas operam, em geral, em frequências específicas, a saber: $915 \mathrm{MHz} ; 2,45 \mathrm{GHz}$ (fornos domésticos); 5,8 GHz e 24,124 GHz.

Microondas são geradas a partir de eletricidade por um dispositivo chamado "magnetron". São ondas coerentes, polarizadas, e obedecem às leis da ótica, podendo ser transmitidas, refletidas ou absorvidas quando incidem sobre um material. A figura 3 mostra as possíveis interações quando uma microonda atinge um determinado material.

Metais são opacos a microondas, e as refletem, não sendo aquecidos por elas. Materiais transparentes a microondas também não são aquecidos, mas permitem a sua passagem. Os materiais passíveis de serem aquecidos por microondas são aqueles que as absorvem parcial ou totalmente, e a absortividade depende principalmente da condutividade elétrica do material. Assim, isolantes tendem a ser transparentes a microondas, e bons condutores, como os metais, tendem a refleti-las. Materiais com condutividades intermediárias tendem a absorver microondas, e são portanto os que podem ser aquecidos por elas. 


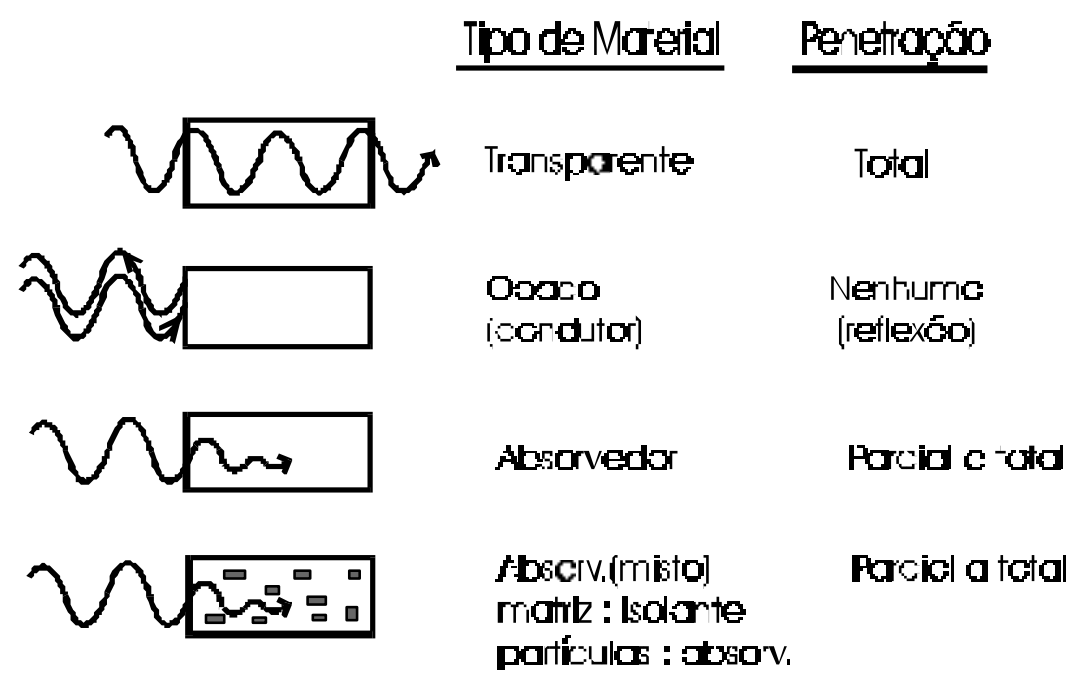

Figura 3: Interação das microondas com diferentes materiais.

O comprimento de onda das microondas são da ordem de centímetros e milímetros, sendo comum classifica-las em faixas, como apresentado na tabela 3 :

Tabela 3: Classificação das microondas quanto ao seu comprimento de onda $(\lambda)$.

\begin{tabular}{|c|c|}
\hline FAIXA & $\lambda(\mathrm{cm})$ \\
\hline $\mathrm{S}$ & 10 \\
\hline $\mathrm{X}$ & 3 \\
\hline $\mathrm{K}$ & 1,1 \\
\hline $\mathrm{Q}$ & 0,8 \\
\hline
\end{tabular}

As microondas, devido ao seu pequeno comprimento, podem ser propagadas por antenas e guias de onda de pequenas dimensões. Isso torna possível a construção de equipamentos como antenas de grande ganho, que permitem focalizar, dirigir e captar novamente as microondas com grande eficiência. As antenas são dispositivos que transferem energia de circuitos elétricos para o espaço e vice-versa. 


\subsubsection{Condução da energia de microondas}

Ondas elétricas de baixa freqüência são transportadas por condutores maciços, já as microondas (ondas elétricas de alta freqüência) são conduzidas por tubos metálicos ocos, denominados dutos ou guias de onda, que têm a secção geralmente retangular. A onda eletromagnética caminha por dentro do duto, refletindo-se em suas paredes, percorrendo assim um caminho em ziguezague, de modo que a velocidade dentro do duto é menor que ao ar livre.

A onda dentro do duto não se comporta como uma onda plana, isto é, ela não é igual num plano transversal ao duto, sendo máxima no centro e nula junto às paredes, como mostrado na figura 4:

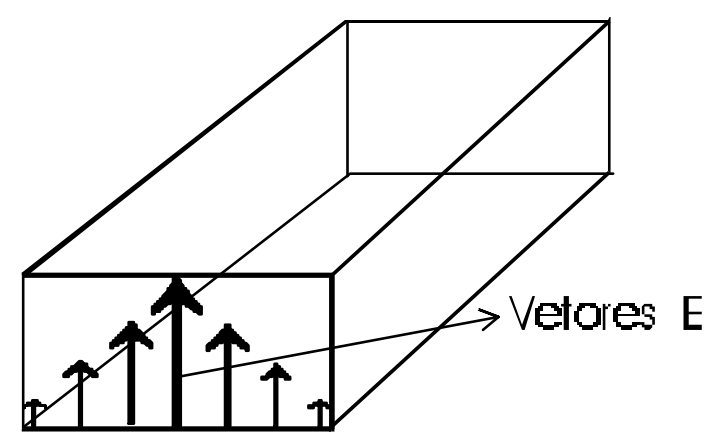

Figura 4: Campo no interior de um duto retangular

Seja $\lambda_{\mathrm{o}}$ o comprimento de onda no vácuo, medido perpendicularmente à frente de onda, dentro do duto essa medida varia conforme a direção da medida, denominando-se $\lambda_{\mathrm{g}}$ o comprimento de onda medido na direção de seu eixo. Esses dois comprimentos de onda estão ligados pela relação: 


$$
\lambda_{g}=\frac{\lambda_{o}}{\sqrt{1-\left(\frac{\lambda_{o}}{2 a}\right)^{2}}}
$$

Através da expressão (7) vê-se que $2 a$ deve ser maior que $\lambda_{\mathrm{o}}$, ou seja, que a largura "a" do duto tem que ser maior que $\lambda / 2$, pois caso contrário tem-se um comprimento de onda imaginário medido ao longo do seu eixo, o que significa que não teríamos propagação no duto. Pode-se mudar o comportamento das ondas no interior dos dutos, mudando-se as relações entre as dimensões e o comprimento de onda.

Uma onda introduzida num duto com um obstáculo sofrerá uma reflexão e caminhará no sentido contrário, somando-se ou subtraindo-se à onda introduzida inicialmente, de acordo com as fases relativas das duas ondas.

Quando um duto é fechado nas duas extremidades, ele é chamado de cavidade, e uma onda nele introduzida reflete-se nas duas extremidades. No caso particular em que o comprimento da cavidade é igual a $\lambda_{\mathrm{g}} / 2$, as ondas incidente $\mathrm{e}$ refletida estão em fase, e se somam, tendendo a se manter na cavidade com um valor máximo. Nessas condições a cavidade é chamada de ressonante e as ondas em seu interior não sofrem atenuação.

A cavidade de um forno pode ser imaginada como um duto com as duas extremidades fechadas, alimentado por um "magnetron", que é ressonante para várias freqüências dadas por: 


$$
\lambda=2\left\{\left(\frac{m}{w}\right)^{2}+\left(\frac{n}{d}\right)^{2}+\left(\frac{p}{h}\right)^{2}\right\}^{-1 / 2}
$$

onde: $\lambda$ - comprimento de onda, em metros, na freqüência de ressonância;

$m, n$ e $p$ - número de meias onda de variação do campo $\mathrm{E}$, nas direções $w$ (largura), $d$ (profundidade) e $h$ (altura).

As variações da meia onda não podem ser menores que uma meia onda no espaço livre.

\subsubsection{O Magnetron ${ }^{21}$}

Vários dispositivos elétricos podem gerar ou produzir as microondas, o mais comum é a válvula "magnetron", que é um oscilador e seu tipo mais simples consiste num duplo diodo com mostrado na figura 5.

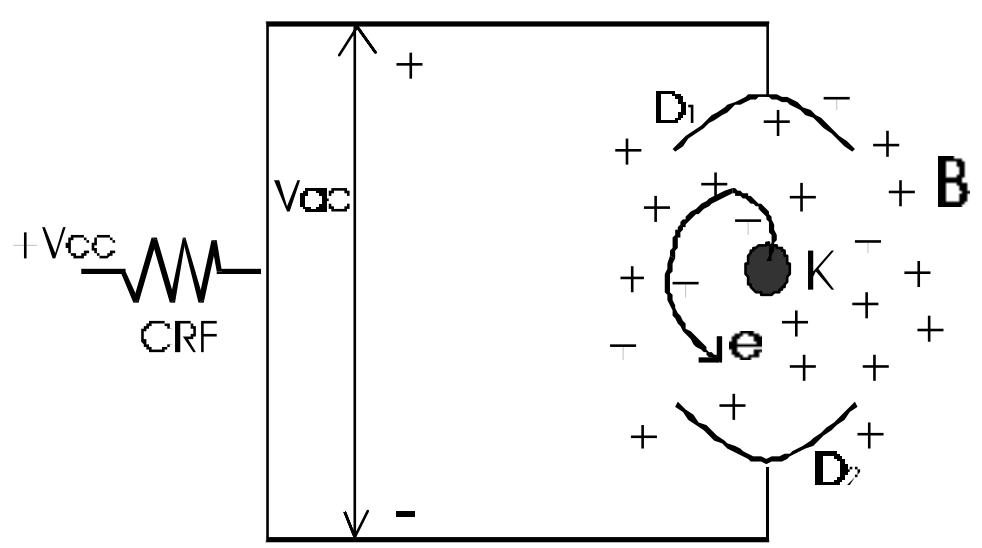

Figura 5: Esquema de um "magnetron"simples. 
As placas $D_{1}, D_{2}$ e a linha formam um circuito ressonante na freqüência desejada e esse conjunto é alimentado com uma tensão contínua +Vcc. Também é aplicada às placas uma tensão alternada Vca, fornecida pelo circuito oscilante CRF, de modo que ambas estão positivas, mas com valores diferentes.

Os elétrons emitidos pelo cátodo $\mathrm{K}$ são atraídos pela placa que estiver mais positiva no momento, ou seja, além da tensão contínua Vcc, estiver com a tensão alternada a seu favor. No caso representado na figura $5, \mathrm{D}$ está mais positivo que $D_{2}$, assim um elétron que sair de $K$ vai se dirigir para $D_{1}$.

Há ainda um campo magnético $\mathrm{B}$, constante e normal à folha no desenho, que desvia a trajetória do elétron, o qual em movimento equivale a uma corrente elétrica submetida à ação motora do campo magnético. Com isso, em vez do elétron ir para a placa mais positiva, acabará na placa menos positiva $D_{2}$. Vê-se então que haverá uma relação negativa entre a tensão e a corrente.

Essa válvula tem o que se denomina "resistência dinâmica negativa", a qual não dissipa energia do circuito, mas sim traz energia da fonte Vcc para o circuito, ao contrário de uma da resistência comum do tipo positiva.

Na prática, o "magnetron" se apresenta como vários módulos simples agrupados ao redor de um cátodo comum, sendo a linha e as placas substituídas por cavidades ressonantes. 


\subsubsection{Aquecimento por ondas de alta freqüiência}

\subsubsection{Aquecimento Dielétrico ${ }^{22,24}$}

O aquecimento dielétrico é obtido irradiando-se o material a aquecer com ondas eletromagnéticas de alta freqüência. A faixa de freqüência estende-se, normalmente, de 1 a $200 \mathrm{MHz}$. O processo se realiza pela colocação da carga dielétrica entre dois eletrodos através dos quais se aplica uma alta tensão alternada de freqüência elevada.

O requisito básico para o aquecimento dielétrico é o estabelecimento de um campo elétrico alternado de alta freqüência no interior do material a ser aquecido. Estabelecido esse campo elétrico, uma segunda exigência para o aquecimento envolve as características das perdas dielétricas do material. Essas perdas dielétricas ocorrem em conseqüência da polarização elétrica do material.

A interação de um campo elétrico com um dielétrico tem sua origem na resposta da carga das partículas ao campo aplicado.

Existem, pelo menos, quatro tipos reconhecidos de polarização: dois deles provocados pelo campo, constituindo a polarização induzida; e dois outros que são inerentes à disposição das partículas formadoras do próprio material e determinados por tal disposição.

Os mecanismos de perda dielétricas são:

- polarização eletrônica (deslocamento dos elétrons ao redor do núcleo); 
- polarização atômica (deslocamento relativo do núcleo atômico devido à distribuição desigual das cargas na formação das moléculas);

- orientação de dipolo (alguns dielétricos, ditos polares, têm dipolos permanentes devido à distribuição assimétrica das cargas);

- polarização de carga espacial (acúmulo de cargas na interface entre componentes de sistemas heterogêneos).

Os dois últimos são mais notáveis no aquecimento dielétrico.

O exemplo mais comum de aquecimento que utiliza a energia de microondas é o caso da molécula de água, onde o principal fenômeno responsável pelo aquecimento é a rotação dipolar. Pode-se descrever sucintamente esse fenômeno lembrando que a molécula de água, apesar de ter carga elétrica total nula, apresenta-se como um dipolo elétrico, pois o centro de gravidade das cargas positivas não coincide com o das cargas negativas. Diz-se que a molécula da água é polar. Sob a ação de um campo elétrico externo, esse mesmo dipolo tende a girar, orientando-se na direção do campo. Essa rotação do dipolo encontra resistência, o que resulta em dissipação de energia eletromagnética do campo, sob forma de calor, com o conseqüente aumento da temperatura.

Generalizando, quando a radiação de microondas penetra e se propaga através de um material dielétrico, os campos elétricos internos gerados no volume exposto induzem movimentos translacionais de cargas livres (elétrons) ou ligadas (íons) e movimentos rotacionais de dipolos elétricos. A resistência a 
esses movimentos induzidos, devido à forças inerciais, elásticas e de atrito, causam perdas de energia, provocando o aquecimento do material.

Existem diferenças fundamentais entre o aquecimento por microondas e os processos de aquecimento convencional. Num aquecimento por microondas o calor é gerado internamente no material, enquanto que nos processos convencionais o calor de uma fonte externa é absorvido pela superfície do material. Como consequiência desse aquecimento interno, os gradientes térmicos e os fluxos de calor nos materiais aquecidos por microondas são reversos aos do aquecidos convencionalmente, como mostra a figura $6^{23}$.
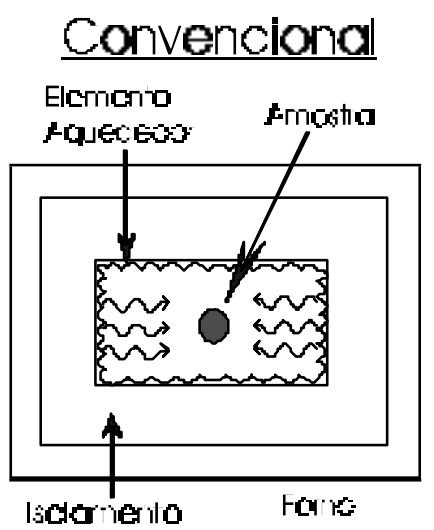

Microondas

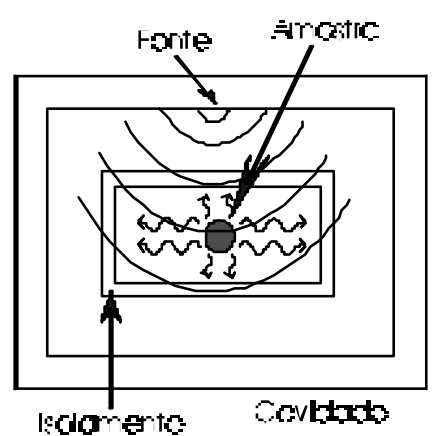

Figura 6: Padrões de aquecimento em forno convencional e de microondas.

Num material dielétrico, a potência dissipada por unidade de volume $\left(\mathrm{P}_{\mathrm{v}}\right)$, pode ser expressa como:

$$
P_{v}=K \times E^{2} \times f \times \varepsilon^{\prime}{ }_{r} \times \tan \delta \times 10^{-12}
$$


onde: $\mathrm{P}_{\mathrm{v}}$ - potência dissipada por unidade de volume $\left(\mathrm{W} / \mathrm{m}^{3}\right)$;

$\mathrm{K}$ - constante;

E - campo elétrico $(\mathrm{V} / \mathrm{m})$;

f - freqüência do campo elétrico $(\mathrm{Hz})$;

$\varepsilon_{\mathrm{r}}^{\prime}-$ constante dielétrica relativa do material;

$\tan \delta$ - tangente do ângulo entre a tensão e a corrente no dielétrico, ou seja, o complemento do ângulo do fator de potência.

O produto de $\varepsilon_{\text {r }}$ por tan $\delta$ é chamado "fator de perda" e aparece em tabelas de propriedade dielétricas (como a Tabela 5).

\subsubsection{Aquecimento por microondas}

No caso das microondas, o aquecimento é simplesmente um material dielétrico sendo aquecido em frequiências ainda mais altas, realizado numa cavidade cujas dimensões são da ordem de grandeza do comprimento de onda, diferentemente do que ocorre em freqüências baixas, quando os comprimentos de onda são muito maiores que as dimensões da peças.

As duas freqüências usadas predominantemente nas microondas para aquecimento são 915 e $2450 \mathrm{MHz}$. Como o processo é realizado em freqüências de 10 a 100 vezes mais elevadas do que no aquecimento dielétrico, é necessária uma tensão mais baixa, caso o fator de perda seja constante. 
Nessas freqüências existe um parâmetro conhecido como espessura pelicular ou profundidade de penetração, que é obtido através da seguinte expressão:

$$
d=\frac{v}{2 \pi f}\left(\frac{2}{\varepsilon_{r}^{\prime}\left(\sqrt{1+\tan ^{2}} \delta-1\right)}\right)^{1 / 2}
$$

onde: $\mathrm{d}$ - profundidade de penetração $(\mathrm{m})$;

$\mathrm{v}$ - velocidade da luz $(\mathrm{m} / \mathrm{s})$;

f - freqüência do campo elétrico $(\mathrm{Hz})$;

$\varepsilon_{\mathrm{r}}^{\prime}$ - constante dielétrica relativa do material;

$\tan \delta$ - tangente do ângulo entre a tensão e a corrente no

dielétrico, ou seja, o complemento do ângulo do fator de potência.

A utilização do aquecimento pela energia de microondas, em muitos casos, supera a simples substituição ou complementação do aquecimento de certo material, pois as microondas têm a capacidade de penetrarem nos materiais dielétricos (conforme equação (10)) e serem absorvidas por todo o volume da peça, propiciando assim uma geração uniforme de calor. Outro fator é a seletividade inerente ao aquecimento que oferece um mecanismo de autolimitação da energia absorvida por materiais heterogêneos, tornando o superaquecimento improvável. 


\subsubsection{Parâmetros Dielétricos ${ }^{23,24}$}

Os materiais dielétricos são caracterizados pelos seguintes parâmetros: permissividade (ou constante dielétrica) $\varepsilon^{\prime}$, e o fator de perdas $\varepsilon$ ". Costuma-se também definir a tangente de perdas que é dada pelo quociente:

$$
\tan \delta=\frac{\varepsilon^{\prime \prime}}{\varepsilon^{\prime}}
$$

Quando um dielétrico é colocado sob a ação de um campo elétrico variável, em todo o ciclo de variação do campo, o material armazena e devolve energia eletromagnética (análogo a uma mola sujeita a uma força alternada de compressão). Nessas condições, a constante dielétrica $\varepsilon^{\prime}$ mede a energia armazenada por segundo, por unidade de volume, ao passo que o fator de perdas $\varepsilon "$ mede a energia dissipada.

Pode-se então deduzir que a potência dissipada numa amostra de material dielétrico, por unidade de volume, é dada por:

$$
P_{v}=2 \pi \times f \times \varepsilon^{\prime \prime} \times E^{2}
$$

onde:

$\mathrm{P}_{\mathrm{v}}$ - potência dissipada por unidade de volume $\left(\mathrm{W} / \mathrm{m}^{3}\right)$;

f - frequiência do campo elétrico $(\mathrm{Hz})$;

$\varepsilon "$ - fator de perdas $(\mathrm{F} / \mathrm{m})$;

E - valor eficaz do campo elétrico variável no ponto considerado no interior do material $(\mathrm{V} / \mathrm{m})$. 
Costuma-se referir $\varepsilon^{\prime}$ e $\varepsilon^{\prime \prime}$ à constante dielétrica do vácuo; $\varepsilon_{\mathrm{o}}=8,85 \times 10^{-12} \mathrm{~F} / \mathrm{m}$, definindo-se assim a constante dielétrica relativa:

$$
\varepsilon_{r}^{\prime}=\frac{\varepsilon^{\prime}}{\varepsilon_{o}}
$$

e o fator de perdas relativas:

$$
\varepsilon_{r}^{\prime \prime}=\frac{\varepsilon^{\prime \prime}}{\varepsilon_{o}}
$$

desta forma, escrevendo novamente a equação (12) tem-se:

$$
P_{v}=5,56 \times 10^{-11} \times f \times E^{2} \times \varepsilon_{r}^{\prime \prime}
$$

ou:

$$
P_{v}=5,56 \times 10^{-11} \times f \times E^{2} \times \varepsilon_{r}{ }^{\prime} \times \tan \delta
$$

Os valores de $\varepsilon_{\mathrm{r}}^{\prime}$ e $\tan \delta$ variam numa ampla faixa para diversos materiais de uso industrial. A Tabela 4 mostra valores representativos, para materiais sólidos e líquidos na temperatura ambiente. Vê-se por essa tabela que há materiais cujas propriedades dielétricas pouco variam com a freqüência e para outros a variação é grande. 
Tabela 4: Valores de $\varepsilon_{\mathrm{r}}^{\prime}$ e $\tan \delta$, a $25^{\circ} \mathrm{C}$, em três frequiências determinadas ${ }^{25}$.

\begin{tabular}{|c|c|c|c|c|}
\hline \multicolumn{2}{|c|}{ Freqüência ( MHz) } & 1 & 100 & 3000 \\
\hline \multirow{2}{*}{ Óxido de Alumínio } & $\varepsilon_{\mathrm{r}}^{\prime}$ & 8,80 & 8,80 & 8,80 \\
\cline { 2 - 5 } & $\tan \delta$ & 0,0033 & 0,0031 & 0,001 \\
\hline \multirow{2}{*}{$\begin{array}{c}\text { Vidro } \\
\text { (borossilicato) }\end{array}$} & $\varepsilon_{\mathrm{r}}^{\prime}$ & 4,84 & 4,84 & 4,82 \\
\cline { 2 - 5 } & $\tan \delta$ & 0,0036 & 0,0033 & 0,0054 \\
\hline \multirow{2}{*}{ Etanol } & $\varepsilon_{\mathrm{r}}^{\prime}$ & 24,5 & 23,7 & 6,5 \\
\cline { 2 - 5 } & $\tan \delta$ & 0,090 & 0,062 & 0,25 \\
\hline \multirow{2}{*}{$\begin{array}{c}\text { Tetracloreto de } \\
\text { Carbono }\end{array}$} & $\varepsilon_{\mathrm{r}}^{\prime}$ & 2,17 & 2,17 & 2,17 \\
\cline { 2 - 5 } & $\tan \delta$ & 0,0001 & 0,0002 & 0,0004 \\
\hline \multirow{2}{*}{ Gelo (-12 $\left.{ }^{\circ} \mathrm{C}\right)$} & $\varepsilon_{\mathrm{r}}^{\prime}$ & 4,15 & 3,45 & 3,20 \\
\cline { 2 - 5 } & $\tan \delta$ & 0,12 & 0,035 & 0,0009 \\
\hline \multirow{2}{*}{ Água destilada } & $\varepsilon_{\mathrm{r}}^{\prime}$ & 78,2 & 78,0 & 76,7 \\
\cline { 2 - 5 } & $\tan \delta$ & 0,040 & 0,005 & 0,157 \\
\hline
\end{tabular}

Por meio da Tabela 4 observa-se também que o fator de perdas relativas $\left(\varepsilon_{\mathrm{r}}^{\prime}\right)$ é obtido pelo produto:

$$
\varepsilon_{r}^{\prime \prime}=\varepsilon_{r}^{\prime} \times \tan \delta \quad(17), \mathrm{e}
$$

varia fortemente de um dielétrico para outro. Percebe-se isso para o caso da água, em que no estado sólido apresenta baixas perdas (pouco aquecimento pela energia de microondas) e ao passar para o estado líquido, torna-se um dielétrico de perdas elevadas. Como visto na equação (15), a potência dissipada está diretamente relacionada com o fator de perdas $\varepsilon_{\mathrm{r}}$ " ; na Tabela 5 é apresentado valores do fator de perdas dielétricas para alguns materiais, de acordo com valores preliminares levantados pelo Laboratório de Microondas do Instituto Mauá de Tecnologia (São Caetano,SP) ${ }^{\mathbf{2 5}}$. Além das variações devidas à diferença entre os materiais, tem-se importantes diferenças devidas ao estado de agregação e a densidade, para o mesmo material. 
Tabela 5: Valores do Fator de Perdas Dielétricas, $\varepsilon_{\mathrm{r}}$ ", para alguns materiais a $2450 \mathrm{MHz}$ e a $25^{\circ} \mathrm{C}$.

\begin{tabular}{|c|c|c|}
\hline Material & $\varepsilon_{\mathrm{r}}{ }^{\prime}$ & $\begin{array}{c}\text { Densidade } \\
\left(\mathrm{g} / \mathrm{cm}^{3}\right)\end{array}$ \\
\hline Água & 12,04 & --- \\
\hline Gelo & 0,003 & --- \\
\hline Alumina & 0,009 & --- \\
\hline Vidro & 0,026 & --- \\
\hline Goetita & 0,38 & 4,04 \\
\hline Ilmenita & 11,2 & 4,75 \\
\hline Hematita & 0,17 & 1,4 \\
\hline Hematita & 0,32 & 1,8 \\
\hline Hematita & 2,23 & 5,0 \\
\hline Óxido de $\mathrm{Mn}$ & 1,20 & 1,9 \\
\hline Óxido de $\mathrm{Mn}$ & 2,32 & 2,5 \\
\hline Óxido de $\mathrm{Mn}$ & 10,7 & 5,0 \\
\hline
\end{tabular}

\subsubsection{Perdas Magnéticas ${ }^{26}$}

Nos processos de aquecimento por meio de ondas de alta freqüiência, as perdas dielétricas são as mais importantes, entretanto deve-se considerar que para materiais que apresentam altas perdas magnéticas, a sua contribuição é significativa no aquecimento desses materiais.

O fator de perdas magnéticas $\left(\mu_{\text {eff }}\right)$ é devido a fenômenos de relaxação e ressonância sob a influência de um campo magnético alternado e é 
associado à camada limite magnética e à ressonância dos spins dos elétrons, sendo independente das perdas por histerese e por correntes parasitas.

A potência dissipada por unidade de volume, quando o material apresenta perdas magnéticas, é dada por:

$$
P_{v}=k \times f \times H^{2} \times \mu^{\prime \prime}{ }_{e f f}
$$

onde: $\mathrm{P}_{\mathrm{v}}$ - potência dissipada por unidade de volume $\left(\mathrm{W} / \mathrm{m}^{3}\right)$;

$\mathrm{k}$ - constante;

f - freqüência do campo elétrico $(\mathrm{Hz})$;

H - valor eficaz do campo magnético variável no ponto considerado no interior do material $(\mathrm{A} / \mathrm{m})$;

$\mu_{\text {eff }}$ - fator de perdas magnéticas.

\subsubsection{Penetração do campo eletromagnético ${ }^{25}$}

A intensidade do campo elétrico E (que aparece na fórmula 16), num ponto no interior do material, é sempre menor do que o valor do campo sobre a superfície, pois ocorre dissipação de energia no percurso da superfície até o ponto considerado. Supondo que uma onda eletromagnética plana incida perpendicularmente sobre a superfície plana do dielétrico, o campo elétrico $\mathrm{E}(\mathrm{Z})$ no interior do material, à distância $\mathrm{Z}$ da superfície, é dado por:

$$
E(Z)=E(0) \times e^{-\alpha \cdot Z}
$$


onde $\mathrm{E}(0)$ é o valor do campo na superfície. Vê-se, portanto, que há uma queda exponencial do campo elétrico com expoente $\alpha$, que é denominado "constante de atenuação" e cujo valor depende da frequiência e das propriedades dielétricas do material. Pode-se deduzir que:

$$
\alpha=1,48 \times 10^{-8} \times f \times\left\{\varepsilon^{\prime}{ }_{r}\left[\sqrt{1+\tan ^{2}} \delta-1\right]\right\}^{1 / 2}
$$

Introduzindo o efeito da atenuação na expressão (16) tem-se a potência dissipada por unidade de volume, num ponto à distância $\mathrm{Z}$ da superfície:

$$
P_{v}(Z)=5,56 \times 10^{-11} \times f \times E(0)^{2} \times \varepsilon^{\prime}{ }_{r} \times \tan \delta \times e^{(-2 . \alpha Z)}
$$

Finalmente, a potência $\mathrm{P}_{\mathrm{v}}(\mathrm{Z})$ dissipada corresponde a um aumento local de temperatura por segundo, dado por:

$$
\frac{\partial T(Z)}{\partial t}=\frac{P_{v}(Z)}{\rho \cdot C_{p}} \quad{ }^{\circ} \mathrm{C} / \mathrm{s}
$$

onde: $\rho\left(\mathrm{kg} / \mathrm{m}^{3}\right)$ a densidade específica e $\mathrm{C}_{\mathrm{p}}\left(\mathrm{J} / \mathrm{kg}{ }^{\circ} \mathrm{C}\right)$ o calor específico.

Tem-se agora uma idéia da complexidade do fenômeno e de alguns problemas técnicos encontrados nos processos de aquecimento dielétrico. Por exemplo, observa-se pela equação (16) que a potência é proporcional à 
freqüência, mantidas constantes as demais variáveis. Pela Tabela 4, verifica-se que o fator de perdas dielétricas relativas, $\varepsilon^{\prime \prime}$, varia com a freqüência. Por outro lado, pela equação (20), a constante de atenuação é proporcional à freqüência, o que leva a crer (pela fórmula (21)) que o quanto se ganha aumentando-se o fator proporcional $f$, perde-se com o fator exponencial que contém $f$.

\subsubsection{Equipamento de Microondas}

Um sistema de aquecimento por microondas é constituído por geradores e aplicadores. Um gerador de microondas é um dispositivo que converte a energia elétrica na freqüência industrial $(60 \mathrm{~Hz})$ em microondas (915 ou $2450 \mathrm{MHz}$ ), com uma eficiência que varia de 50 a $80 \%$, conforme o tipo do gerador, o nível de potência e outras características.

Todos os geradores industriais de microondas são constituídos, basicamente, pelas mesmas partes encontradas no gerador de um forno de microondas doméstico, ou seja, uma fonte de alta tensão e uma válvula osciladora tipo "magnetron".

Não existem geradores do estado sólido que possam competir, em potência e em preço, com os geradores que usam "magnetron". A potência dos geradores individuais pode ser de algumas centenas de Watts (caso doméstico), até algumas dezenas de kWatts (caso industrial). Potências mais elevadas são 
exigidas nos processos de alta produtividade, são obtidas combinando-se vários geradores.

Aplicadores são os dispositivos que permitem submeter os materiais à ação da energia eletromagnética fornecida pelos geradores de microondas.

Existem vários tipos de aplicadores, sendo que, para cada processo, deve-se projetar, construir e adaptar um aplicador específico, a fim de se obter o máximo de transferência de energia eletromagnética para o interior do material que se deseja aquecer. Sistemas de microondas bem projetados e ajustados podem apresentar rendimento global superior a 50\% "da tomada ao produto", ou seja, mais da metade da energia elétrica retirada da rede de distribuição ${ }^{\mathbf{2 5}}$.

O tipo de aplicador mais comum é a cavidade retangular de paredes metálicas, no interior da qual é injetada energia eletromagnética por meio de uma antena que, na maioria dos casos, tem a forma de uma simples abertura, formada pela seção de um guia de ondas (duto metálico retangular), o qual, por sua vez, transmite a energia proveniente do gerador.

Um material dielétrico com perdas dielétricas, colocado no interior de um forno, fica sujeito à ação do campo eletromagnético e se aquece, enquanto que as paredes, por serem metálicas, não são penetradas pelo campo e não se aquecem diretamente. Os fornos de microondas não necessitam de grossas paredes externas de material isolante térmico, como ocorre nos fornos industriais convencionais.

Uma das limitações desse tipo de aplicador (descontínuos ou por batelada) está na falta de uniformidade da distribuição da energia eletromagnética 
na cavidade, o que acarreta diferenças no aquecimento de materiais localizados em pontos diferentes do forno. Melhora-se em parte a uniformidade por meio de refletores giratórios e outros artifícios, mas permanece a limitação básica, que advém da relação entre as dimensões da cavidade e do comprimento de onda $(12,2 \mathrm{~cm}$ em $2450 \mathrm{MHz})$. Por isso, não se pode esperar um aquecimento uniforme num forno doméstico, que é sempre de dimensões reduzidas, o que não ocorre necessariamente no caso de fornos industriais.

\subsection{Trabalhos com utilização da energia de microondas.}

A aplicação da energia de microondas está presente de várias formas e nos mais variados processos fisico-químicos. Uma primeira aplicação da energia de microondas se refere à absorção direta das microondas para efetuar o aquecimento rápido e eficaz de materiais dielétricos sem aquecer as vizinhanças ou outros materiais com pequena constante dielétrica. Essa forma de energia radiante é usada para processamento de alimentos em indústrias e produtos como cerâmicas, substâncias químicas, material eletrônico, produtos de madeira e vários outros. As funções típicas que se realizam são a colagem, a cura, a secagem, a formação de espumas, a fusão, o tratamento térmico, a polimerização e a selagem $^{24}$. 
A utilização da energia de microondas também está sendo estudada em outros processos de forma alternativa, complementar ou inovadora; como mostrado a seguir pelos trabalhos dos pesquisadores:

Kocakusak ${ }^{27}$ estudou a obtenção de óxido de boro $\left(\mathrm{B}_{2} \mathrm{O}_{3}\right)$ a partir da desidratação do ácido ortobórico $\left(\mathrm{H}_{3} \mathrm{BO}_{3}\right)$ utilizando o aquecimento por microondas e mostrou que o produto obtido era de alta pureza, podendo ser empregado em cerâmicas especiais, além de o processo se mostrar de fácil controle. As velocidades de desidratação obtidas foram altas, pois as moléculas dos materiais reagentes eram do tipo polar, proporcionando um rápido aquecimento através da irradiação de microondas.

Sutton $^{\mathbf{2 3}}$ em seu trabalho apresentou aspectos fundamentais da teoria de microondas, como mecanismos de interação e parâmetros dielétricos; listou vários materiais que são susceptíveis ao aquecimento pela energia de microondas. Entre esses materiais, tem-se a magnetita $\left(\mathrm{Fe}_{3} \mathrm{O}_{4}\right)$ e o material carbonoso, e com relação à magnetita é mostrado que ela pode ser aquecida a $1100{ }^{\circ} \mathrm{C}$ após 3 min em um forno de microondas de $2,45 \mathrm{GHz}$ e $1000 \mathrm{~W}$. O autor fez um extensa revisão bibliográfica, onde foi discutido variáveis do processo de aquecimento por microondas (como peso e densidade da amostra, potência utilizada, efeito de aditivos), além da influência dos valores da constante dielétrica relativa no aquecimento das amostras estudadas. 
Morita e Sano ${ }^{28}$ estudaram o processo de reciclagem de escórias, de produção de aço, com a recuperação de ferro e fósforo por meio de redução carbotérmica num forno de microondas (2450 MHz e $1600 \mathrm{~W})$. Foi observado que quando a escória era misturada com o carbono a temperatura atingia $1787^{\circ} \mathrm{C}$ em, aproximadamente, 7 minutos, com uma alta taxa de recuperação de ferro e de fósforo. A recuperação de ferro foi aproximadamente $90 \%$ quando a quantidade de $\mathrm{C}_{\mathrm{eq}}$ era de 1,5. Mostraram que a taxa de aquecimento aumentava com o aumento do teor de carbono e que essa relação possuía um comportamento linear. Morita e Sano também relataram a ocorrência da formação do fenômeno de arco no interior do forno de microondas quando a temperatura superava $1200{ }^{\circ} \mathrm{C}$, evidenciando a formação de fase metálica na amostra.

Segundo Hassine ${ }^{29}$, a síntese de carbonetos de metais refratários (TiC e TaC) é possível através da redução carbotérmica em fornos de microondas. Problemas foram relatados com relação à síntese do carboneto de titânio (como a formação de fases intermediárias), mas para o carboneto de tântalo os resultados foram positivos, com a conversão de $\mathrm{Ta}_{2} \mathrm{O}_{5}$ diretamente para $\mathrm{TaC}$ e em condições de processo mais favoráveis: temperatura de conversão a $1500{ }^{\circ} \mathrm{C}$ durante $1 \mathrm{~h}$, ao passo que no processo convencional a reação ocorre a $1750{ }^{\circ} \mathrm{C}$ durante $6 \mathrm{~h}$. Foi utilizado um forno de microondas, cuja potência variava de 500 a $5000 \mathrm{~W}$ e, para controle da temperatura, utilizou-se um termômetro de fibra ótica. Os resultados experimentais para a conversão do TiC mostraram que o processo se adapta a um 
modelo parabólico indicando que a difusão controla o processo quando se utiliza a energia de microondas.

Ghoreshy e Pickles ${ }^{6}$ trabalharam no tratamento de pós gerados em fornos elétrico a arco e mostraram a eficiência da energia de microondas na recuperação dos elementos zinco e ferro. Utilizaram um forno de microondas doméstico adaptado (900W - $2450 \mathrm{MHz}$ ), no qual a amostra ficava num cadinho de alumina isolado. Relataram que o aumento do tamanho da partícula de carbono favorece na taxa de aquecimento por microondas. Em ensaios com duração de 10 min, atingiu-se a temperatura de $950{ }^{\circ} \mathrm{C}$ para carbono $<200$ mesh e $1100{ }^{\circ} \mathrm{C}$ para carbono > 12 mesh. Estudaram também o efeito da massa da amostra na porcentagem de remoção do óxido de zinco e perceberam que o aumento da massa, aumentava o teor de remoção: utilizando $5 \mathrm{~g}$ de amostra se obtia, aproximadamente, $45 \%$ de remoção, ao passo que, com $15 \mathrm{~g}$ de amostra, a porcentagem de remoção do óxido de zinco atingia $70 \%$, e isso foi devido, segundo os autores, pela elevação da temperatura quando se aumentava a massa da amostra ensaiada.

Zhong ${ }^{1}$, et al estudaram a redução do minério de ferro por carbono através de aquecimento por irradiação de microondas. O minério de ferro utilizado corresponde à taconita (que é rica em magnetita $\left(\mathrm{Fe}_{3} \mathrm{O}_{4}\right)$ ), o qual apresentava uma espécie de baixo teor de sílica e outro com alto teor de sílica; e o carbono estava na forma de coque e carvão mineral. Foi utilizado um 
equipamento industrial para a geração de microondas, o qual poderia chegar até $15000 \mathrm{~W}$ de potência, numa freqüência de $2450 \mathrm{MHz}$. Verificou-se que a maior porcentagem de redução acontecia em misturas constituídas por minério de ferro de alto teor de sílica e agente redutor na forma de carvão mineral ( $90 \%$ de redução em 10 minutos), sendo que esse resultado foi obtido com excesso de $20 \%$ de carbono, em relação ao valor estequiométrico, numa temperatura de , aproximadamente, $1000{ }^{\circ} \mathrm{C}$.

Os autores analisaram a influência da massa da amostra no grau de redução do minério de ferro. Amostras de $50 \mathrm{~g}$ e $5 \mathrm{~g}$ foram levadas em teste por 15 minutos à $1000{ }^{\circ} \mathrm{C}$, e foi observado que a porcentagem de redução, para os dois tipos de amostras, ficou ao redor de 95\%, mostrando que a variação volumétrica da amostra não interfere no processo de redução do minério de ferro, pois foi exposto que o aquecimento por energia de microondas ocorre rapidamente para todo o interior do material. Resultados contraditórios aos de Ghoreshy e Pickles ${ }^{6}$.

O trabalho de Rambo ${ }^{9}$ envolveu a exposição de palha de arroz (subproduto agro-industrial), à irradiação de microondas e à campos eletromagnéticos na faixa de radiofreqüência, em diferentes atmosferas, para promover a pirólise de seus componentes com a intenção de obter como produto o carbeto de silício ( $\mathrm{SiC})$ que é um material cerâmico utilizado na industria de refratários, em materiais compósitos, entre outros. Utilizou-se um forno de microondas doméstico (900 W - $2450 \mathrm{MHz}$ ) adaptado com controle de temperatura através de um pirômetro e termopar. Foi verificado que o carbeto de silício pode ser sintetizado, pela energia de microondas, por pirólise da palha de 
arroz, sendo que o tempo para obtenção desse composto, 15 a $35 \mathrm{~min}$, é menor em relação à outras formas convencionais de processamento, 30 a 120 min.

A seguir é mostrado na figura 7 o comportamento da temperatura em função do tempo de exposição de microondas ao material palha de arroz, onde se percebe diferentes taxas de aquecimento: de $1 \rightarrow 2$ devido à liberação de água; de $2 \rightarrow 3$ o autor supõe que seja devido à transformação de fase, da sílica amorfa em $\alpha$-cristobalita; de $3 \rightarrow 4$ pela formação de $\mathrm{SiC}$ e a partir de $1250{ }^{\circ} \mathrm{C}(4 \rightarrow 5$ ) pela recristalização do $\mathrm{SiC}$ como supõe o autor. As diferenças entre as inclinações das curvas nos estágios pode ser atribuída às diferentes constantes dielétricas das fases presentes em cada faixa de temperatura.

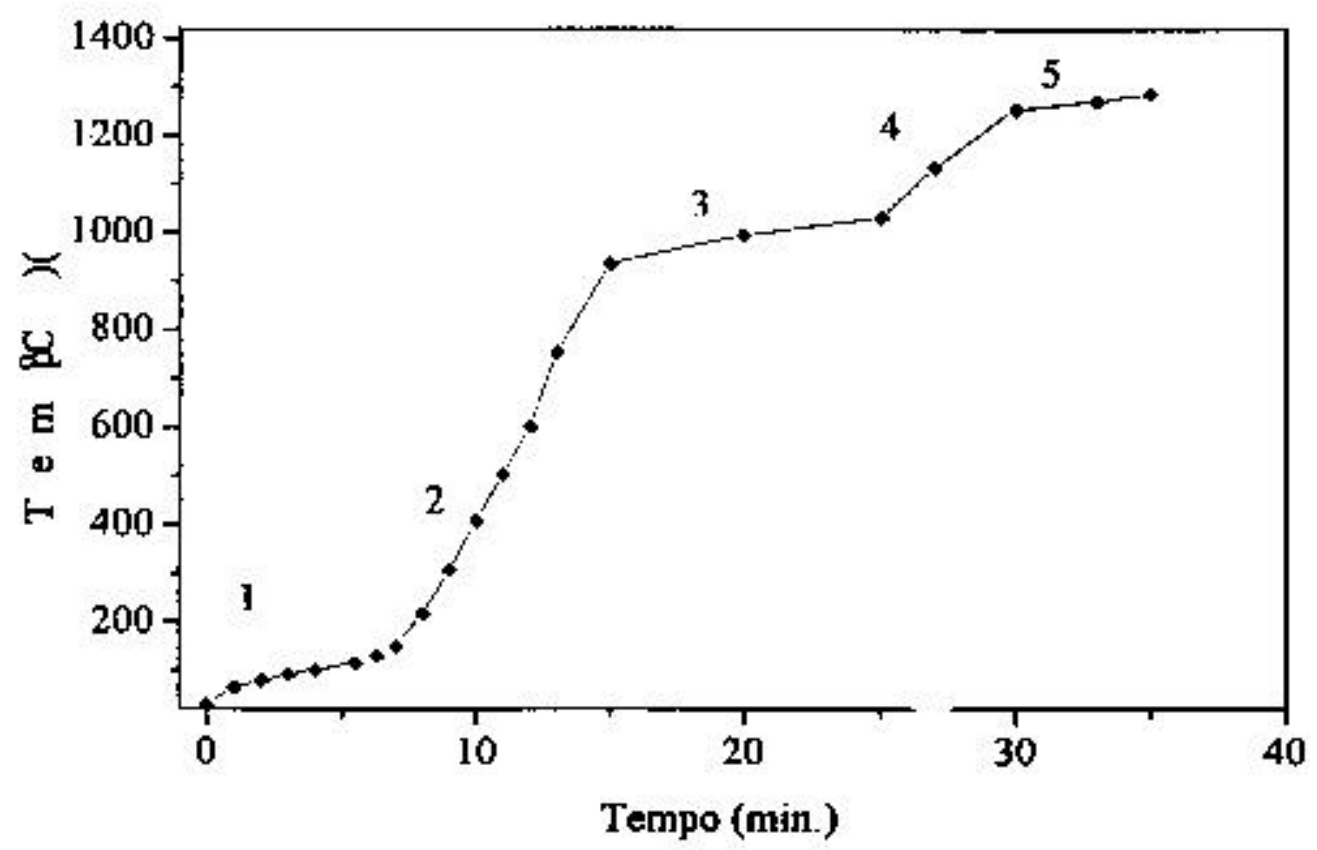

Figura 7: Variação da temperatura $\left({ }^{\circ} \mathrm{C}\right)$ em função do tempo de exposição à irradiação por microondas $(900 \mathrm{~W}-2450 \mathrm{MHz}){ }^{9}$ 
No trabalho de Standish e Pramusanto ${ }^{\mathbf{1 0}}$ se utilizou a energia de microondas num tratamento de pré-redução do minério de ferro que seria posteriormente reduzido pelo monóxido de carbono $(\mathrm{CO})$. O equipamento empregado correspondeu a um forno de microondas de $2450 \mathrm{MHz}$ com potência variando de $700 \mathrm{~W}$ a $1300 \mathrm{~W}$ e o controle da temperatura foi através de um termopar Cr-Al, o qual estava aterrado para evitar flutuações no registro devido ao campo eletromagnético das microondas.

O minério de ferro utilizado pelos autores era rico em magnetita, desta forma se observou uma rápida taxa de aquecimento, foi atingida uma temperatura máxima de $800{ }^{\circ} \mathrm{C}$ em 1 minuto. Foram feitas diversas experiências combinando-se a potência e o tempo de exposição às microondas, para posterior redução desse minério de ferro por $\mathrm{CO}$, e verificou-se que as maiores porcentagens de redução acontecia para o minério tratado durante 6 min. a 1300W, sendo obtido os seguintes graus de redução: 96\% para o minério descrito acima, "versus" $84 \%$ de redução para um minério sem um pré-tratamento por microondas. Segundo o autor isso ocorreu, após análises microscópicas, pela maior porosidade encontrada no minério tratado, e essa maior porosidade ocasionada pelo trincamento das partículas do minério, que ocorreu devido ao aquecimento seletivo que as microondas proporcionam.

Von Krüger ${ }^{33}$, em sua dissertação de mestrado, fez uma avaliação da viabilidade do emprego de microondas para a redução da umidade de minério de ferro, de manganês e de concentrado de fosfatos. Realizou uma comparação entre 
a secagem convencional e a secagem por microondas. Foi analisada a influência da umidade inicial e da massa do minério na secagem por microondas. Avaliouse também parâmetros dielétricos e magnéticos, responsáveis pela absorção de microondas pelo minério. Concluiu-se que o valor calculado do campo elétrico, para a água, é inversamente proporcional ao volume da amostra irradiada, e que o fator de perdas relativas tem uma variação diretamente proporcional à densidade aparente da amostra irradiada. $\mathrm{O}$ autor relata também que a variação da taxa de secagem inicial dos minérios praticamente independe da umidade, para uma mesma potência.

Foram realizadas experiências para verificar o comportamento da temperatura do minério de ferro com o tempo de exposição às microondas e isso foi efetuado por meio de inserção de dois termopares para mostrar também que existem diferentes graus de absorção de microondas, conforme a posição da amostra na cavidade do forno; pode-se observar os resultados através da figura 8:

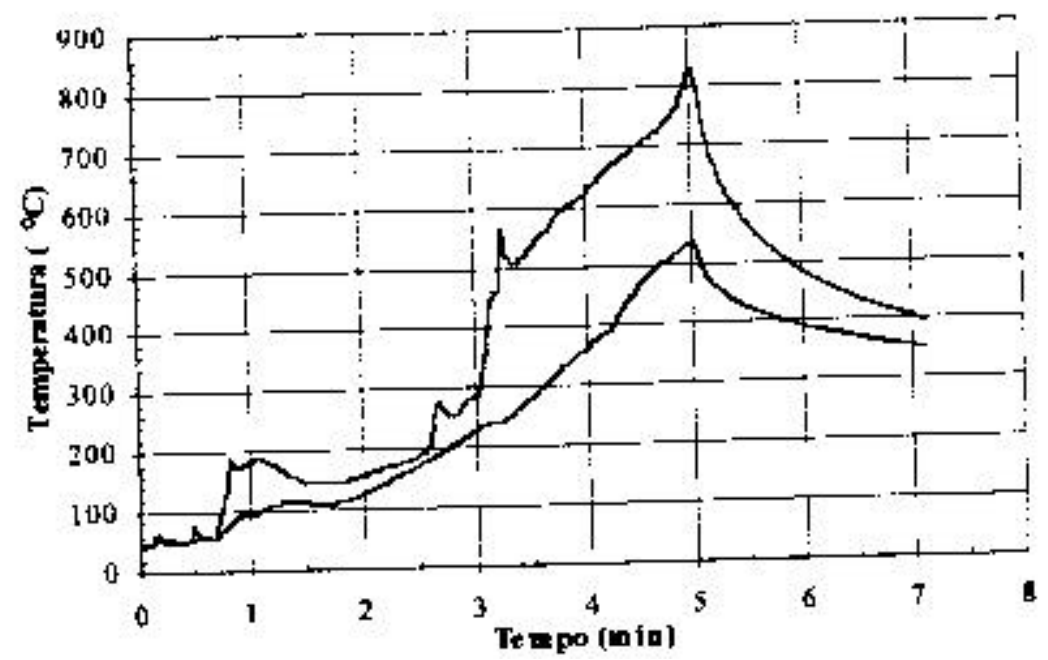

Figura 8: Variação da temperatura em função do tempo de exposição à irradiação por microondas, em dois pontos distintos da cavidade do forno. ${ }^{33}$ 


\section{Materiais e Métodos}

\subsection{Materiais Utilizados}

Os materiais utilizados para a produção das pelotas auto-redutoras foram os seguintes:

- minério de ferro tipo Cauê ;

- como agente redutor, moinha de coque e carvão vegetal;

- como aglomerante o cimento Portland tipo ARI.

As composições químicas do minério de ferro, da moinha de coque e do cimento estão apresentadas nas tabelas 6, 7 e 8 . Na tabela 9 tem-se a análise imediata feita para os agentes redutores utilizados. Todas as análises foram efetuadas na Cia Siderúrgica Paulista - COSIPA ,com exceção da composição química do cimento que foi obtida do trabalho de Takano 5

Tabela 6: Composição Química (\% em peso) - Minério de Ferro Cauê

\begin{tabular}{|c|c|c|c|c|c|c|c|}
\hline $\mathrm{Fe}(\mathrm{t})$ & $\mathrm{SiO}_{2}$ & $\mathrm{Al}_{2} \mathrm{O}_{3}$ & $\mathrm{CaO}$ & $\mathrm{MgO}$ & $\mathrm{P}$ & $\mathrm{MnO}$ & P.F. \\
\hline 68,99 & 0,94 & 0,35 & 0,044 & 0,013 & 0,014 & 0,071 & 0,24 \\
\hline
\end{tabular}

Tabela 7: Composição Química (\% em peso) - Moinha de Coque

\begin{tabular}{|c|c|c|c|c|c|c|}
\hline $\mathrm{C}$ & $\mathrm{SiO}_{2}$ & $\mathrm{Cão}$ & $\mathrm{Al}_{2} \mathrm{O}_{3}$ & $\mathrm{MnO}$ & $\mathrm{MgO}$ & $\mathrm{S}$ \\
\hline 91,94 & 2,90 & 2,25 & 1,16 & 1,03 & 0,16 & 0,56 \\
\hline
\end{tabular}

Tabela 8 : Composição Química (\% em peso) - Cimento Portland ARI

\begin{tabular}{|c|c|c|c|c|c|c|c|c|c|}
\hline $\mathrm{CaO}$ & $\mathrm{SiO}_{2}$ & $\mathrm{Al}_{2} \mathrm{O}_{3}$ & $\mathrm{Fe}_{2} \mathrm{O}_{3}$ & $\mathrm{SO}_{2}$ & $\mathrm{~K}_{2} \mathrm{O}$ & $\mathrm{MgO}$ & $\mathrm{Na}_{2} \mathrm{O}$ & $\begin{array}{c}\mathrm{CaO} \\
\text { Livre }\end{array}$ & Outros \\
\hline 64,3 & 19,05 & 4,92 & 2,78 & 2,63 & 0,73 & 0,55 & 0,04 & 1,01 & 3,99 \\
\hline
\end{tabular}

Tabela 9: Análise Imediata dos Agentes Redutores (\%)

\begin{tabular}{|c|c|c|c|}
\hline & Cinzas & $\mathrm{MV}$ & $\mathrm{C}_{\mathrm{fixo}}$ \\
\hline Carvão Vegetal & 5,47 & 32,88 & 61,65 \\
\hline Moinha de Coque & 13,26 & 4,93 & 81,81 \\
\hline
\end{tabular}




\subsection{Pelotização}

A etapa de pelotização foi efetuada da seguinte forma: inicialmente o material era pesado em balança digital, marca OHAUS, (precisão de miligramas) e posteriormente homogeneizado num misturador TURBULA (figura 9) por 30 min. A esta mistura então (óxido + redutor + aglomerante) efetuava-se uma pelotização manual onde se adicionava, aproximadamente, 10\% em água para proporcionar a ligação intergranular dos componentes.

Após a pelotização, as pelotas permaneciam por 7 dias ao ar para a obtenção do completo ciclo de cura e, antes de serem submetidas ao reator, as pelotas eram levadas à estufa durante 1 dia $\left(\mathrm{T}=120{ }^{\circ} \mathrm{C}\right)$ para a eliminação de umidade, caso contrário, poderia haver a ocorrência da crepitação ${ }^{34}$.

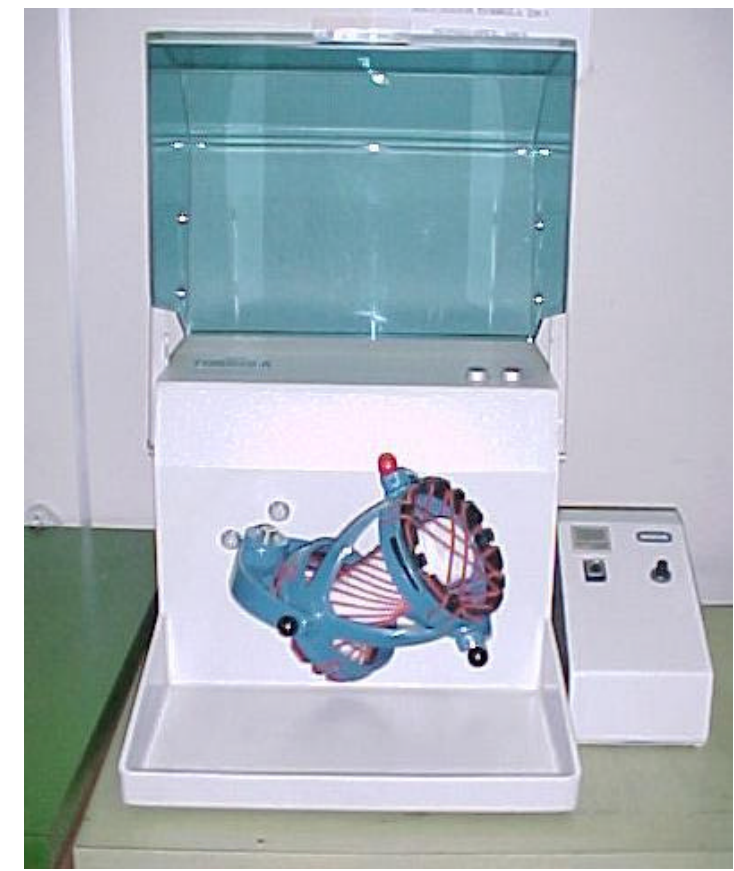

Figura 9: Fotografia do misturador Turbula utilizado para a homogeneização da mistura a ser pelotizada. 


\subsection{Composição das Pelotas}

As composições das pelotas utilizadas estão apresentadas na Tabela 10. Sua constituição foi determinada com a intenção de se analisar a influência de algumas variáveis no processo de redução a que essas amostras seriam submetidas. A primeira análise foi com relação à influência do aglomerante (obtida pela comparação entre as pelotas A e B - Tabela 10), depois a ação da quantidade do agente redutor (comparações entre as pelotas $\mathrm{B}$ e $\mathrm{C}$ e também entre as pelotas E e F), influência da granulometria do agente redutor (pelotas $\mathrm{C}$ e D) e influência do tipo de agente redutor (pelotas B e E).

A quantidade de material carbonáceo (coque ou carvão vegetal) adicionado à mistura foi calculado baseando-se na quantidade de oxigênio combinado ao minério de ferro. Foram usadas duas relações diferentes entre material carbonáceo e oxigênio combinado: $\mathrm{C} / \mathrm{O}=1,0$ e $\mathrm{C} / \mathrm{O}=1,33$ (tanto para coque como para carvão vegetal), onde "C" representa a quantidade de material carbonáceo. Esse critério de relação das massas foi adotado para se tentar manter condições similares de aquecimento para ambos os materiais.

Também foi analisada a influência de um isolamento térmico sobre as pelotas ensaiadas em forno de microondas, utilizando para isso, uma manta isolante de alumina.

Todas as composições de pelota (de "A" a "F") possuíam diâmetros e pesos semelhantes: de 15 a $18 \mathrm{~mm}$ e de 4 a $6 \mathrm{~g}$, respectivamente. 
Tabela 10: Composição (\% em peso) das Pelotas Auto-Redutoras

\begin{tabular}{|c|c|c|c|c|c|c|}
\hline \multirow{2}{*}{ MATERIAL } & \multicolumn{7}{|c|}{ PELOTA TIPO } \\
\cline { 2 - 7 } & A & B & C & D & E & F \\
\hline Min. Fe Cauê & 81,6 & 76,3 & 71,9 & 71,9 & 76,3 & 71,9 \\
\hline Moinha de Coque & 18,4 & 17,2 & 21,6 & 21,6 & --- & --- \\
\hline Carvão Vegetal & --- & --- & --- & --- & 17,2 & 21,6 \\
\hline Cim. Portland ARI & --- & 6,5 & 6,5 & 6,5 & 6,5 & 6,5 \\
\hline
\end{tabular}

A seguir é mostrado na Tabela 11 a granulometria do agente redutor, moinha de coque e carvão vegetal, das 6 composições de pelotas estudadas:

Tabela 11: Granulometria do agente redutor utilizado nas pelotas auto-redutoras

\begin{tabular}{|c|c|c|c|c|c|c|}
\hline Pelota & A & B & C & D & E & F \\
\hline Mesh & $100-150$ & $100-150$ & $100-150$ & $35-50$ & $100-150$ & $100-150$ \\
\hline
\end{tabular}

Percebe-se apenas na composição "D" uma diferenciação de granulometria, e para sua identificação será referida como coque "grosso", devido ao maior tamanho de partícula da moinha de coque em relação às outras composições. Para o minério de ferro Cauê e para o cimento Portland ARI, não foi efetuado nenhum tipo de separação para se obter determinada faixa granulométrica, sendo que a granulometria do cimento era toda menor que 150 mesh e na tabela 12 tem-se a distribuição granulométrica do minério de ferro Cauê.

Com relação ao aglomerante (cimento Portland - tipo ARI), a porcentagem fixada foi de $6,5 \%$, menos para a pelota tipo A que não possuía 
aglomerante; esse valor foi escolhido tendo como base o trabalho desenvolvido por Takano ${ }^{\mathbf{5}}$, onde a maior eficiência ao endurecimento das pelotas autoredutoras se dá na faixa de 6 a $8 \%$ do aglomerante.

Tabela 12: Distribuição Granulométrica do Minério de Ferro - Cauê (\% retida)

\begin{tabular}{|c|c|}
\hline Peneira ASTM & Minério de Ferro \\
\hline 40 & 0,20 \\
\hline 70 & 1,46 \\
\hline 100 & 6,43 \\
\hline 140 & 9,00 \\
\hline 200 & 24,79 \\
\hline 270 & 9,56 \\
\hline 325 & 5,81 \\
\hline$<325$ & 42,75 \\
\hline
\end{tabular}

\subsection{Ensaios Termogravimétricos}

A caracterização do comportamento cinético das pelotas autoredutoras durante o processo de redução direta, nas diferentes faixas de temperaturas, foi obtido através da porcentagem de material reagido. O cálculo da quantidade de material que reagiu durante cada experimento realizado foi efetuado empregando-se a seguinte equação:

$$
P R=\left(\frac{M_{i}-M_{t}}{M \times M_{i}}\right) \times 100
$$


onde: PR - porcentagem de reação;

$\mathrm{M}_{\mathrm{i}}$ - peso inicial da amostra $(\mathrm{g})$;

$\mathrm{M}_{\mathrm{t}}$ - peso $(\mathrm{g})$ no instante $\mathrm{t}$;

M - porcentagem máxima de perda de peso.

Foi obtido então gráficos de porcentagem de reação em função do tempo, figuras 13 e 14, para as pelotas que foram ensaiadas em forno convencional de resistência e, figuras de 15 a 23 para as pelotas submetidas ao forno de microondas. As experiências que utilizaram a energia de microondas foram processadas de maneira descontínua, ou seja, utilizou-se várias amostras de determinada composição para o levantamento da curva "porcentagem de reação X tempo", de tal forma que a experiência era interrompida quando se atingia o tempo especificado de antemão, até o tempo limite de 30 minutos. Desta forma, foi possível a análise microscópica e por difração de raio-X de tempos intermediários do processo de redução do min. de ferro (seção 4.5 e 4.6).

As experiências termogravimétricas foram feitas em um forno de microondas Panasonic (1100W - $2450 \mathrm{MHz})$, que foi adaptado para possibilitar a entrada do gás argônio e saída dos gases da reação, e para proporcionar a medição da temperatura por meio de um termopar tipo R, o qual foi inserido no interior da pelota. O isolamento da atmosfera de reação era proporcionado por um becker adaptado para tal condição, lembrando que seu material é transparente à irradiação por microondas, assim era possível um contato visual com a amostra 
durante toda a experiência de redução do minério de ferro. A figura 10 mostra o esquema do aparato experimental utilizado:

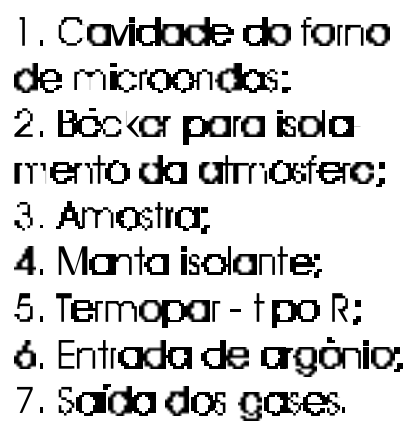

As experiências que utilizaram como energia a resistência elétrica foram processadas em um forno de resistência, marca LINDBERG/BLUE, que tem como características a temperatura máxima de $1500{ }^{\circ} \mathrm{C}$, tensão de $240 \mathrm{~V}$ e potência de $7200 \mathrm{~W}$; o esquema desse forno está mostrado na figura 11 e sua foto na figura 12. Tanto para as experiências em forno de resistência, quanto para aquelas efetuadas em forno de microondas, a vazão de gás argônio foi sempre fixada em 4 1/min.

Terminado os ensaios termogravimétricos, as amostras permaneciam por mais 10 minutos sob o fluxo de argônio, em forno de resistência e em forno de microondas, para evitar a reoxidação. 


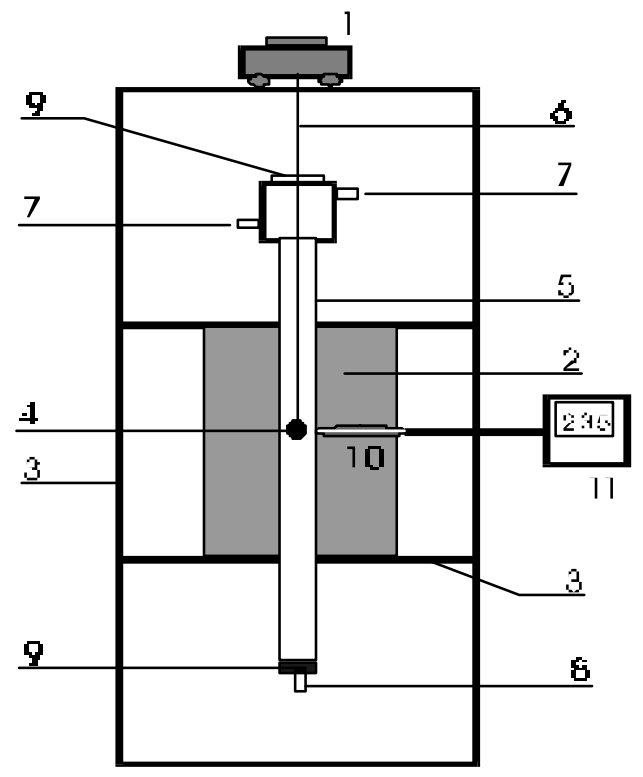

1 Enlanga Elathon cos

2 Forng Tubular

3 Supars e Guirs

4 incostro

5 Tutod de Aco lnox

6 Flo de Cr-NI

7 Entroja e saida:

do Egu

g Eriliado de Agónio

9 Tompas ge Motenlal

Rératório

IG Тстгісра Tpo R

I I Conirolador Dgilol

Figura 11: Esquema do forno de resistência utilizado nos ensaios termogravimétricos.

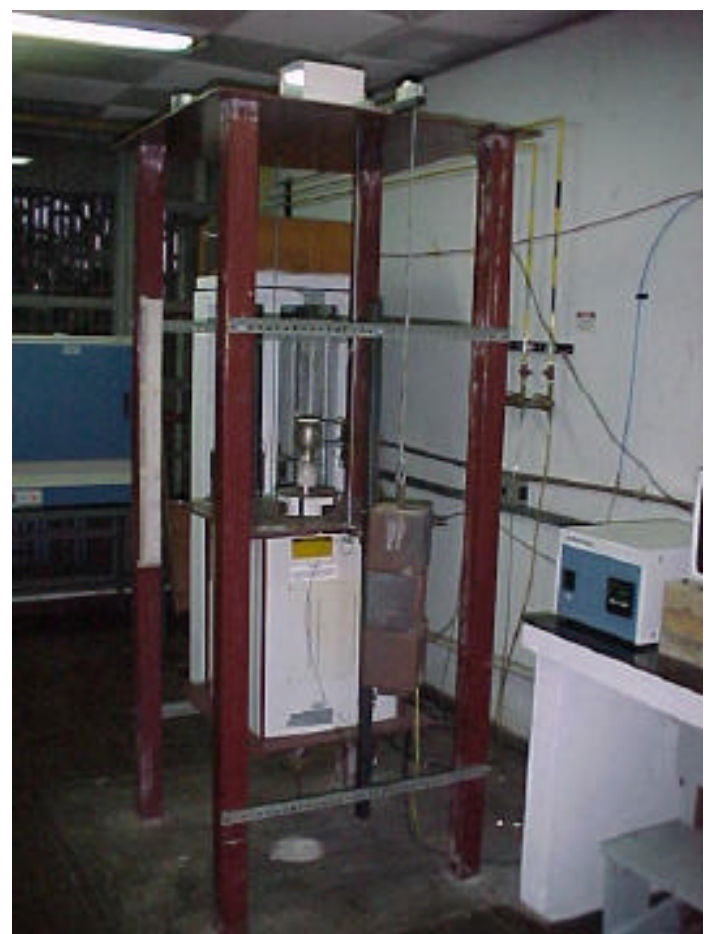

Figura 12: Foto do forno de resistência utilizado nos ensaios termogravimétricos . 


\section{Resultados e Discussões}

\subsection{Termogravimetria em forno de resistência}

Os primeiros resultados obtidos foram os ensaios termogravimétricos para as pelotas ensaiadas em forno de resistência, figuras 13 e 14. Estes experimentos foram conduzidos de forma isotérmica e serão utilizados para comparações com o método em que se utiliza a energia de microondas para a redução do minério de ferro.

Na figura 13 tem-se os resultados obtidos para todas as composições de pelota estudadas na temperatura de $1150{ }^{\circ} \mathrm{C}$, e esse valor foi escolhido pois sabe-se ${ }^{3}$ que, nesta temperatura, a reação de redução do minério de ferro se completa totalmente e que o mecanismo controlador é a reação de Boudouard. A figura 14 corresponde às mesmas composições da figura 13, mas ensaiadas na temperatura de $950{ }^{\circ} \mathrm{C}$. Percebe-se um comportamento semelhante em relação à ordem das composições no grau de redução, sendo que os melhores resultados foram da pelota "F" que possui carvão vegetal como agente redutor e os piores valores para a pelota "A" constituída de moinha de coque como agente redutor e sem a presença do cimento Portland ARI como aglomerante. As curvas da figura 13 e 14 foram construídas por meio da equação (23) cujo valor de "M" (porcentagem máxima de perda de peso) foi extraído das experiências a $1150{ }^{\circ} \mathrm{C}$ e posteriormente utilizado para todas as outras experiências termogravimétricas, podendo assim ser feita uma comparação coerente dos valores encontrados. 


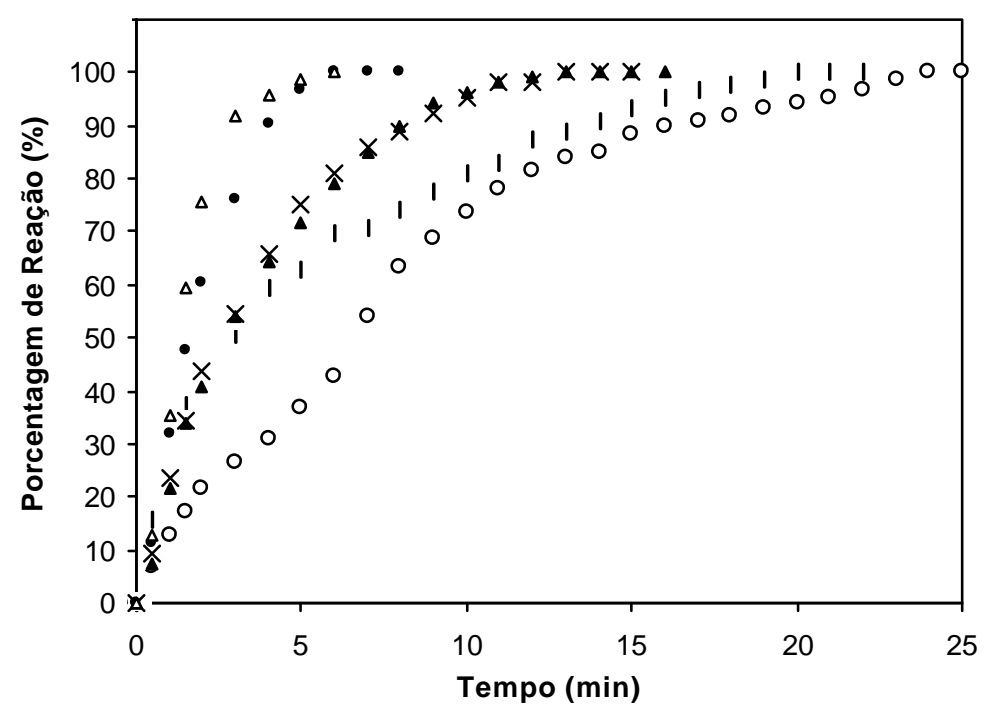

- A (coque; $\mathrm{C} / \mathrm{O}=1,0$; sem cimento)

I $\mathrm{B}$ (coque; $\mathrm{C} / \mathrm{O}=1,0 ;$ com cimento)

$\times \mathrm{C}$ (coque; $\mathrm{C} / \mathrm{O}=1,33$; com cimento)

$\Delta \mathrm{D}$ (coque grosso; $\mathrm{C} / \mathrm{O}=1,33$; com cimento)

- $\mathrm{E}$ (carvão vegetal; $\mathrm{C} / \mathrm{O}=1,0$; com cimento)

$\Delta \mathrm{F}$ (carvão vegetal; $\mathrm{C} / \mathrm{O}=1,33$; com cimento)

Figura 13: Porcentagem de reação em função do tempo, a $1150{ }^{\circ} \mathrm{C}$, de várias composições de pelotas (tabela 10), em forno de resistência.

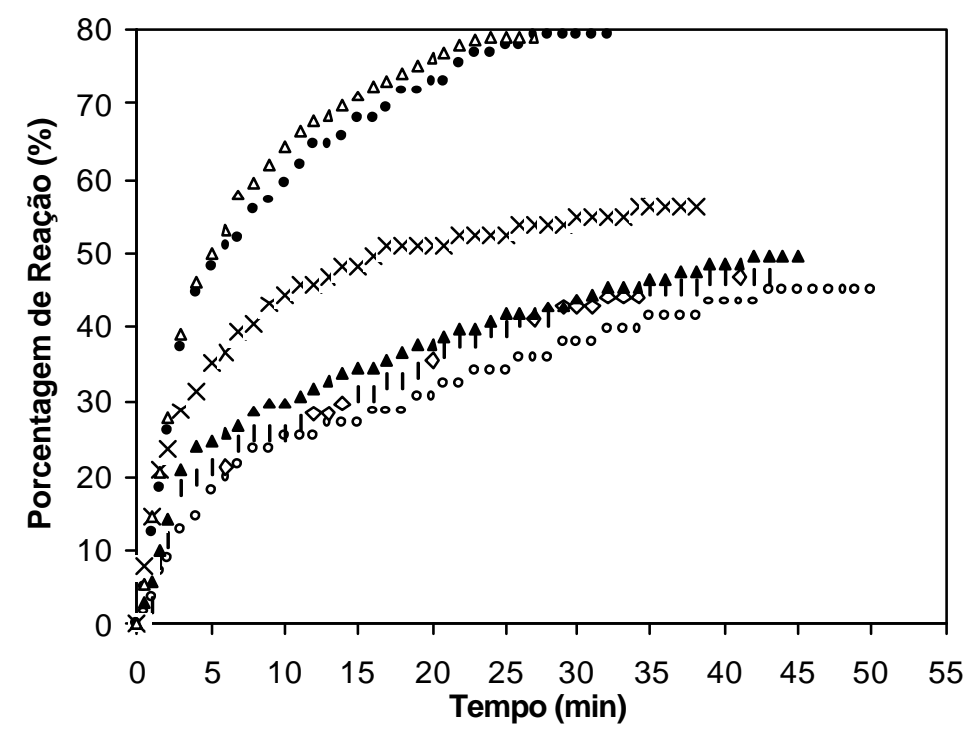

- $A$ (coque; $C / O=1,0$; sem cimento)

I $\mathrm{B}$ (coque; $\mathrm{C} / \mathrm{O}=1,0 ;$ com cimento)

$\times C$ (coque; $\mathrm{C} / \mathrm{O}=1,33$; com cimento)

$\Delta \mathrm{D}$ (coque grosso; $\mathrm{C} / \mathrm{O}=1,33$; com cimento)

- $\mathrm{E}$ (carvão vegetal; $\mathrm{C} / \mathrm{O}=1,0$; com cimento)

$\Delta \mathrm{F}$ (carvão vegetal; $\mathrm{C} / \mathrm{O}=1,33$; com cimento)

Figura 14: Porcentagem de reação em função do tempo, a $950{ }^{\circ} \mathrm{C}$, de várias composições de pelotas (tabela 10), em forno de resistência. 
Outro aspecto a observar é com relação às composições C e D, essas pelotas possuem a mesma constituição química com a diferença na granulometria da moinha de coque (entre 100 a 150 mesh para a pelota $\mathrm{C}$ e 35 a 50 mesh para a pelota D), vê-se que na temperatura de $1150{ }^{\circ} \mathrm{C}$ os resultados da termogravimetria dessas pelotas foram praticamente os mesmos, ao passo que a $950{ }^{\circ} \mathrm{C}$ existe uma diferença significativa, mostrando portanto que o tamanho da partícula do agente redutor exerce influência em temperaturas baixas de modo a diminuir o grau de redução à medida que se aumenta o tamanho da partícula da moinha de coque.

\subsection{Termogravimetria em forno de microondas}

A seguir são mostrados os resultados obtidos nas experiências termogravimétricas onde se utilizou a energia de microondas na redução do minério de ferro na forma de pelotas auto-redutoras, figuras 15 a 23 . As curvas dessas figuras mostram a porcentagem de reação em função do tempo de exposição à irradiação por microondas e também o perfil de temperatura encontrado nas amostras durante o processo de redução. Esses ensaios foram feitos para todas as composições de pelota (de A até F) além de experiências termogravimétricas em que a amostra era isolada termicamente por meio de uma manta isolante (figuras 19, 21 e 23). 


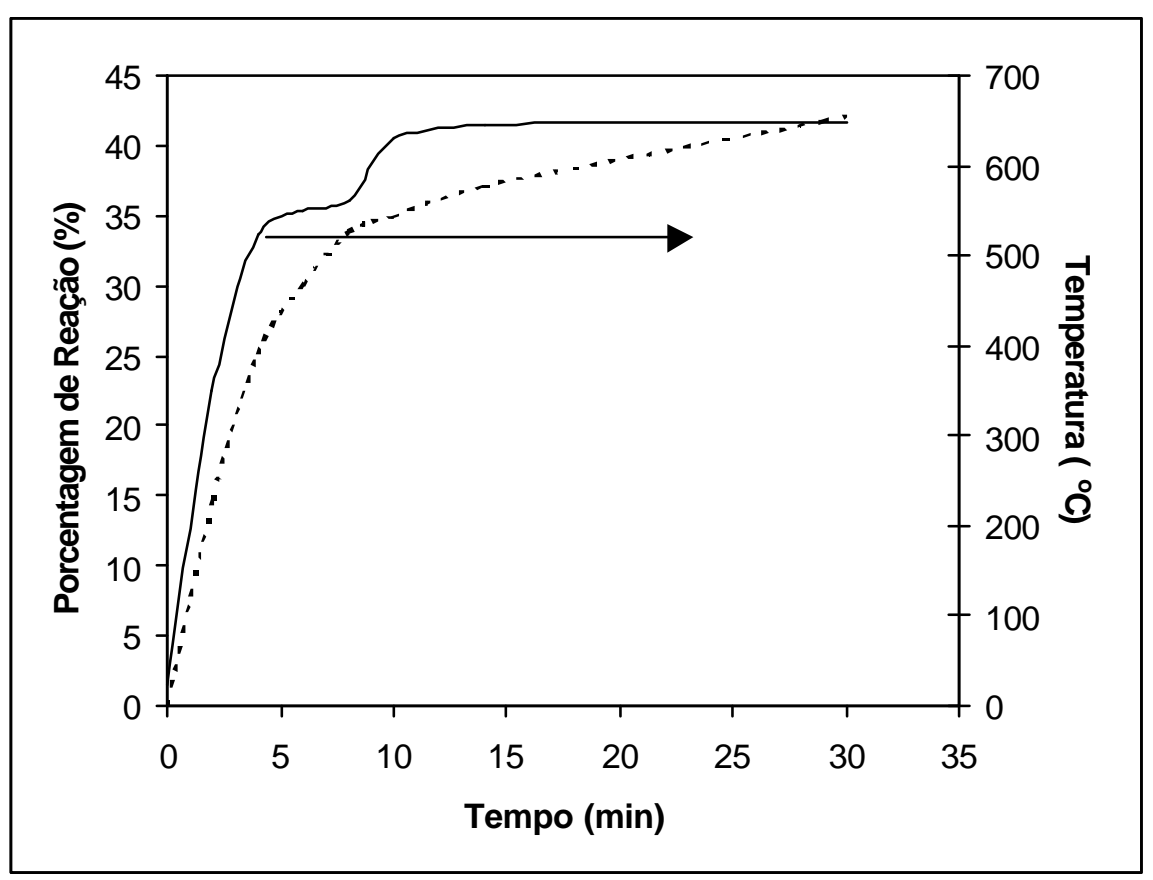

Figura 15: Porcentagem de Reação (\%) e Temperatura $\left({ }^{\circ} \mathrm{C}\right)$ em função do Tempo ( $\mathrm{min}$ ) para as pelotas $\mathrm{A}$ (coque; $\mathrm{C} / \mathrm{O}=1,0$; sem cimento).

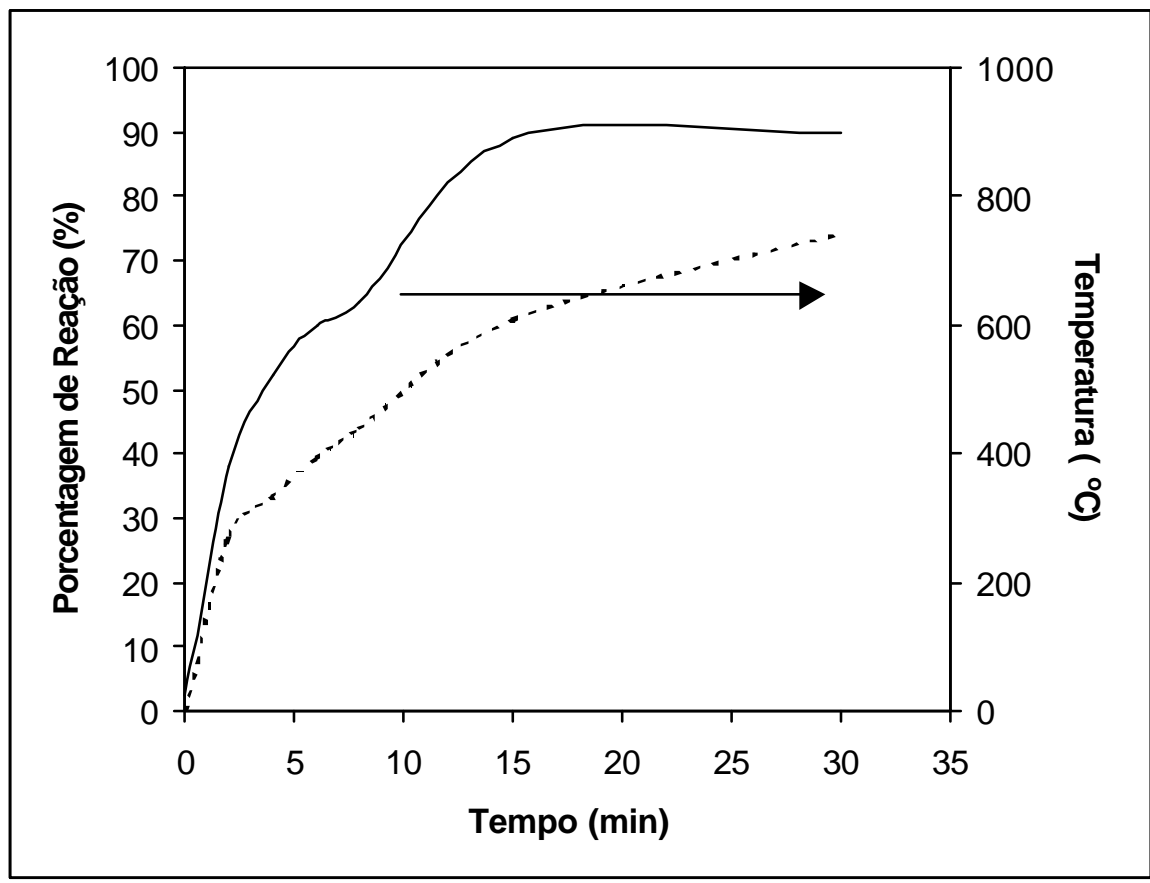

Figura 16: Porcentagem de Reação $(\%)$ e Temperatura $\left({ }^{\circ} \mathrm{C}\right)$ em função do Tempo ( $\mathrm{min}$ ) para as pelotas $\mathrm{B}$ (coque; $\mathrm{C} / \mathrm{O}=1,0$; com cimento). 


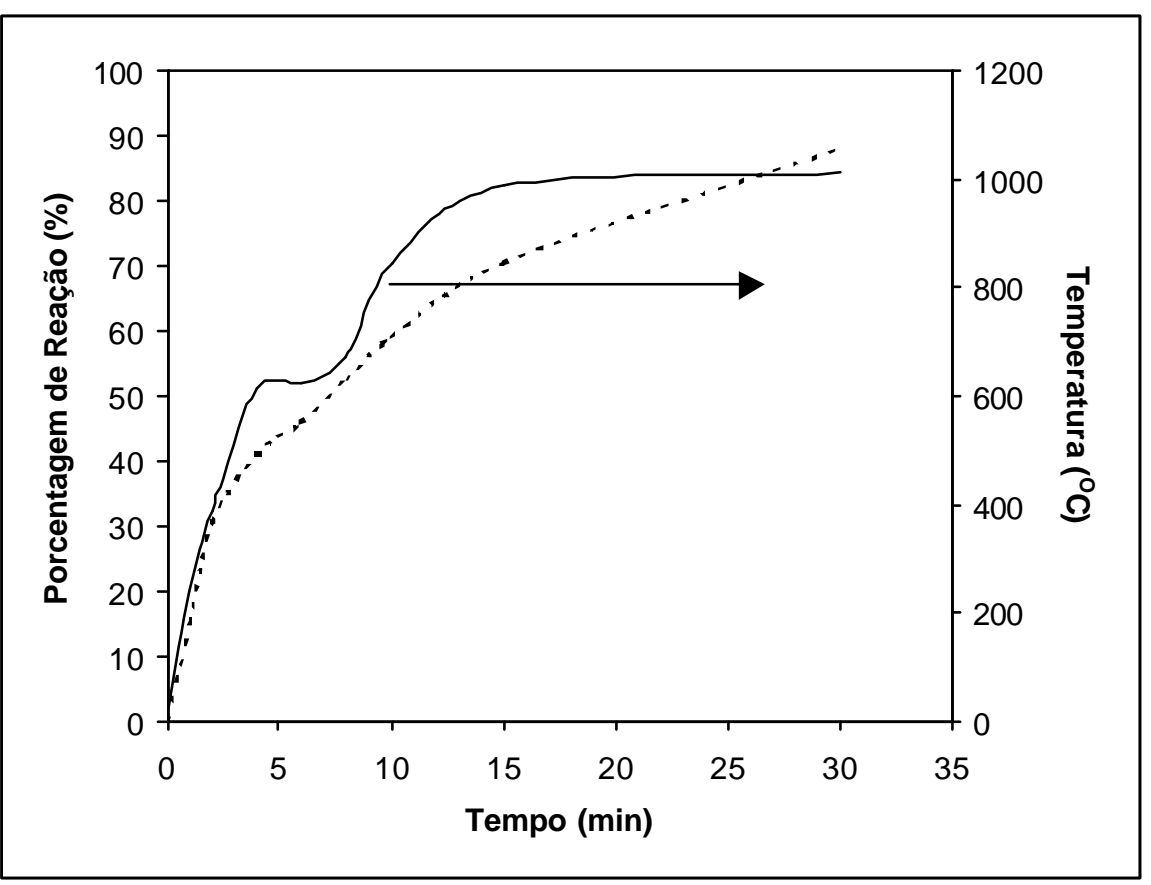

Figura 17: Porcentagem de Reação (\%) e Temperatura $\left({ }^{\circ} \mathrm{C}\right)$ em função do Tempo (min) para as pelotas $\mathrm{C}$ (coque; $\mathrm{C} / \mathrm{O}=1,33$; com cimento).

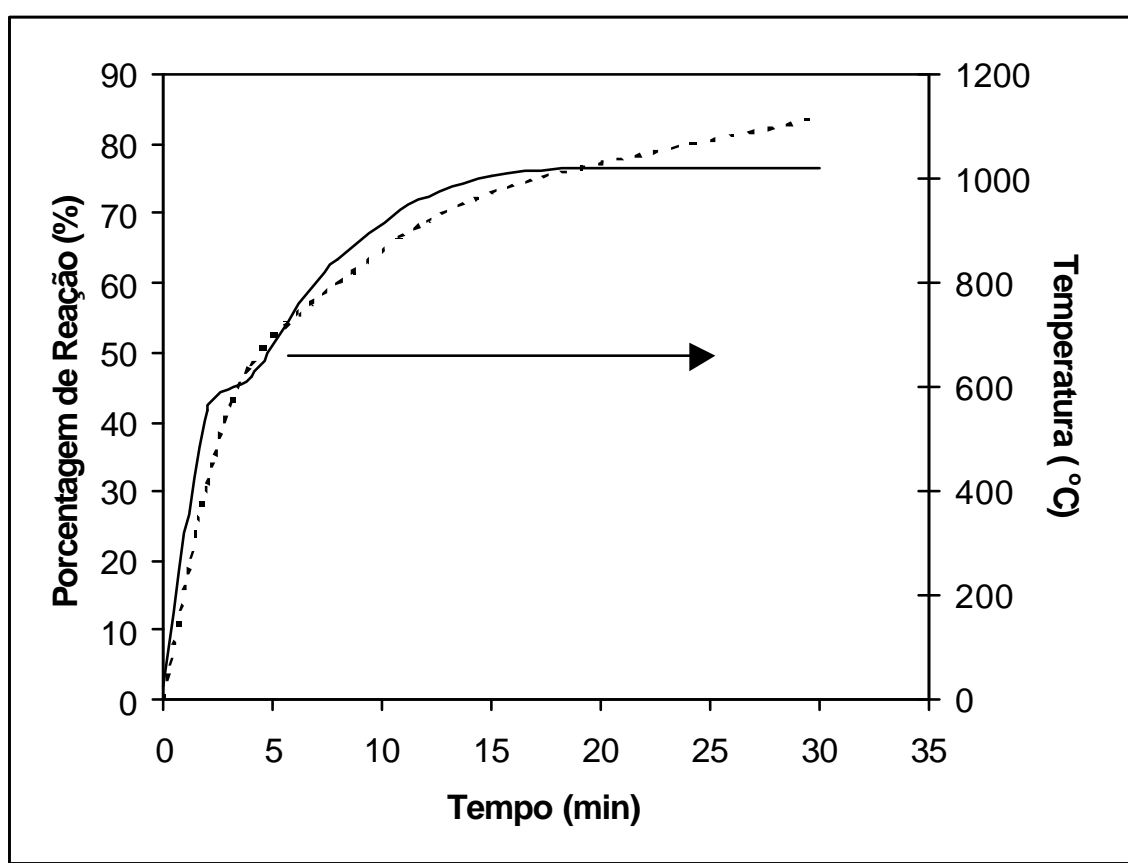

Figura 18: Porcentagem de Reação (\%) e Temperatura $\left({ }^{\circ} \mathrm{C}\right)$ em função do Tempo (min) para as pelotas $\mathrm{D}$ (coque "grosso"; $\mathrm{C} / \mathrm{O}=1,33$; com cimento). 


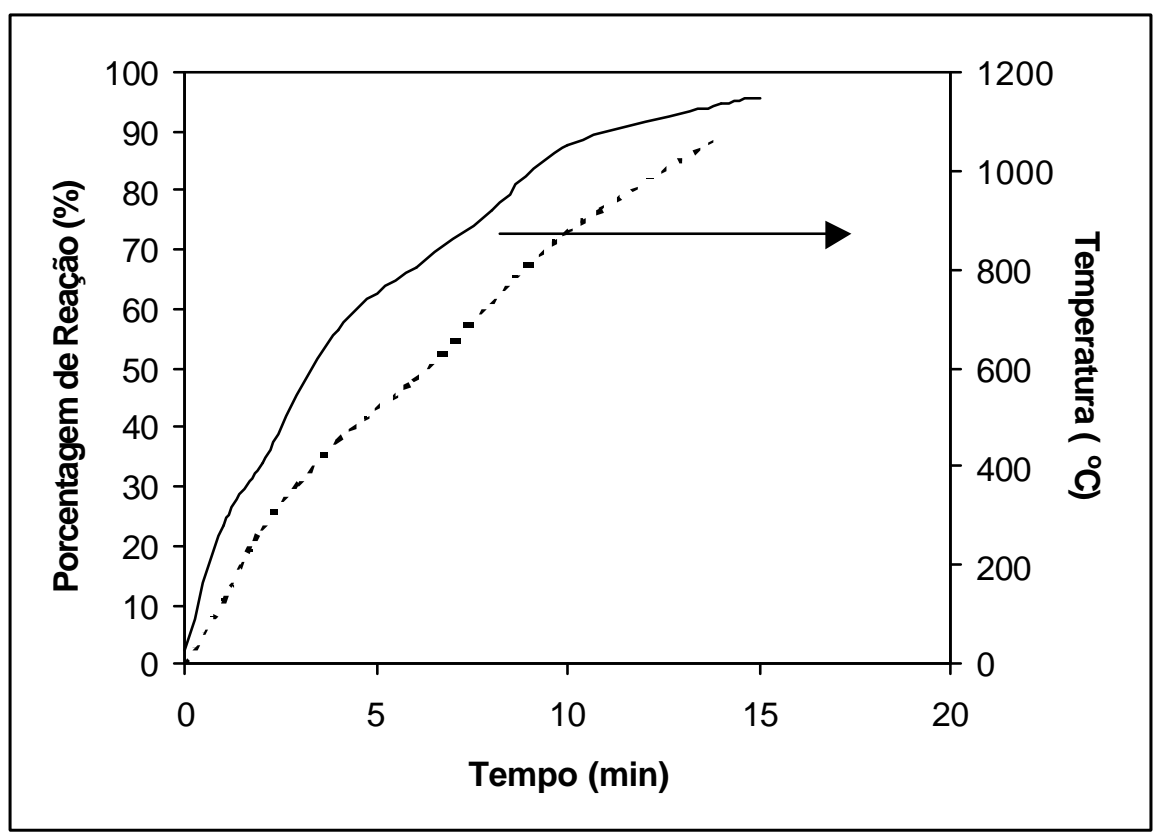

Figura 19: Porcentagem de Reação $(\%)$ e Temperatura $\left({ }^{\circ} \mathrm{C}\right)$ em função do Tempo (min) para as pelotas D isol. (coque "grosso";

$\mathrm{C} / \mathrm{O}=1,33$; com cimento e isolamento térmico).

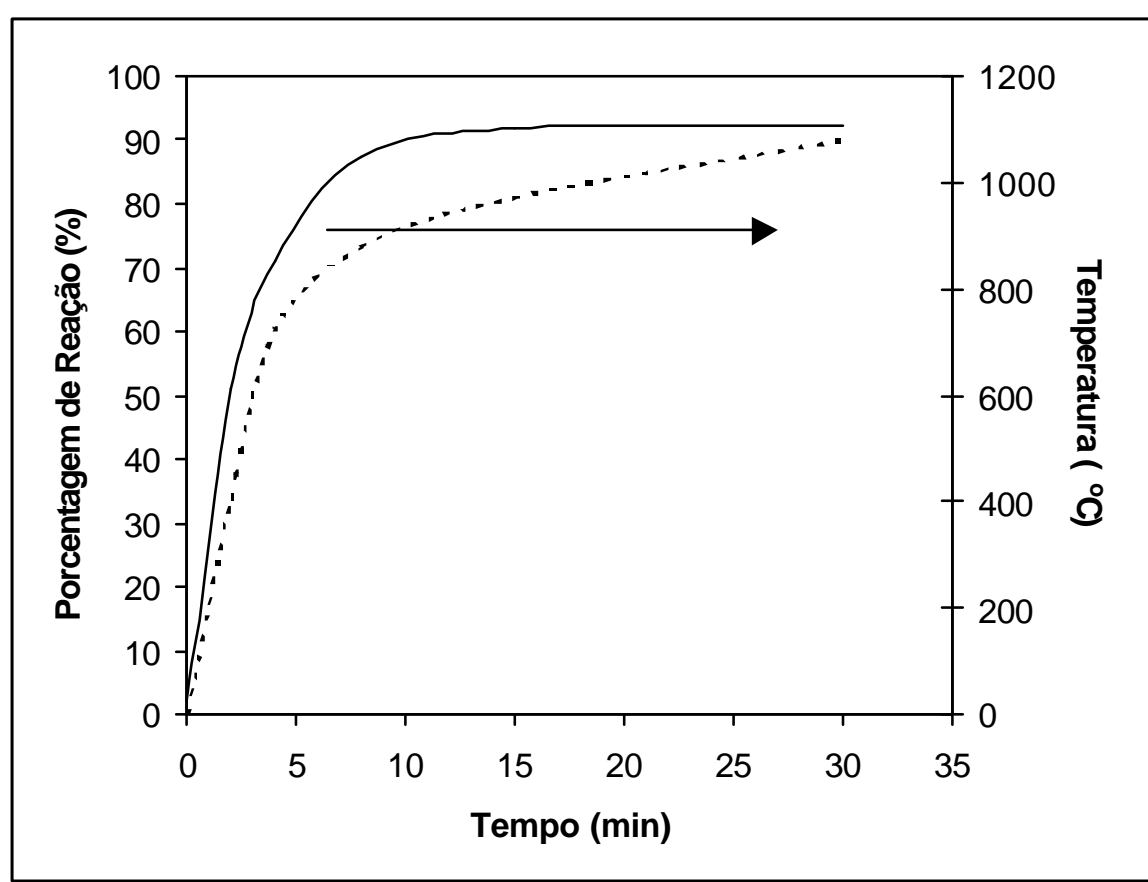

Figura 20: Porcentagem de Reação (\%) e Temperatura $\left({ }^{\circ} \mathrm{C}\right)$ em função do Tempo (min), para as pelotas $\mathrm{E}$ (carvão vegetal; $\mathrm{C} / \mathrm{O}=1,0$; com cimento). 


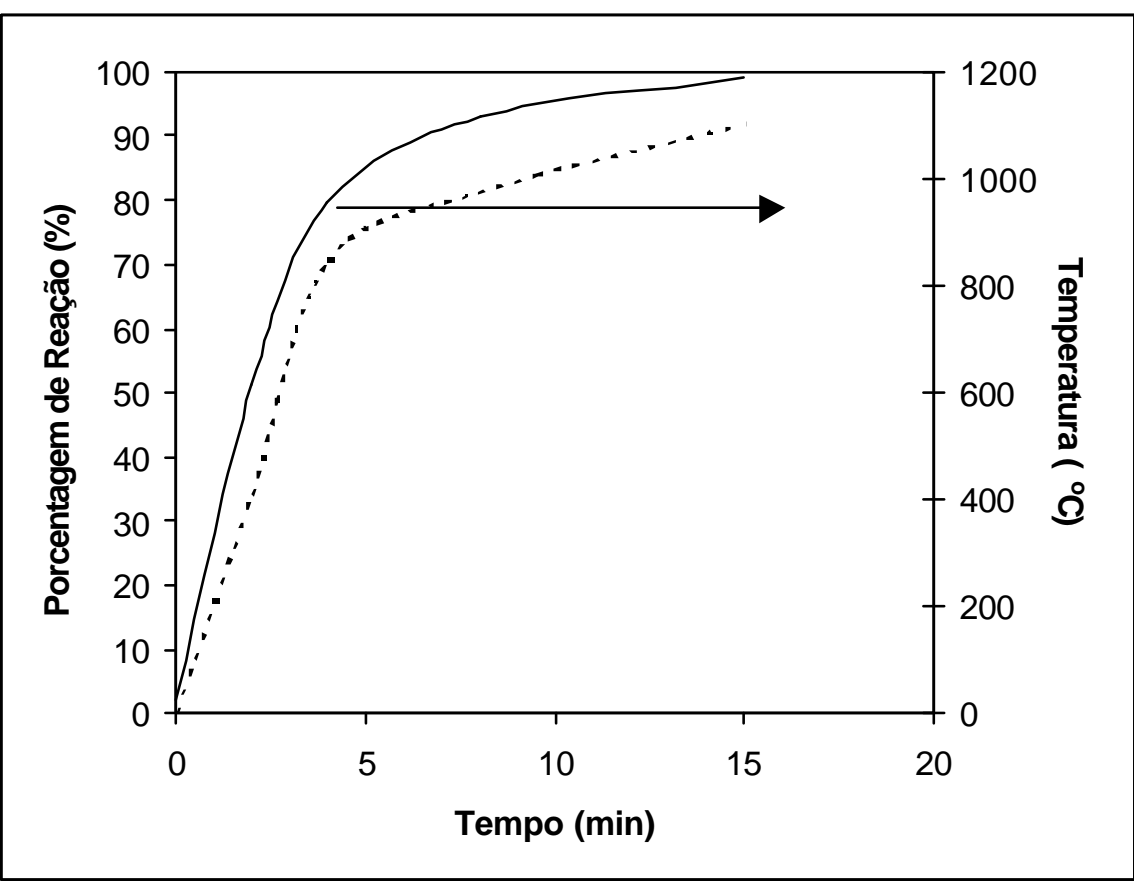

Figura 21: Porcentagem de Reação (\%) e Temperatura $\left({ }^{\circ} \mathrm{C}\right)$ em função do Tempo (min) para as pelotas $\mathrm{E}$ isol. (carvão vegetal; $\mathrm{C} / \mathrm{O}=1,0$; com cimento e isolamento térmico).

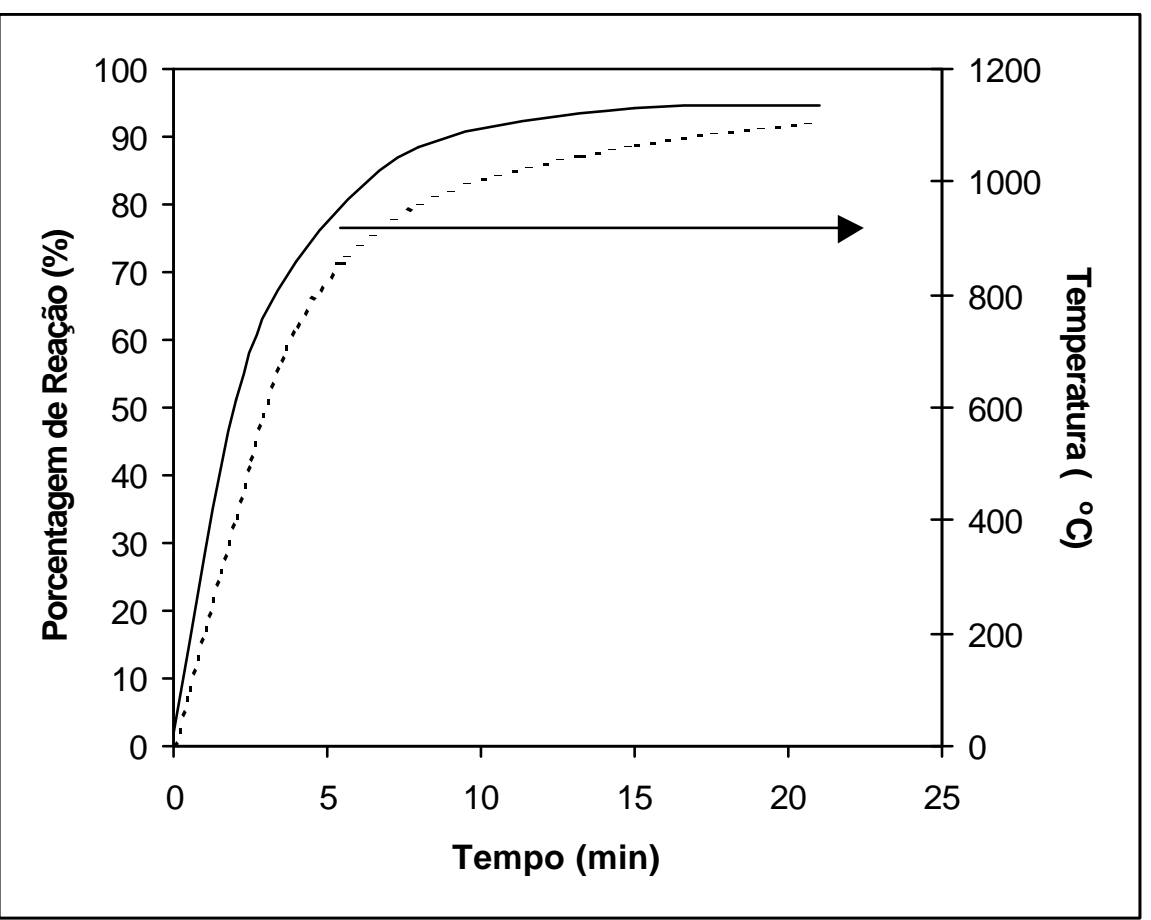

Figura 22: Porcentagem de Reação $(\%)$ e Temperatura $\left({ }^{\circ} \mathrm{C}\right)$ em função do Tempo (min), para as pelotas $\mathrm{F}$ (carvão vegetal; $\mathrm{C} / \mathrm{O}=1,33$; com cimento). 


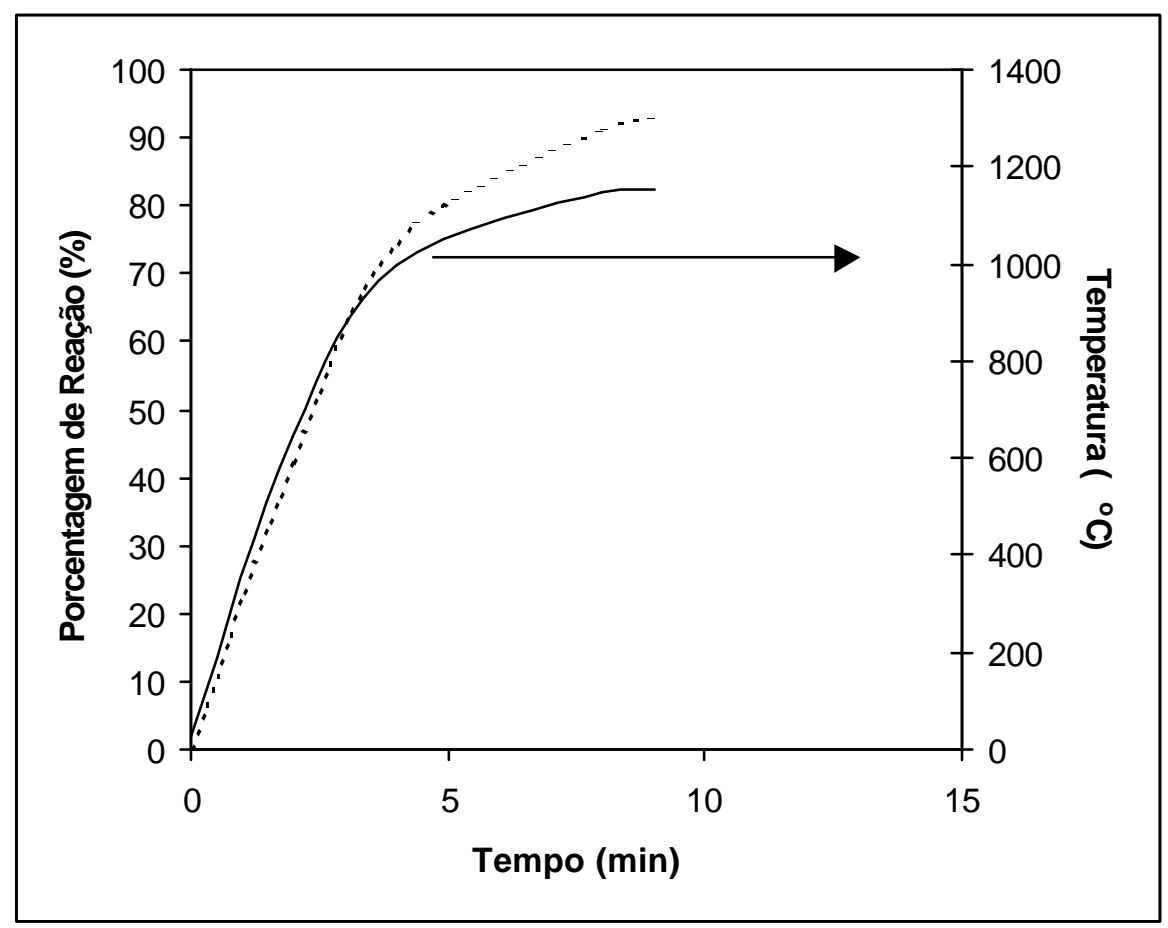

Figura 23: Porcentagem de Reação (\%) e Temperatura $\left({ }^{\circ} \mathrm{C}\right)$ em função do Tempo (min) para as pelotas $\mathrm{F}$ isol. (carvão vegetal; $\mathrm{C} / \mathrm{O}=1,33$; com cimento e isolamento térmico).

Antes de todas as experiências termogravimétricas, as pelotas eram levadas à estufa na temperatura de $120^{\circ} \mathrm{C}$, durante um dia, para a secagem, onde se observou a remoção, em média, de $0,4 \%$ de umidade. Foi observado em todas as experiências termogravimétricas, em forno de microondas, que as pelotas trincavam devido à liberação dos gases de reação no interior da pelota, pois o aquecimento por irradiação de microondas ocorre de dentro para fora. $\mathrm{Na}$ próxima seção deste trabalho será mostrado como os resultados obtidos das figuras 15 a 23 serão analisados . 


\subsection{Análise das Variáveis de Processo}

\subsubsection{Influência da Presença de Aglomerante}

Através dos resultados obtidos nas experiências em que se utilizou a pelota $\mathrm{A}$, constituída apenas por minério de ferro e moinha de coque, e a pelota $\mathrm{B}$ de mesma relação em massa com a pelota $\mathrm{A}$, mas com a presença do cimento Portland - ARI como aglomerante; obteve-se então a figura 24, construída através das curvas das figuras 15 e 16, onde se percebe uma acentuada melhora na porcentagem de reação para a amostra que continha o cimento (pelota B), mostrando que os compostos do cimento empregado, basicamente $\mathrm{CaO}$ e $\mathrm{SiO}_{2}$ (Tabela 8), são susceptíveis ao aquecimento por microondas, como já havia sido descrito por Sutton ${ }^{23}$ para o caso da sílica.

Outro fato que também favoreceu as maiores taxas de redução para a pelota que continha cimento, é o acontecimento, durante o processo de aquecimento, da reversão das reações de hidratação dos compostos hidratados do cimento com a liberação de água, havendo a reação:

$$
\mathrm{H}_{2} \mathrm{O}_{(\mathrm{v})}+\mathrm{C}_{(\mathrm{s})} \rightarrow \mathrm{CO}_{(\mathrm{g})}+\mathrm{H}_{2(\mathrm{~g})}
$$

com os produtos gasosos atuando como agentes redutores. 


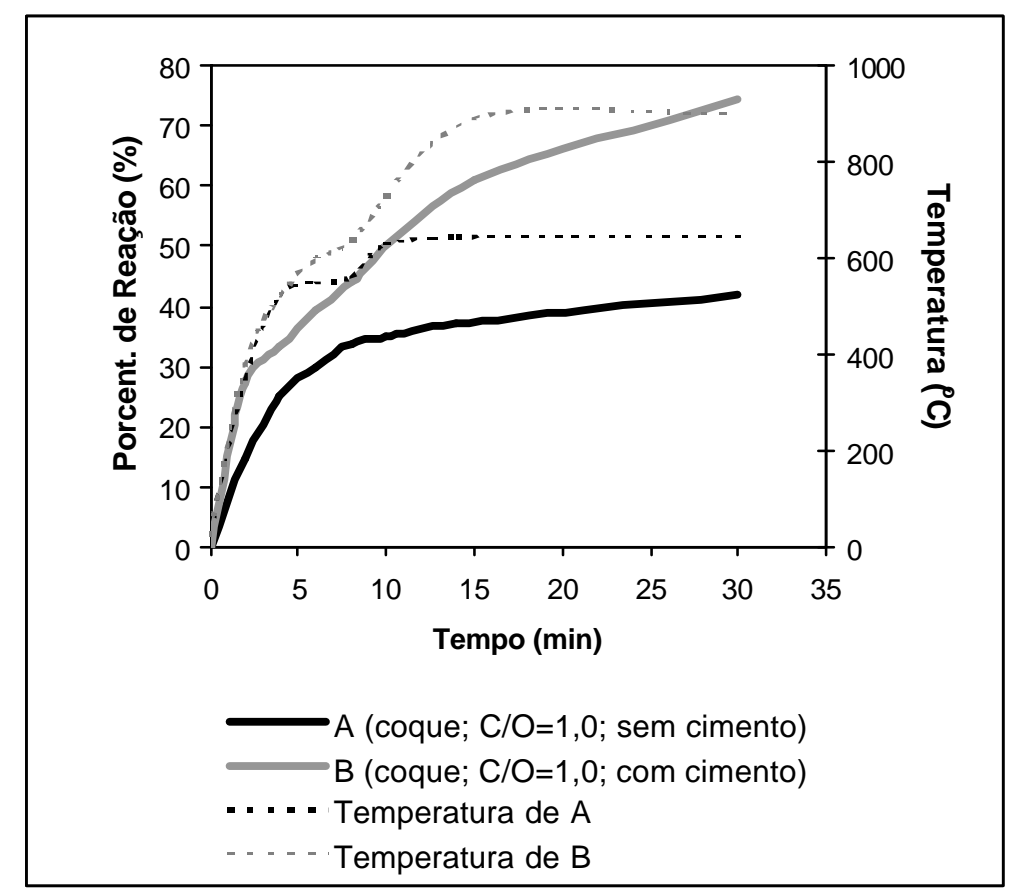

Figura 24: Porcentagem de reação em função do tempo para as pelotas A e B, analisando o efeito da presença do aglomerante-cimento Portland ARI.

\subsubsection{Influência da Quantidade de Agente Redutor}

A segunda análise efetuada foi com relação à quantidade de agente redutor, no caso moinha de coque. Para isso produziu-se as pelotas tipo B e C com a pelota $\mathrm{C}$ apresentando maior quantidade de carbono, segundo tabela 10 , relação entre os elementos carbono e oxigênio: $\mathrm{C} / \mathrm{O}=1,0$ para a pelota $\mathrm{B}$ e $\mathrm{C} / \mathrm{O}=$ 1,33 para a pelota $\mathrm{C}$, além de $6,5 \%$ de cimento para as pelotas $\mathrm{B}$ e $\mathrm{C}$. A seguir construiu-se a figura 25 através das curvas das figuras 16 e 17, onde se percebe uma pequena melhora nos valores da porcentagem de reação para a pelota com maior quantidade de moinha de coque, mostrando que o aumento do teor de carbono favorece no processo de redução, mas esse efeito não foi muito 
pronunciado: após 30 minutos de ensaio, chegou-se a $74 \%$ de redução para a pelota tipo B e $80 \%$ de redução para a pelota tipo C.

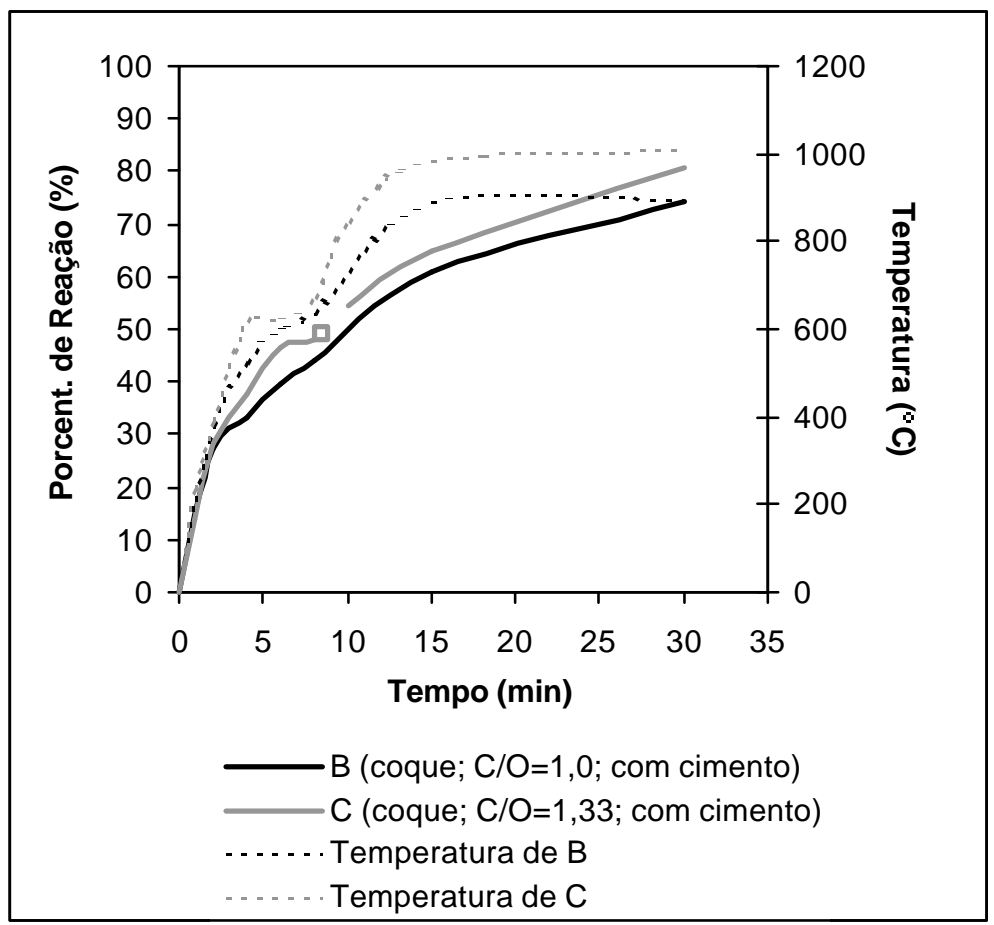

Figura 25: Porcentagem de reação em função do tempo para as pelotas B e C, analisando o efeito da quantidade do agente redutor - moinha de coque.

A mesma análise da influência da quantidade de agente redutor foi efetuada agora para o carvão vegetal (figura 26), onde se fabricou as pelotas E e $\mathrm{F}$, de mesma composição em peso em relação às pelotas $\mathrm{B}$ e $\mathrm{C}$, sendo que a pelota $\mathrm{F}$ possui maior quantidade de agente redutor (carvão vegetal) quando comparada com a pelota $\mathrm{E}$, relações $\mathrm{C} / \mathrm{O}=1,33$ e $\mathrm{C} / \mathrm{O}=1,0$ respectivamente. Percebe-se também uma pequena melhora na situação onde se empregou maior quantidade de carvão vegetal e isso é mais evidente nos estágios finais de redução (após 5 minutos de ensaio) como mostrado na figura 26. 


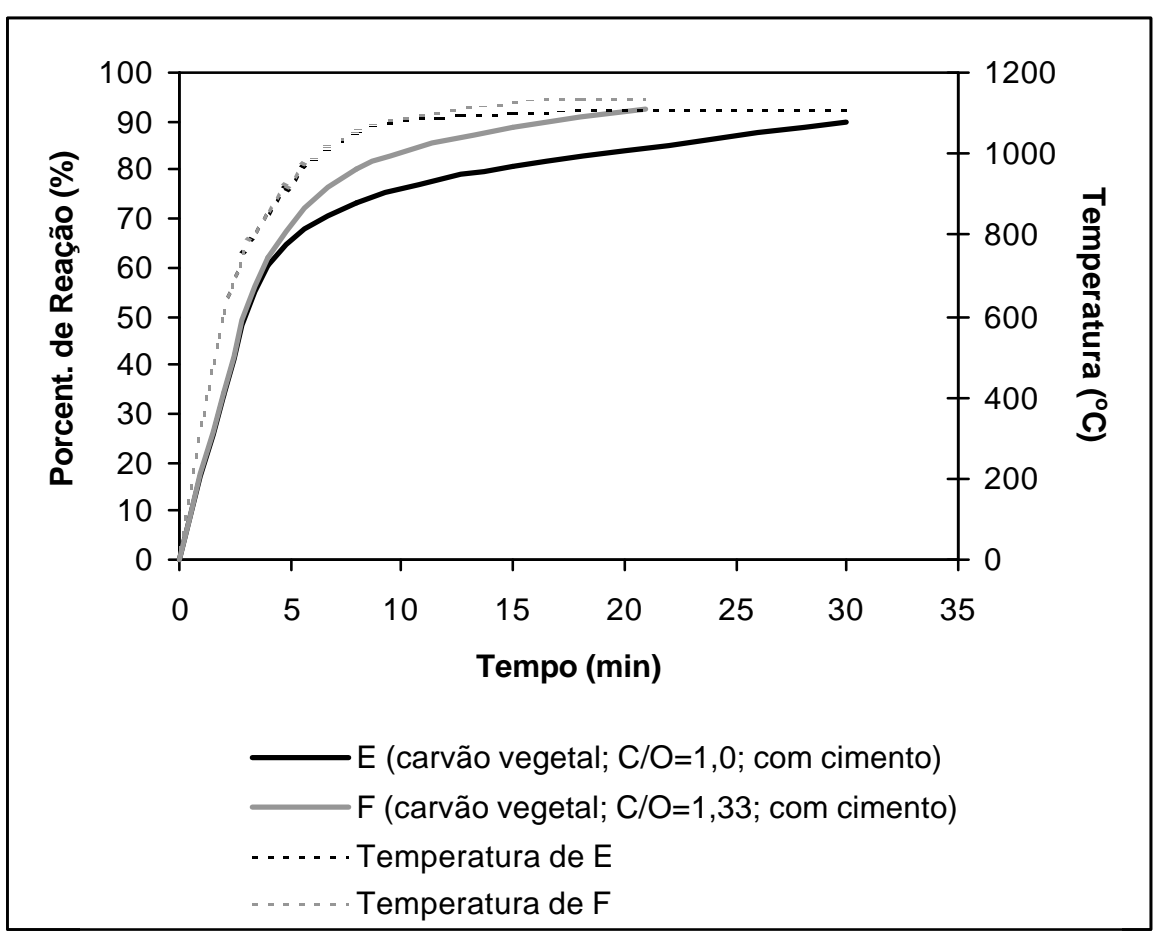

Figura 26: Porcentagem de reação em função do tempo para as pelotas E e F, analisando o efeito da quantidade do agente redutor - carvão vegetal.

\subsubsection{Influência da Granulometria do Agente Redutor}

Nos processos de redução carbotérmica do minério de ferro por meio de energia de microondas, a absorção da energia, e portanto, o aquecimento se dá, principalmente, pelo material carbonáceo. Sabe-se ${ }^{\mathbf{1 4}}$ que, em processos convencionais de redução do minério de ferro, a diminuição do tamanho da partícula de carbono favorece as reações de redução do minério de ferro (reações de (2) a (4)) devido ao aumento dos sítios de reação possíveis do processo. Entretanto utilizando-se a irradiação de microondas isso não foi observado, como mostra a figura 27. As pelotas tipo C e D possuem a mesma composição, mas a granulometria da pelota D é maior: de 35 a 50 mesh para a pelota D e de 100 a 
150 para a pelota C. Foi observado, portanto que o aumento do tamanho de partícula da moinha de coque favoreceu a cinética de redução do minério de ferro com a utilização da energia de microondas.

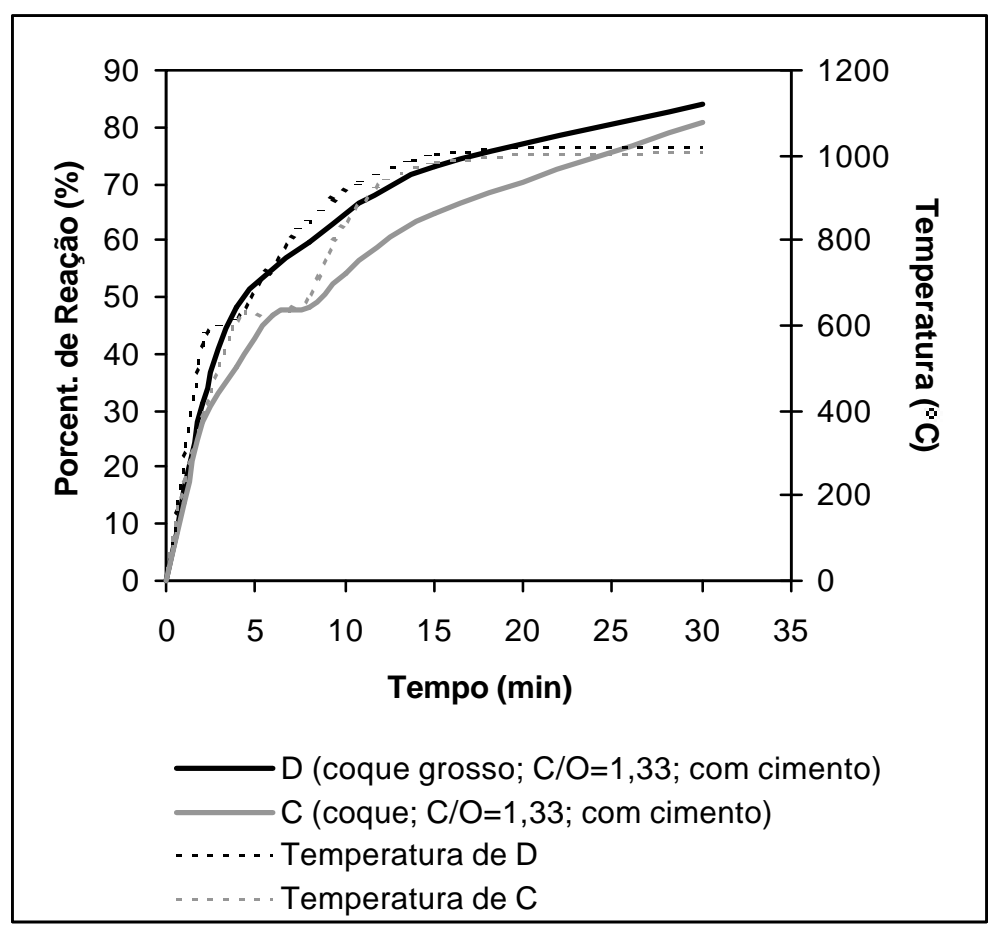

Figura 27: Porcentagem de reação em função do tempo para as pelotas $\mathrm{C}$ e D, analisando o efeito da granulometria do agente redutor, moinha de coque.

Resultados semelhantes também foram encontrados por Ghoreshy e Pickles ${ }^{2}$ e explicações sobre esse comportamento, são encontradas no trabalho de Lorenson $^{35}$, et al; onde é relatado que esse fenômeno acontece até um tamanho ótimo da partícula de carbono, sendo a profundidade de penetração (d) das microondas (equação 10) a principal variável para se analisar nesse comportamento. 


\subsubsection{Influência do Tipo de Agente Redutor}

Estudou-se o comportamento cinético do processo de redução do minério de ferro tendo como agente redutor a moinha de coque (pelota B) e o carvão vegetal (pelota E). Para essas pelotas as proporções em massa dos elementos constituintes e sua granulometria são as mesmas, variando apenas no tipo de agente redutor. Os resultados estão apresentado na figura 28:

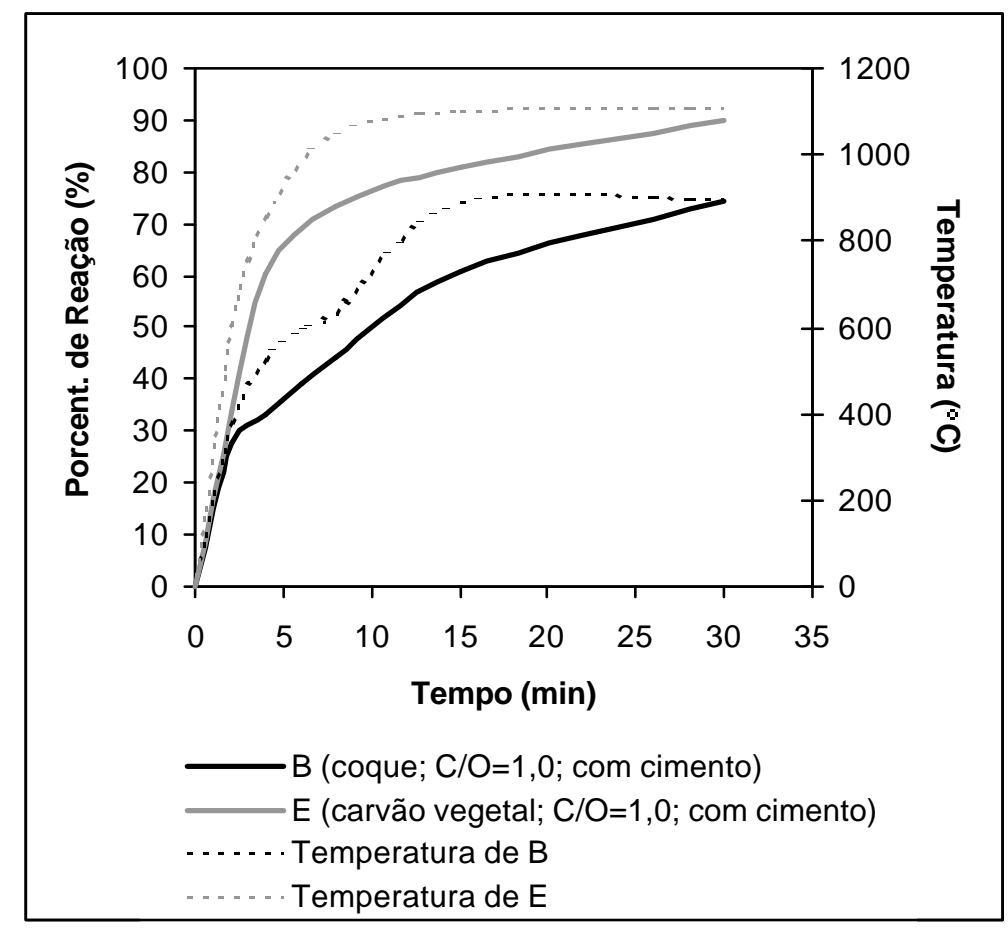

Figura 28: Porcentagem de reação em função do tempo para as pelotas

$\mathrm{B}$ e E, analisando o efeito do tipo de agente redutor empregado.

Percebe-se, através da figura 28, que a pelota "E" (carvão vegetal) apresentou melhores resultados na velocidade de reação e no grau final de redução, aproximadamente $90 \%$ contra $74 \%$ da pelota que continha moinha de coque como agente redutor, mostrando que a maior presença de voláteis (tabela 9) do carvão vegetal favorece as reações de redução, como apresentado por 
Mourão e Capocchi ${ }^{32}$, e outro fato verificado foi a maior temperatura final atingida para as amostras de carvão vegetal: $1100{ }^{\circ} \mathrm{C}$ contra, aproximadamente, $900{ }^{\circ} \mathrm{C}$ para as amostras de moinha de coque, mostrando que o carvão vegetal é mais susceptível ao aquecimento por microondas.

\subsubsection{Influência do Isolamento Térmico da Amostra}

A seguir têm-se as comparações dos valores encontrados para as amostras isoladas e não isoladas, figuras 29,30 e 31 , onde se observa os melhores resultados para as amostras que foram isoladas, através de uma manta isolante. Outro fato constatado durante as experiências com amostras isoladas termicamente, foi a abertura de arco no interior da pelota, fato também relatado por Morita e $\mathrm{Sano}^{\mathbf{2 8}}$, evidenciando a presença de ferro metálico na amostra.

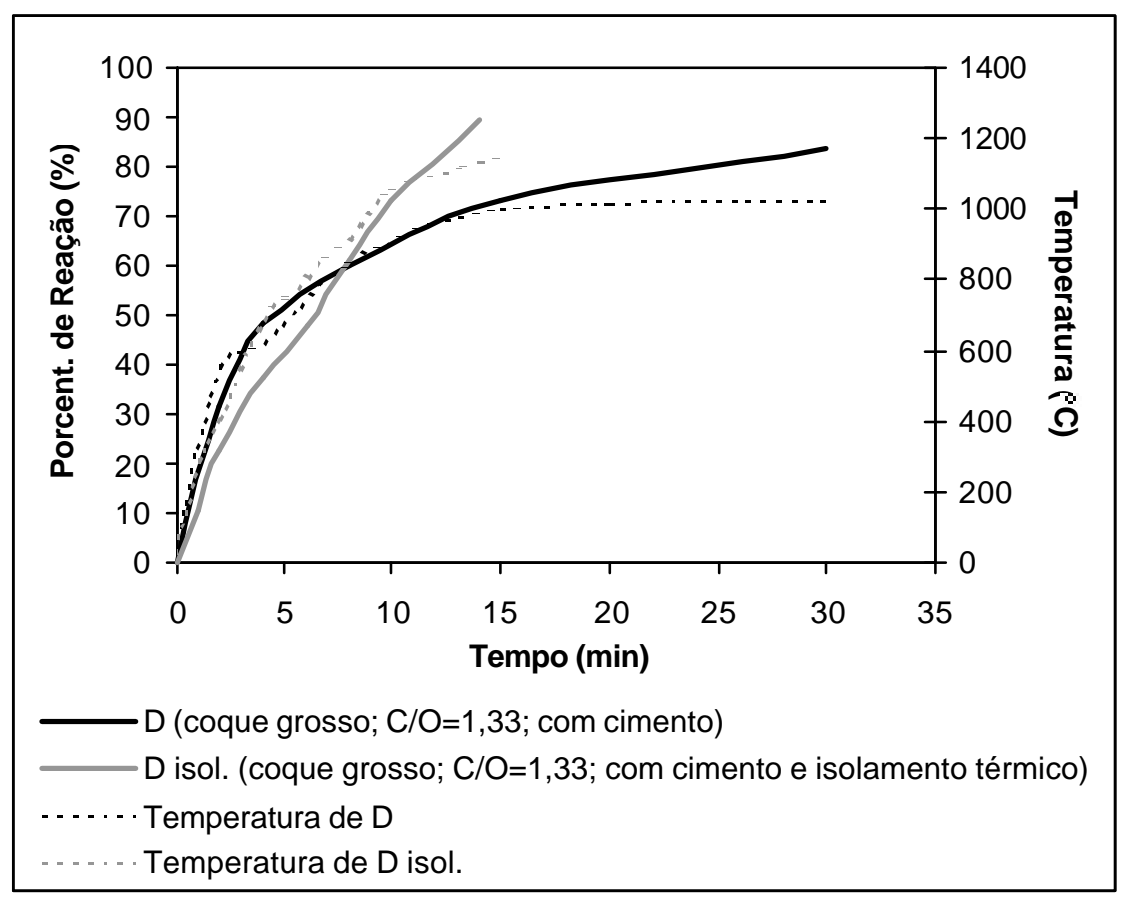

Figura 29: Porcentagem de reação em função do tempo para as pelotas D e D isol., analisando o efeito do isolamento térmico. 


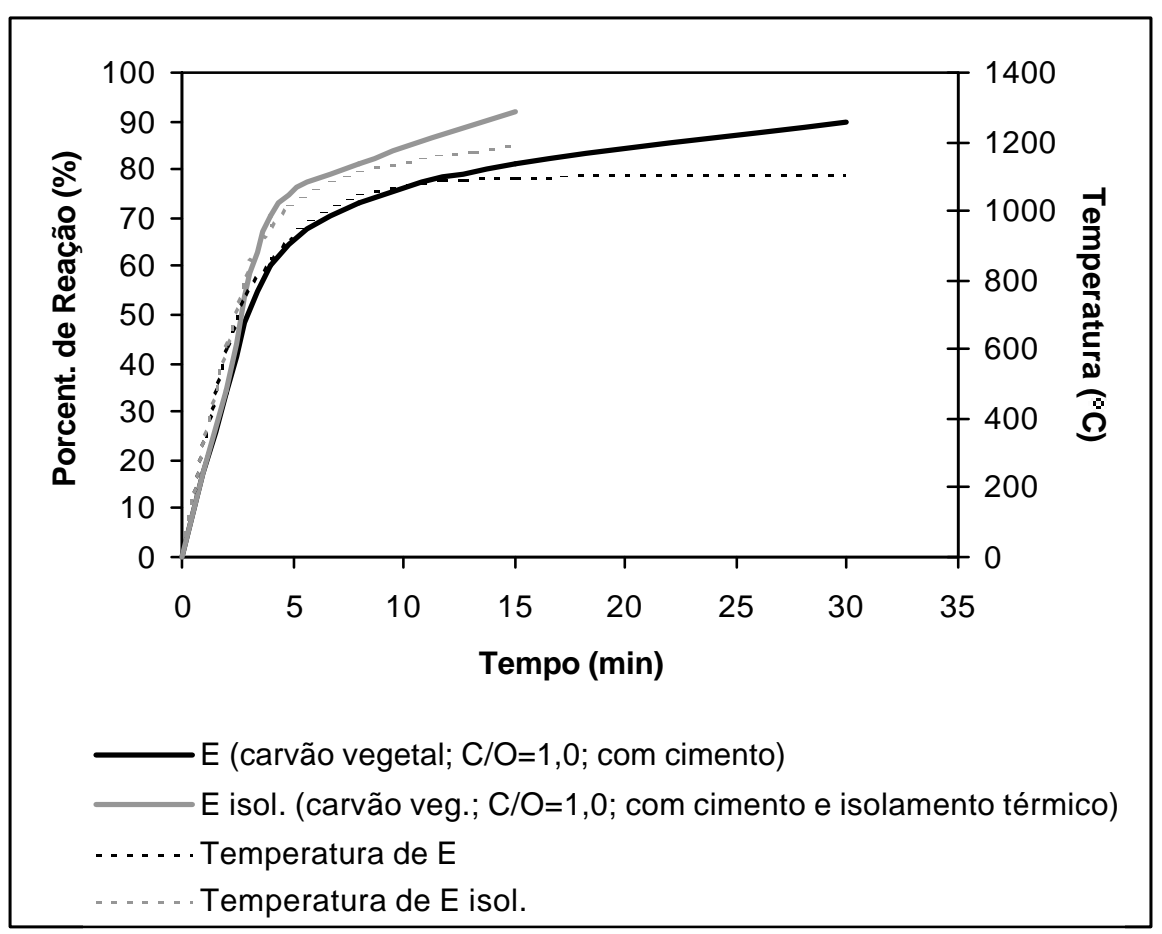

Figura 30: Porcentagem de reação em função do tempo para as pelotas E e E isol., analisando o efeito do isolamento térmico.

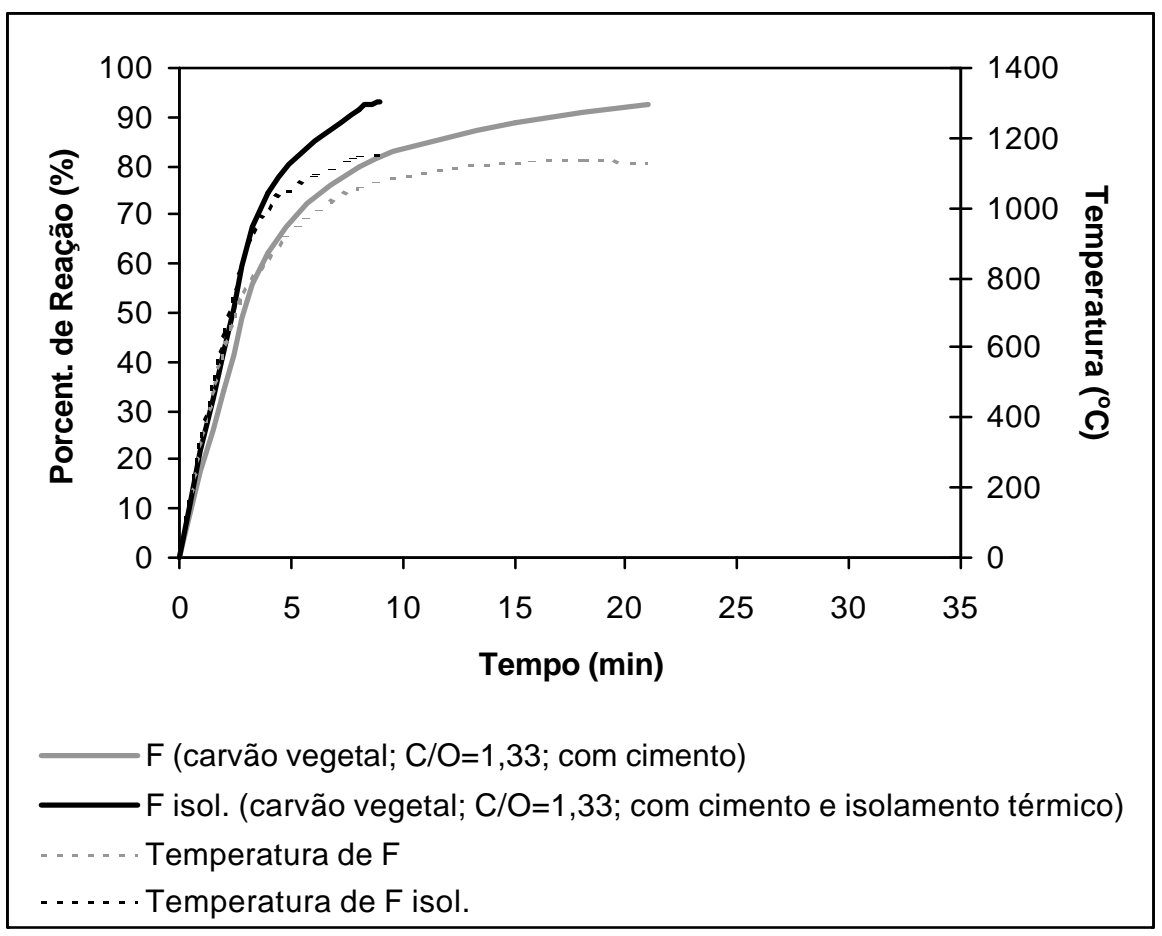

Figura 31: Porcentagem de reação em função do tempo para as pelotas F e F isol., analisando o efeito do isolamento térmico . 


\subsection{Análise Cinética}

A partir dos resultados termogravimétricos com a utilização de energia de microondas na redução do minério de ferro, efetuou-se um modelamento das curvas de porcentagem de reação em função do tempo de exposição à irradiação de microondas (figuras 15 a 23). Os resultados se mostraram satisfatórios ao modelo parabólico, segundo a equação:

$$
P R=\sqrt{k \times t}
$$

onde: PR - porcentagem de reação;

$\mathrm{t}$ - tempo de exposição à microondas (min);

$\mathrm{k}$ - constante cinética $\left(\min ^{-1}\right)$

Construiu-se então gráficos de porcentagem de reação em função da raiz quadrada do tempo, de onde se obtém a constante $\mathrm{k}^{\prime}$, sendo $\mathrm{k}=\left(\mathrm{k}^{\prime}\right)^{2}$, como mostra a figura 32 que apresenta os resultados para as pelotas "C" e "D":
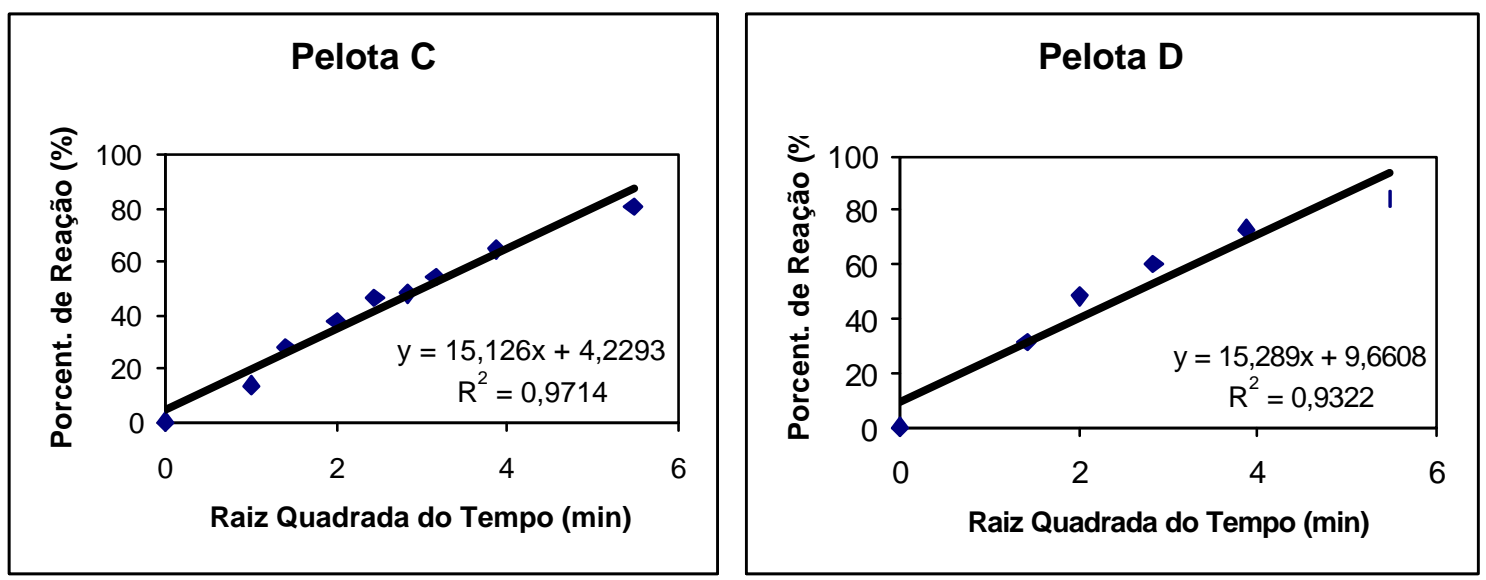

Figura 32: Porcentagem de redução em função da raiz quadrada do tempo de exposição à microondas (modelo parabólico), para as pelotas "C" e "D". 
A tabela 13 apresenta os valores de $\mathrm{k}^{\prime}, \mathrm{k}$ e $\mathrm{R}^{2}$, para todas as composições de pelota estudadas que foram obtidas da mesma forma ao da figura 32 mostrada anteriormente.

Tabela 13: Valores de "k" (constante cinética) segundo modelo parabólico para todas as amostras estudadas.

\begin{tabular}{|c|c|c|c|}
\hline Pelota & $\mathrm{k}^{\prime}$ & $\left.\mathrm{K} \mathbf{~ m i n}^{-1}\right)$ & $\mathrm{R}^{2}$ \\
\hline & & & \\
\hline A & 7,91 & $\mathbf{6 2 , 6}$ & 0,87 \\
\hline B & 13,47 & $\mathbf{1 8 1 , 4}$ & 0,98 \\
\hline C & 15,13 & $\mathbf{2 2 8 , 9}$ & 0,97 \\
\hline D & 15,29 & $\mathbf{2 3 3 , 8}$ & 0,93 \\
\hline E & 16,39 & $\mathbf{2 6 8 , 6}$ & 0,87 \\
\hline F & 20,84 & $\mathbf{4 3 4 , 3}$ & 0,92 \\
\hline D isol. & 24,88 & $\mathbf{6 1 9 , 0}$ & 0,97 \\
\hline E isol. & 24,96 & $\mathbf{6 2 3 , 0}$ & 0,93 \\
\hline F isol. & 32,05 & $\mathbf{1 0 2 7 , 2}$ & 0,98 \\
\hline
\end{tabular}

Através desse modelo, com a utilização da constante "k", pode-se comparar os resultados obtidos de forma rápida. Tratamento semelhante foi apresentado no trabalho de Hassine ${ }^{29}$ com o uso de um modelo parabólico.

Para a redução do minério de ferro na forma de pelotas auto-redutoras com emprego de energia de microondas, os melhores valores para a constante cinética $(\mathrm{k})$ se apresentaram para as pelotas isoladas termicamente, ou seja, o calor gerado internamente na pelota não era dissipado para o ambiente do forno, propiciando assim maiores temperaturas com conseqüente aumento nas taxas de reação . 


\subsection{Análise Microscópica}

Foram escolhidas algumas amostras para serem observadas em um microscópio eletrônico de varredura, marca Cambridge, modelo Stereoscan 240, operado com tensão de aceleração do feixe de elétrons de $20 \mathrm{kV}$. As imagens foram obtidas utilizando-se o microscópio eletrônico de varredura (MEV) no modo BSE (elétrons retro-espalhados) e todas as amostras sofreram o processo de recobrimento com ouro, utilizando-se um metalisador Bal-Tec.

A seguir tem-se a tabela 14 que mostra quais amostras foram submetidas ao MEV, sendo que para algumas micrografias se efetuou a análise por EDS que mostra os elementos químicos presentes em determinada região da micrografia; lembrando que os ensaios termogravimétricos foram efetuados de maneira descontínua, possibilitando assim a análise de amostras de tempos intermediários do processo de redução do minério de ferro. As discussões sobre as micrografias obtidas estão apresentadas ao final desta seção:

Tabela 14: Amostras Analisadas no Microscópio Eletrônico de Varredura - Figura Correspondente

\begin{tabular}{|c|c|c|}
\hline $\begin{array}{c}\text { Tipo da } \\
\text { Pelota }\end{array}$ & $\begin{array}{c}\text { Tempo no Forno } \\
\text { de Microondas (min) }\end{array}$ & $\begin{array}{c}\text { Número } \\
\text { da Figura }\end{array}$ \\
\hline A & 30 & 33 \\
\hline B & 30 & 34 \\
\hline C & 30 & 35 \\
\hline D & 30 & 36 \\
\hline E & 30 & $37 *$ \\
\hline D isol. & 8 & 38 \\
\hline E isol. & 15 & 39 \\
\hline B & 15 & $40^{*}$ \\
\hline C & 8 & $41^{*}$ \\
\hline D & 8 & $42^{*}$ \\
\hline
\end{tabular}

* : micrografias com análise EDS 


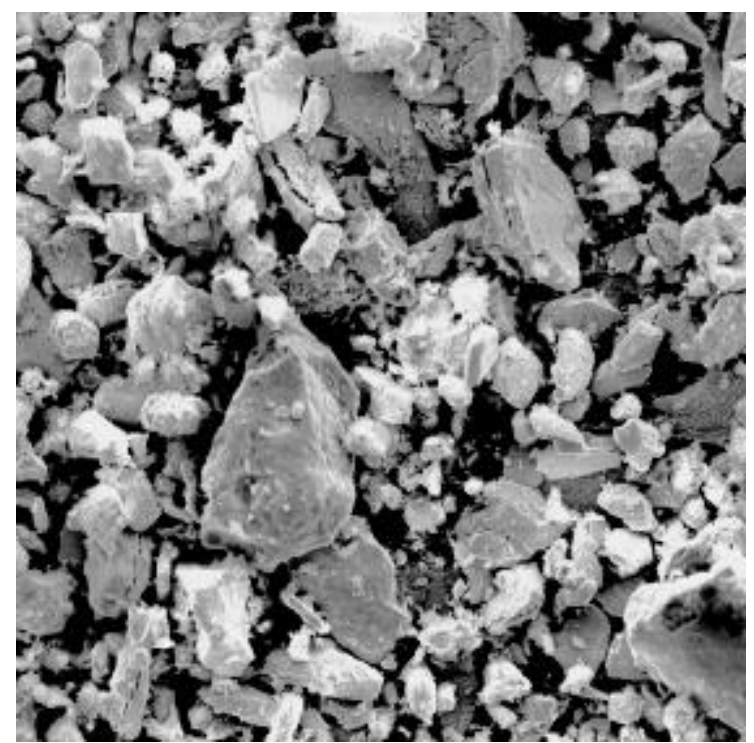

Figura 33: Microscopia eletrônica de varredura de pelota tipo A exposta 30 minutos à irradiação por microondas; $42 \%$ de redução; aumento de 200 X.

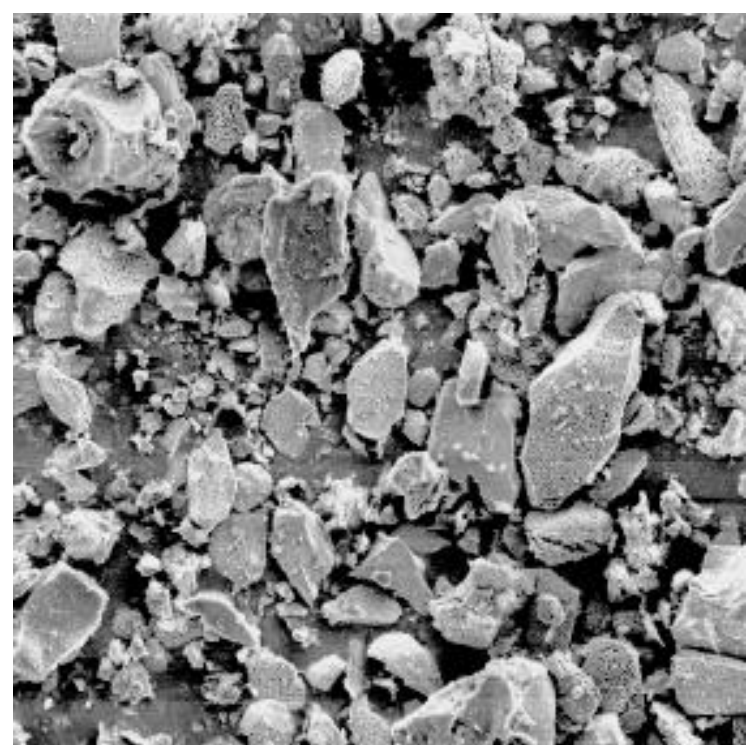

Figura 34: Microscopia eletrônica de varredura de pelota tipo $\mathrm{B}$ exposta 30 minutos à irradiação por microondas; $74 \%$ de redução; aumento de 200 X. 


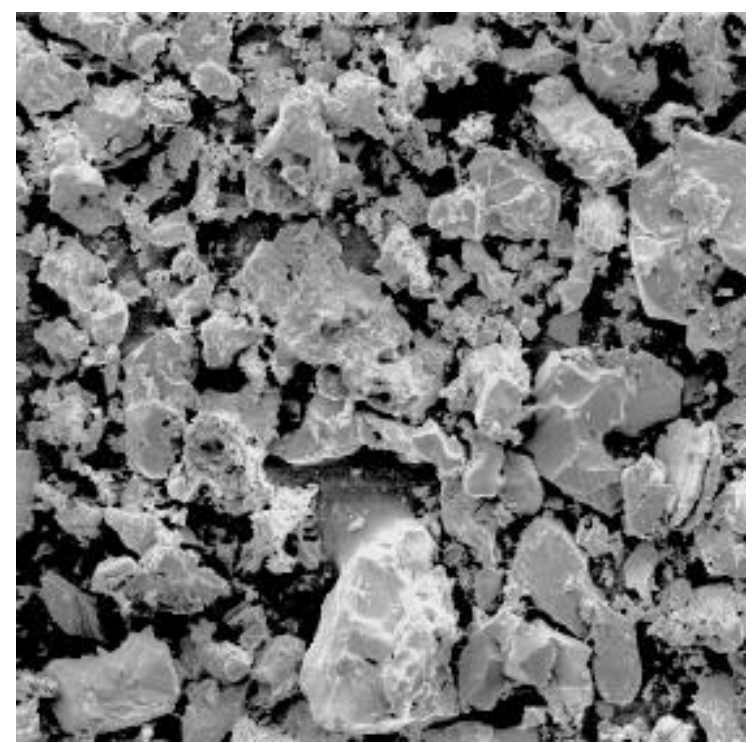

Figura 35: Microscopia eletrônica de varredura de pelota tipo $\mathrm{C}$ exposta 30 minutos à irradiação por microondas; $81 \%$ de redução; aumento de 200 X.

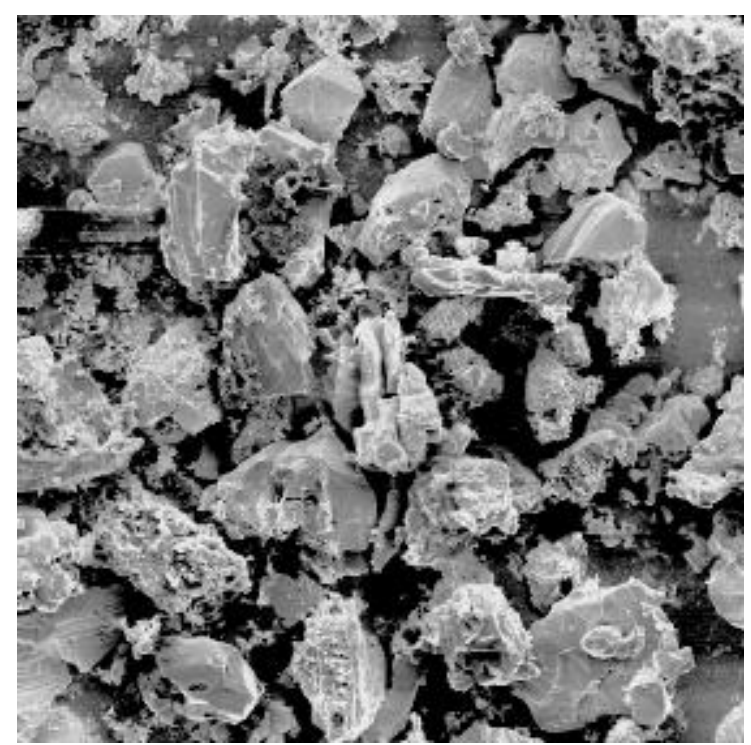

Figura 36: Microscopia eletrônica de varredura de pelota tipo $\mathrm{D}$ exposta 30 minutos à irradiação por microondas; $84 \%$ de redução; aumento de 200 X. 

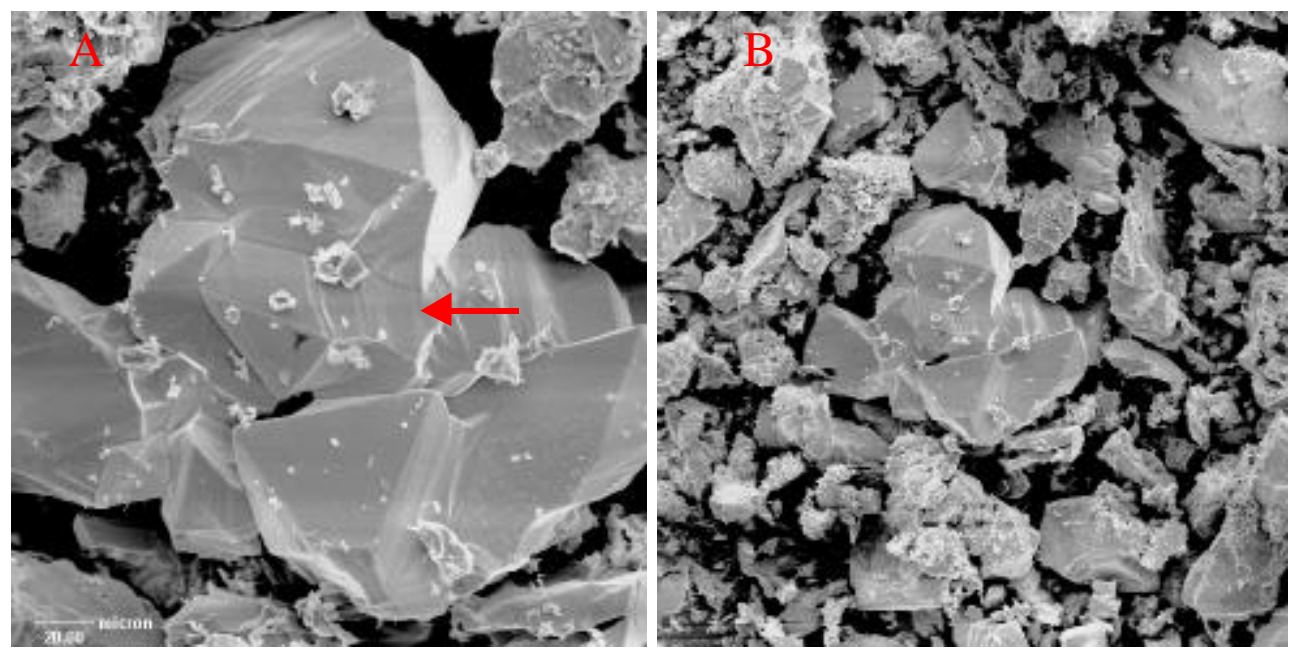

Figura 37: Microscopia eletrônica de varredura de pelota tipo E exposta 30 minutos à irradiação por microondas; $90 \%$ de redução;

(A) aumento de $500 \mathrm{X}$, (B) aumento de $200 \mathrm{X}$.

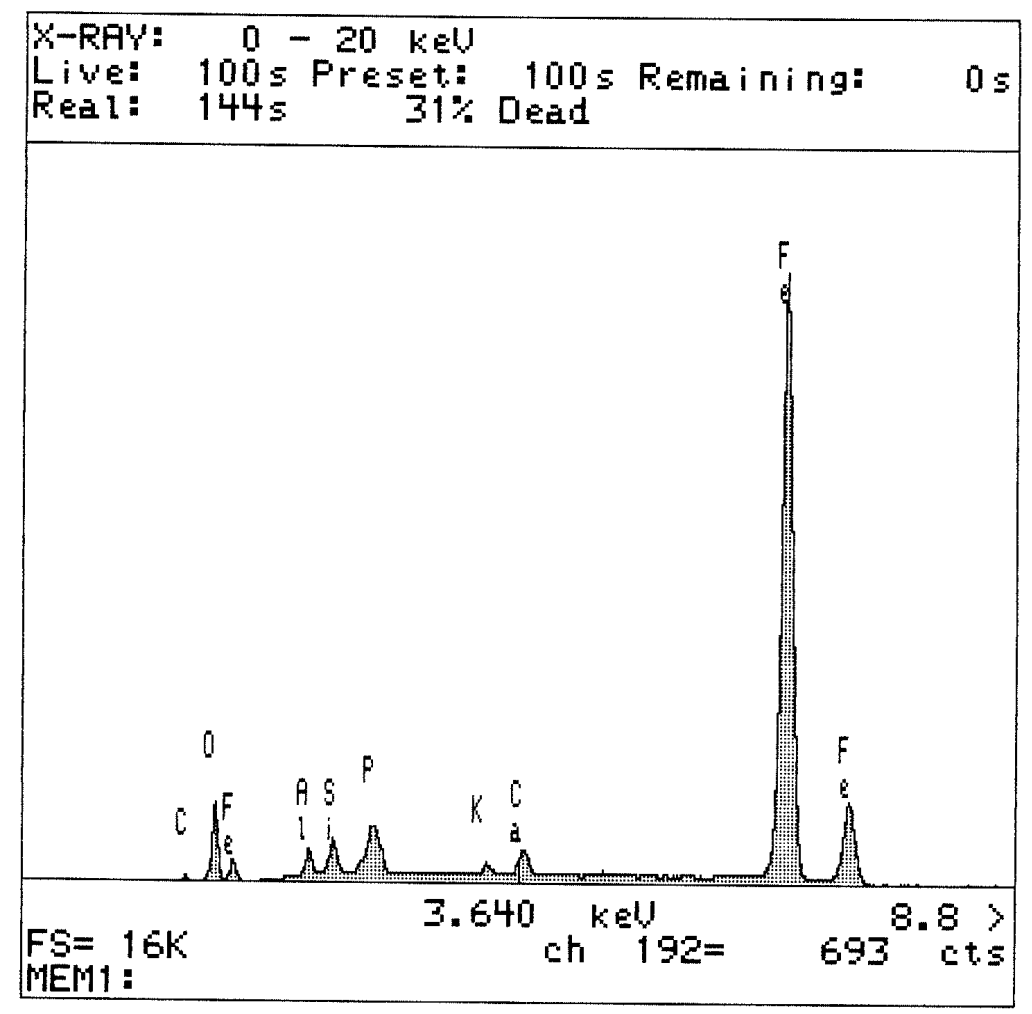

Figura 38: Análise EDS realizada na pelota tipo E, na região marcada da figura $37(\mathrm{~A})$. 


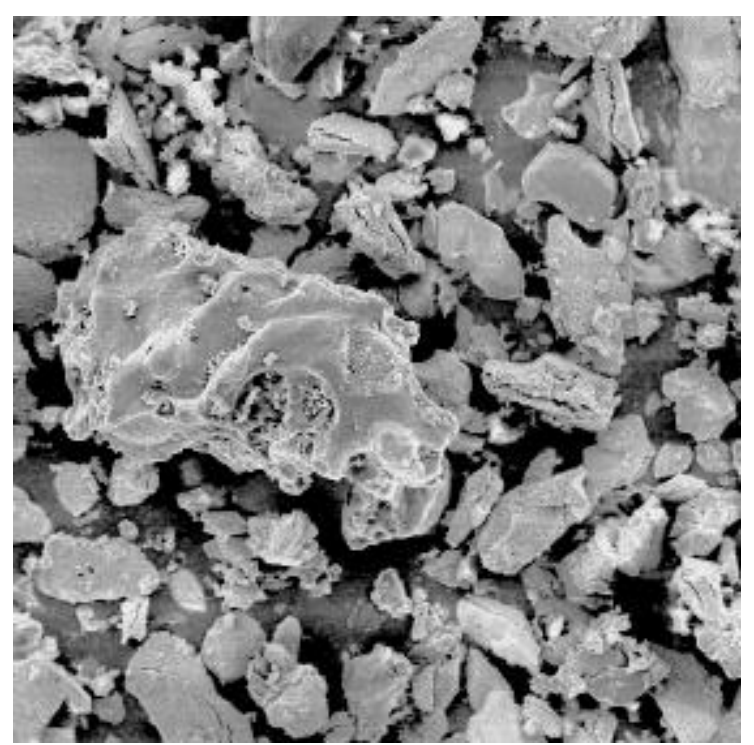

Figura 39:Microscopia eletrônica de varredura de pelota tipo $\mathrm{D}$, isolada termicamente, exposta 8 minutos à irradiação por microondas; $61 \%$ de redução; aumento de $200 \mathrm{X}$.

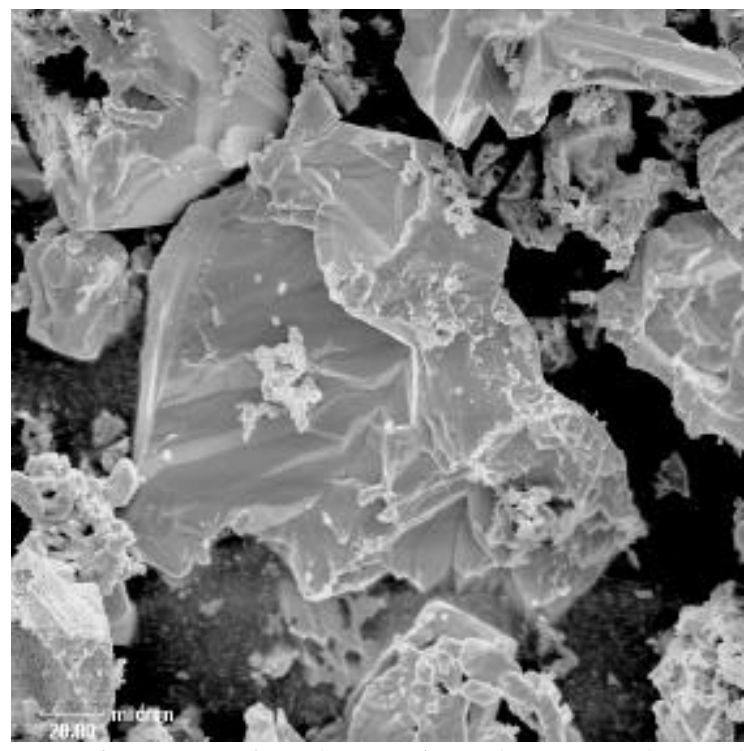

Figura 40:Microscopia eletrônica de varredura de pelota tipo $\mathrm{E}$, isolada termicamente, exposta 15 minutos à irradiação por microondas; $92 \%$ de redução; aumento de $500 \mathrm{X}$. 


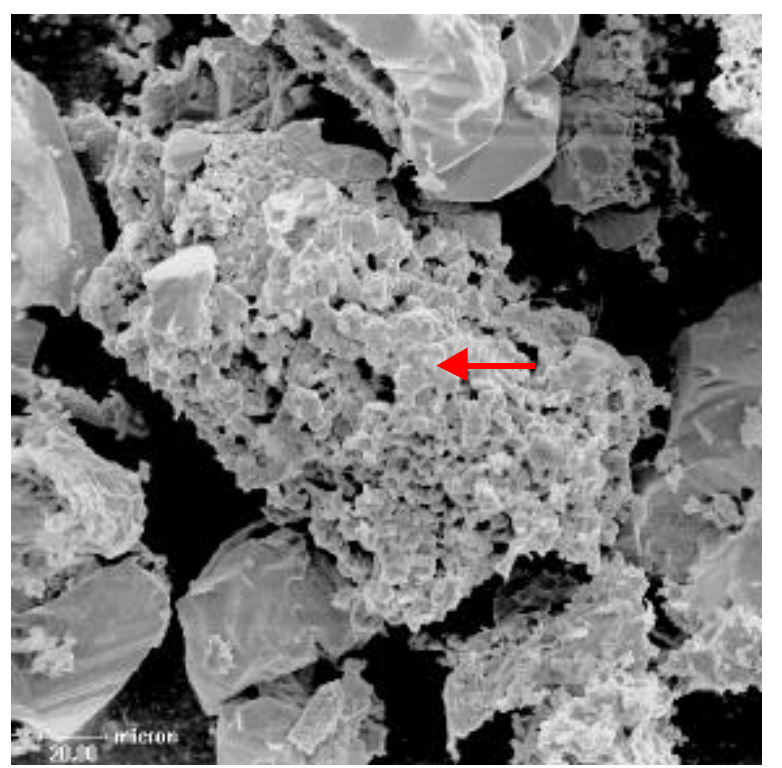

Figura 41:Microscopia eletrônica de varredura de pelota tipo $\mathrm{B}$ exposta 15 minutos à irradiação por microondas; $61 \%$ de redução; aumento de 500 X.

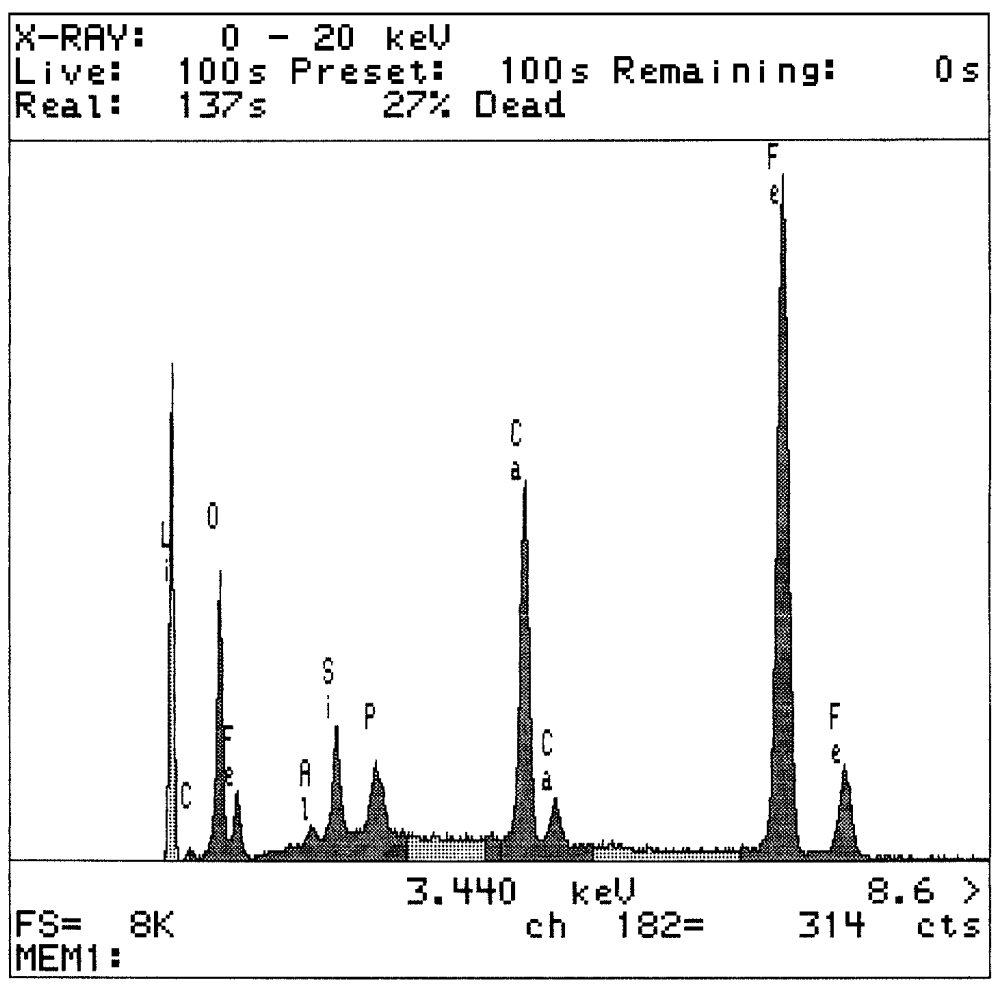

Figura 42: Análise EDS realizada na pelota tipo B, na região marcada da figura 41 . 


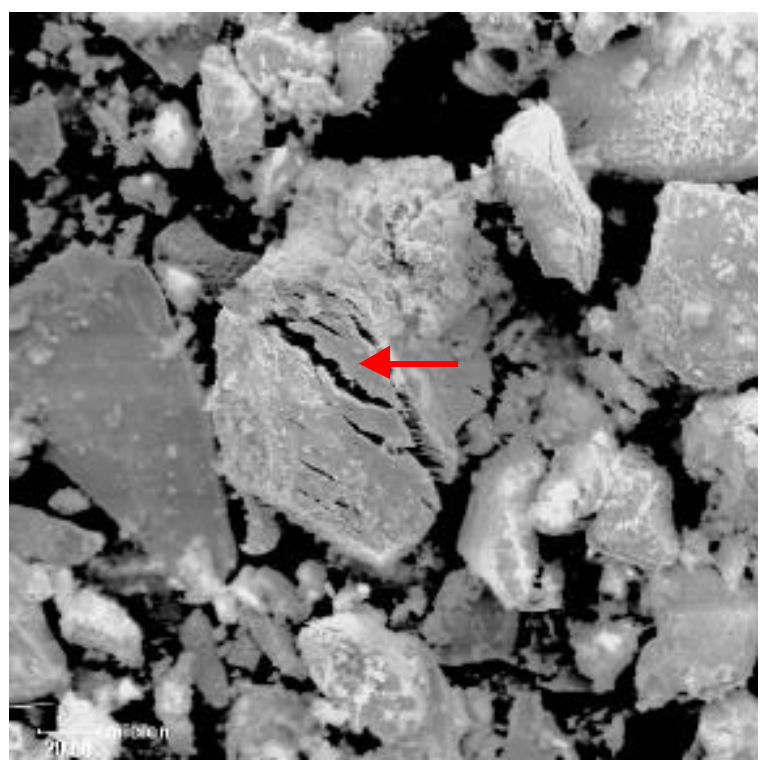

Figura 43:Microscopia eletrônica de varredura de pelota tipo $\mathrm{C}$ exposta 8 minutos à irradiação por microondas; 48 \% de redução; aumento de 400 X.

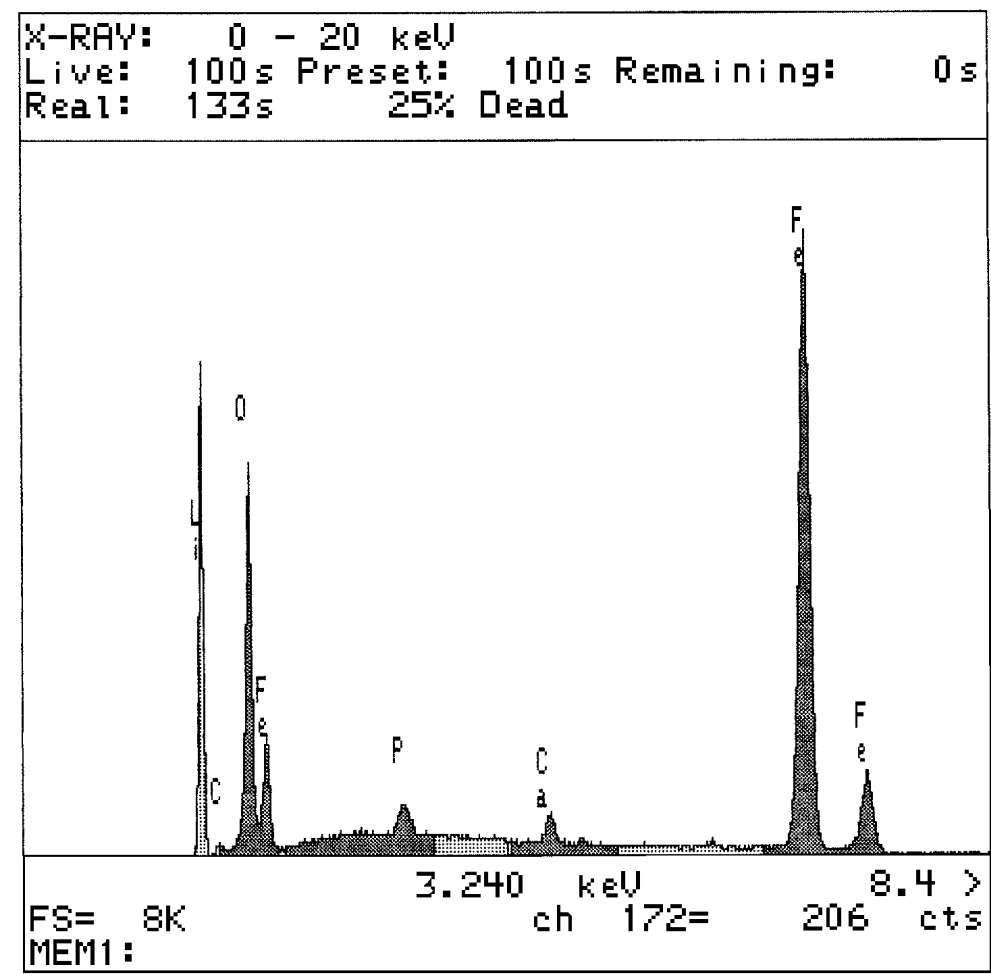

Figura 44: Análise EDS realizada na pelota tipo C, na região marcada da figura 43 . 


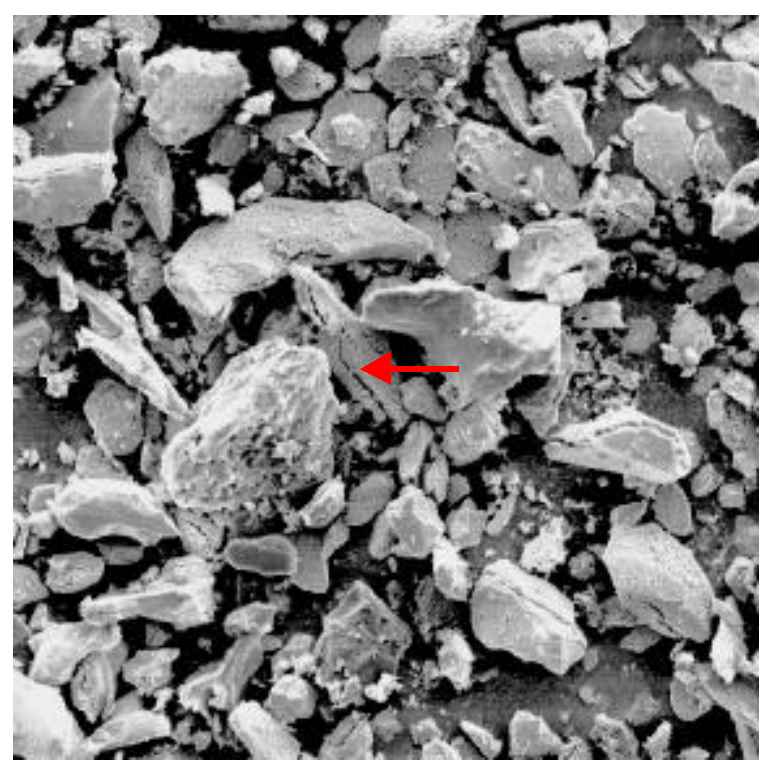

Figura 45:Microscopia eletrônica de varredura de pelota tipo $\mathrm{D}$ exposta 8 minutos à irradiação por microondas; $60 \%$ de redução; aumento de $200 \mathrm{X}$.

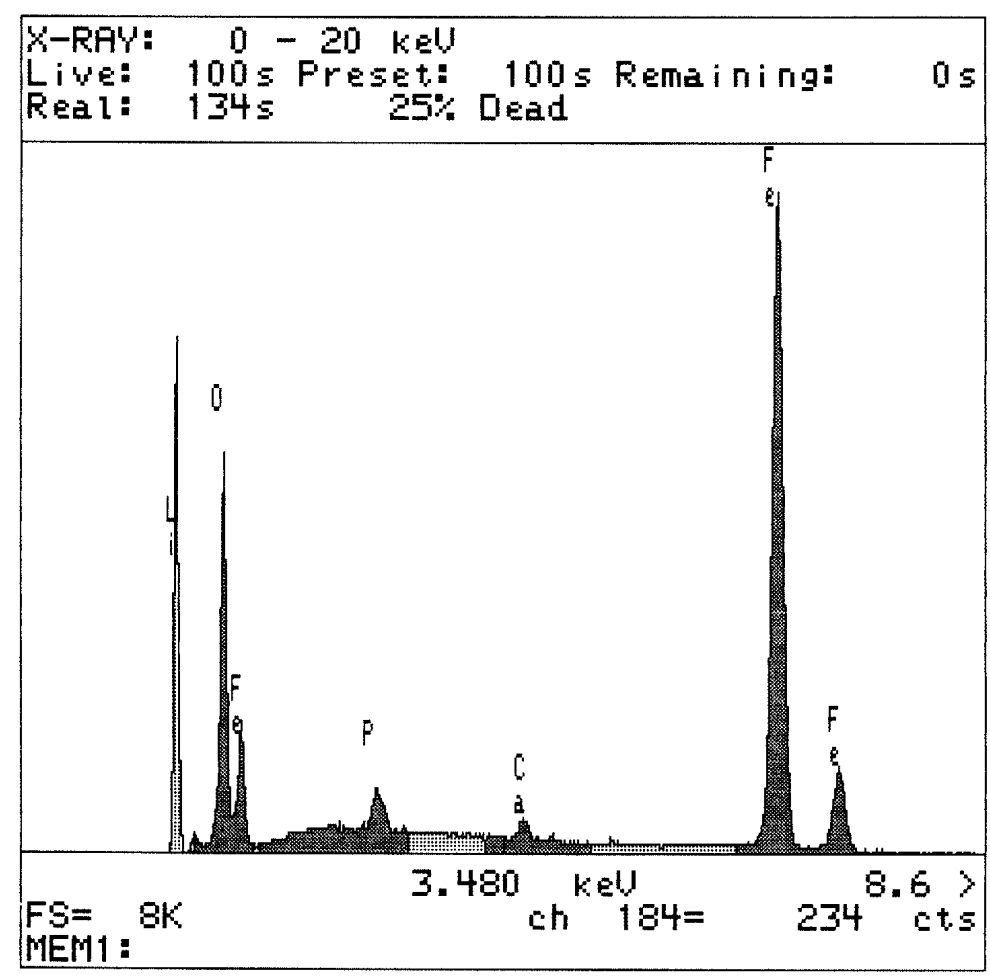

Figura 46: Análise EDS realizada na pelota tipo D, na região marcada da figura 45 . 
Observando as quatro primeiras micrografias (figuras 33 a 36) verifica-se uma morfologia mais densa nas figuras 35 e 36 , respectivamente amostras $\mathrm{C}$ e $\mathrm{D}$, que atingiram maiores graus de redução, lembrando que para essas micrografias o tempo de ensaio e a quantidade de aumento são os mesmos. A constituição das pelotas tipo C e D diferem apenas na granulometria da moinha de coque e no estágio de redução das figuras 35 e $36 \quad(81 \%$ e $84 \%$ respectivamente).

Na figura 37 tem-se a micrografia da pelota tipo E, em dois tamanhos diferentes, que apresenta o carvão vegetal como agente redutor. Verifica-se, através da análise EDS, que a região marcada corresponde à fase metálica com uma morfologia facetada e densa. Morfologia semelhante ocorre para a figura 36, onde se tem o mesmo tipo de pelota, mas com a experiência levada de forma termicamente isolada .Esta micrografia mostra um dos melhores resultados obtidos utilizando-se a energia de microondas na redução do minério de ferro: 92\% de redução em 15 minutos de ensaio.

A figura 41 mostra, provavelmente, a morfologia do cimento recobrindo uma partícula de minério de ferro, como indicado pela análise EDS da figura 42 que mostra a presença dos elementos $\mathrm{Fe}, \mathrm{O}, \mathrm{Ca}, \mathrm{Si}, \mathrm{P}$ e Al; além de Li (lítio) que é devido à adição da tinta de prata utilizada para proporcionar o contato elétrico com a placa de observação no MEV. 
A micrografia da figura 43, obtida de uma pelota de composição C (coque; $\mathrm{C} / \mathrm{O}=1,33$; com cimento), destaca uma região onde se vê trincas em uma partícula de minério de ferro, como indica a análise EDS da figura 44 obtida nesta região. O fenômeno de trincamento das partículas de minério de ferro, foi observado também por Nascimento ${ }^{\mathbf{1 8}}$, onde relata que o trincamento ocorre quando da mudança do óxido de ferro de hematita para magnetita é acompanhado da transformação da estrutura cristalina desses óxidos, havendo assim a geração de tensões internas que causam as trincas transgranulares por toda extensão das partículas de origem hematítica.

A figura 45 destaca a mesma morfologia apresentada anteriormente com trincas em uma partícula de minério de ferro, sendo que para essa micrografia a pelota era do tipo $\mathrm{D}$ ( coque "grosso"; $\mathrm{C} / \mathrm{O}=1,33$; com cimento), com $60 \%$ de redução. 


\subsection{Análise por difratometria de raios-X}

Para a identificação das fases cristalinas presentes em algumas amostras ensaiadas, realizou-se a análise por difratometria de raios-X. Esta técnica utiliza a lei de Bragg para difração, na qual um feixe de raios-X é difratado ao passar por um material e, para cada ângulo, o feixe difratado possui uma intensidade específica. Os ângulos de difração e as respectivas intensidades estão correlacionados aos planos cristalográficos que causam a difração do feixe de raios-X. O equipamento utilizado foi um difratômetro modelo MPD 1880, tipo varredura simples. O intervalo de ângulo de varredura foi de $2,5^{\circ}$ a $90^{\circ}$, com velocidade de $1,8^{\circ} /$ min. São mostrados a seguir os resultados obtidos através da análise por difração de raios-X. Na figura 47 tem-se a pelota tipo $\mathrm{C}$ (coque; $\mathrm{C} / \mathrm{O}$ $=1,33$; com cimento) levada por 8 minutos em forno de microondas, atingindo 48\% de redução. Nas figuras 48 e 49 têm-se os resultados das pelotas tipo E (carvão vegetal; $\mathrm{C} / \mathrm{O}=1,0 ;$ com cimento) ensaiadas em forno de microondas (30 minutos de ensaio, atingindo $90 \%$ de redução) e em forno de resistência (1150 $\left.{ }^{\circ} \mathrm{C}\right)$. Verifica-se na análise onde a amostra atingiu $48 \%$ de redução a presença das fases $\mathrm{Fe}_{3} \mathrm{O}_{4}, \mathrm{FeO}$ e $\mathrm{Fe}$. Na situação de $90 \%$ de redução as fases que contém o elemento ferro foram $\mathrm{FeO}$ e Fe. Percebe-se também através das figuras 48 e 49 , que mostram a análise da pelota E para forno de microondas e de resistência, respectivamente, a semelhança dessas análises, sendo que a presença de $\mathrm{SiO}_{2}$ também ocorreu para a amostra ensaiada em forno de resistência, mas como não era a intenção a verificação de sua presença, não está mostrada na análise. 
Page: 1/1

DI file: $\mathrm{X}: \backslash \mathrm{PMT} \backslash 298-1241 . \mathrm{DI}$

Sample identification: 1

Score Rel. I Disp Card

Name

Formula Score $[\%] \quad[\mu \mathrm{m}]$

$12.520 .43516205-0490$ Quartz, low

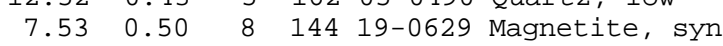

$\begin{array}{llllll}4.32 & 0.72 & 11 & -64 & 46-1312 & W \backslash P I u s t i t e\end{array}$

$2.910 .9758 \quad 14406-0696$ Iron, syn

$4.50 \quad 0.41 \quad 5 \quad 14425-0284$ Graphite, syn

ESC=Quit $F 3=$ Reject $F 5=$ Combine $F 6=$ Sort $F 7=0$ ther list $F 8=$ Graphics $F 9=$ Report F10=Help Shift/F2=More... Shift/F4=Insert

Sample ident.: 1

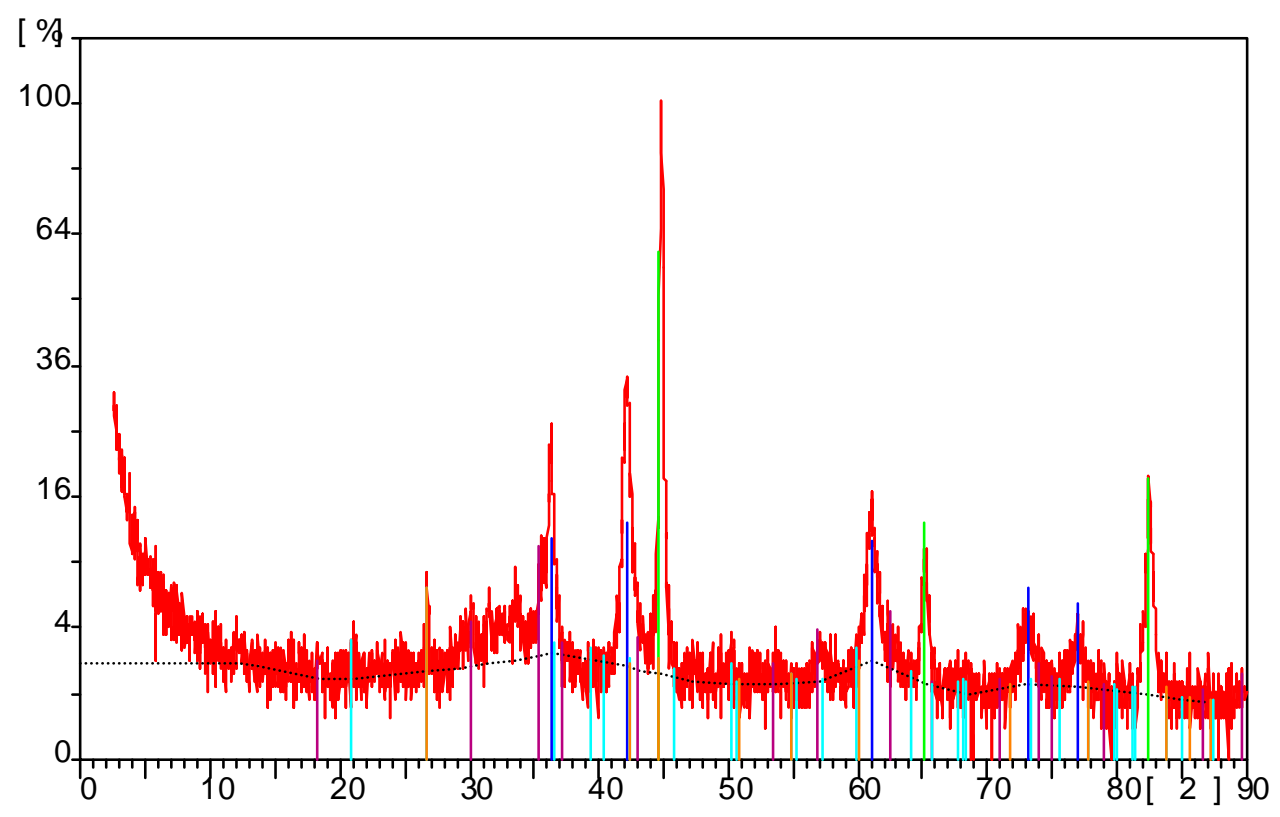

298- 1241

06- 0696

46- 1312

19- 0629

05- 0490

25- 0284

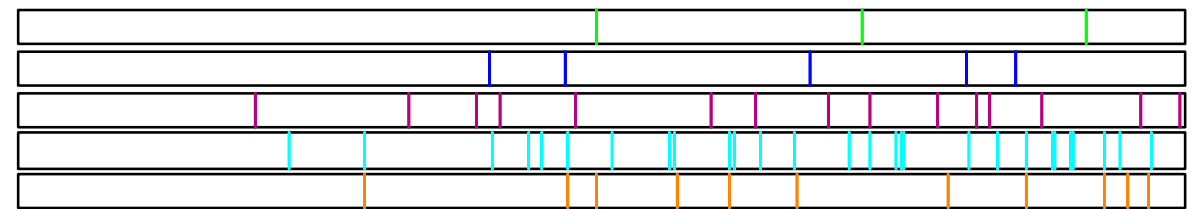

Figura 47: Difratograma de raios-X de uma pelota $\mathrm{C}$ (coque; $\mathrm{C} / \mathrm{O}=1,33$; com cimento) ensaiada em forno de microondas por $8 \mathrm{~min} ., 48 \%$ de redução. 
Page: 1/1

DI file: $X: \backslash P M T \backslash 298-1242$.DI

Sample identification: 2

Score Rel. I Disp Card

Name

Formula

Score $[\%]$ [ $[\mu \mathrm{m}]$

$\begin{array}{llllll}2.96 & 0.99 & 69 & 123 & 06-0696 & \text { Iron, syn }\end{array}$

$4.42 \quad 0.74 \quad 10-125 \quad 46-1312$ W $\backslash$ PIustite

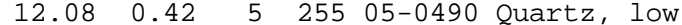

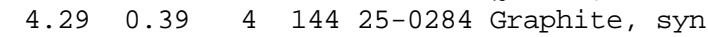

$\mathrm{Fe}$

$\mathrm{FeO}$

$\mathrm{SiO} 2$

$$
\text { C }
$$

EsC=Quit $F 3=$ Reject $F 6=$ Sort $F 8=$ Graphics $F 9=$ Report $F 10=$ Help Shift/F2=More... Shift/F4=Insert

Sample ident.: 2

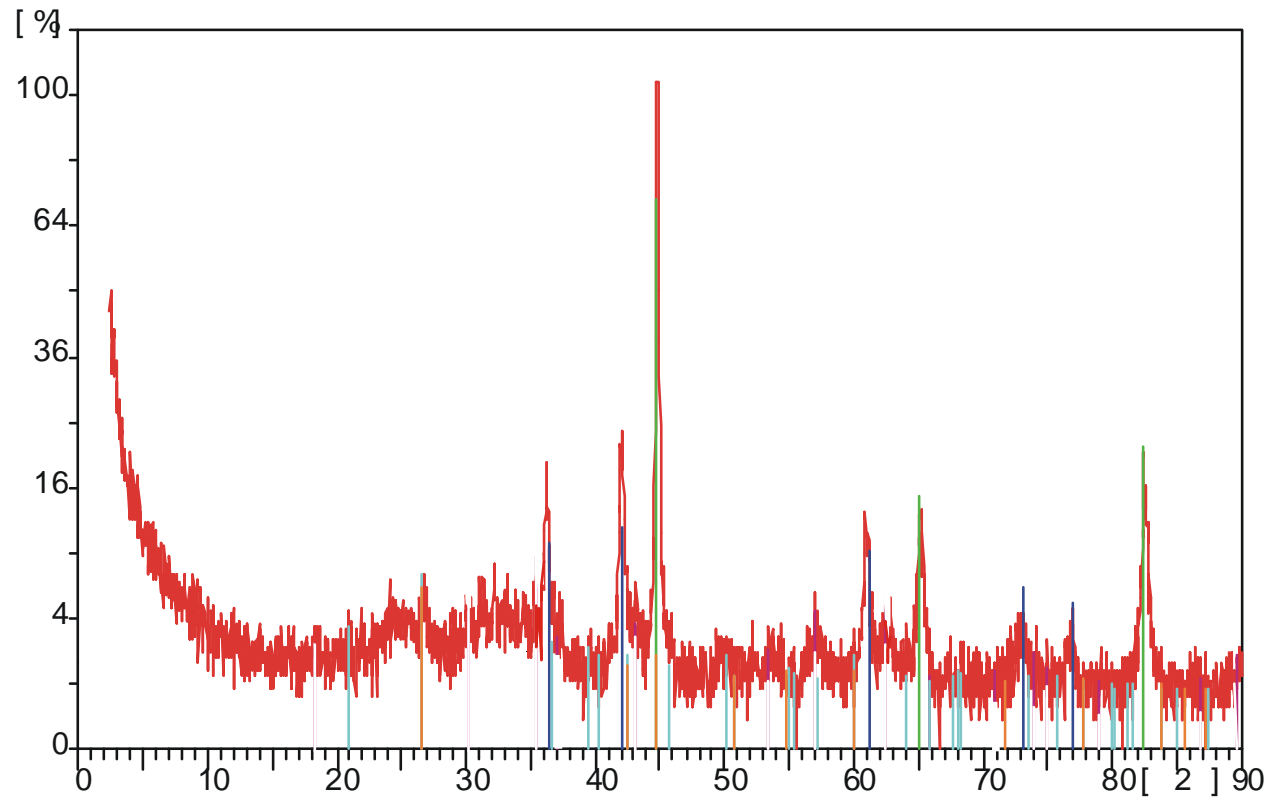

298- 1242

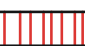

06- 0696

46- 1312

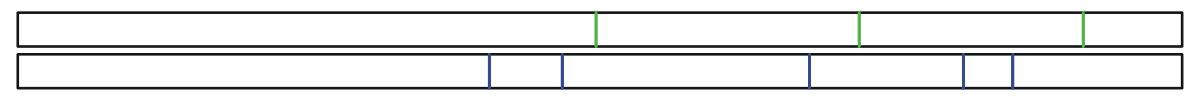

05- 0490

25- 0284

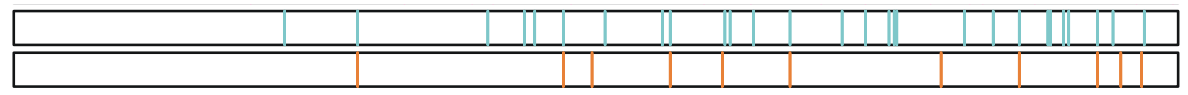

Figura 48: Difratograma de raios- $\mathrm{X}$ de uma pelota $\mathrm{E}$ (carvão vegetal; $\mathrm{C} / \mathrm{O}=1,0$; com cimento) ensaiada em forno de microondas por $30 \mathrm{~min} ., 90 \%$ de redução. 
Page: $1 / 1$

DI file: $X: \backslash P M T \backslash 298-1243 . D I$

Sample identification: 3

Score Rel. I Disp Card Name Formula

Score $[\%][\mu \mathrm{m}]$

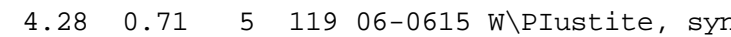

$2.980 .9969 \quad 7306-0696$ Iron, syn

$4.270 .39414425-0284$ Graphite, syn

FeO

$\mathrm{Fe}$

Esc=Quit $F 3=$ Reject $F 6=$ Sort $F 8=$ Graphics $F 9=$ Report $F 10=$ Help Shift/F2=More... Shift/F4=Insert

Sample ident.: 3

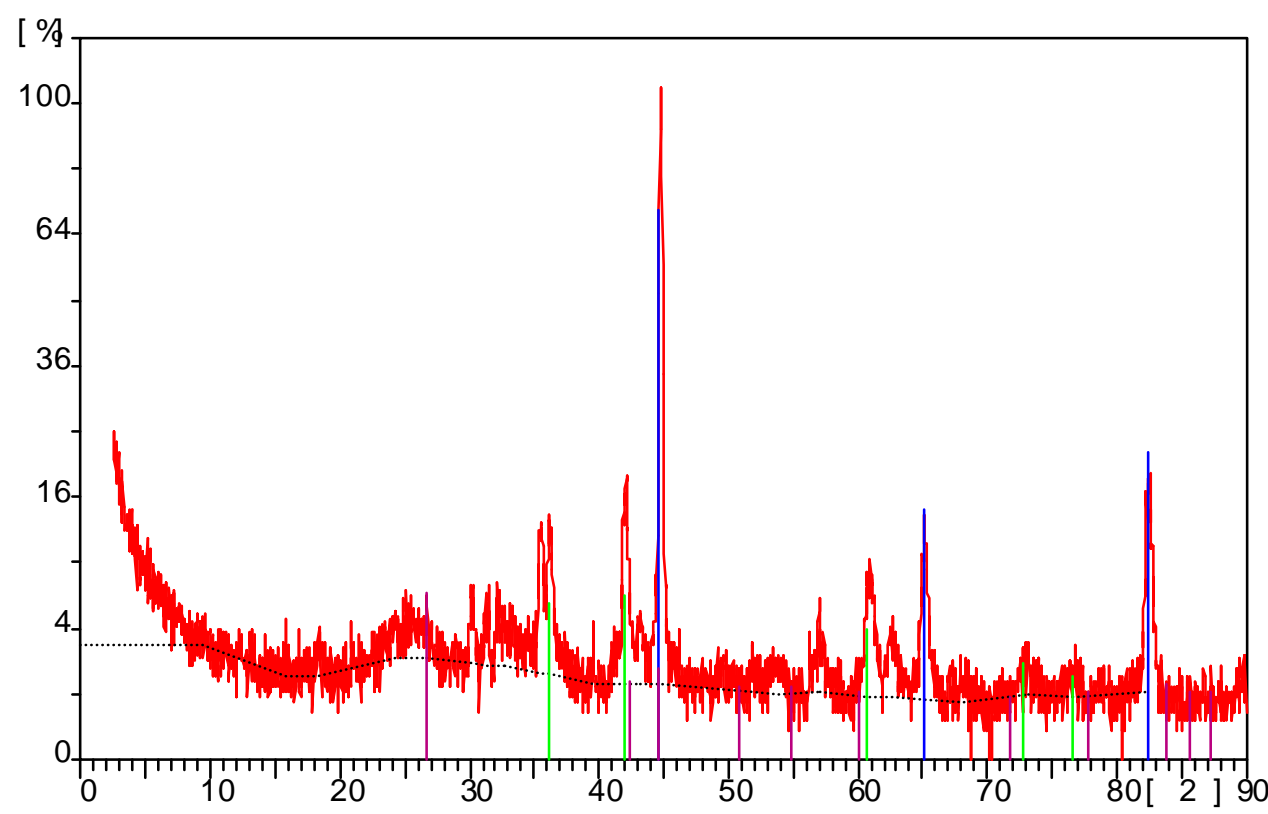

298- 1243

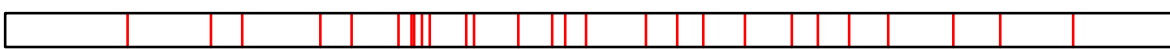

06- 0615

06- 0696

25- 0284

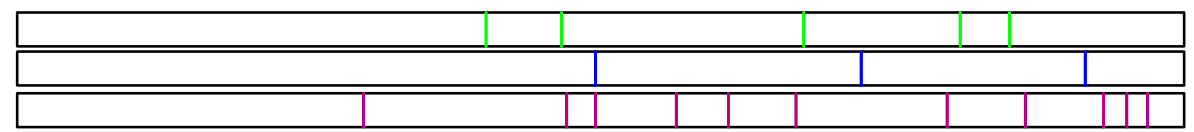

Figura 49: Difratograma de raios-X de uma pelota $\mathrm{E}$ (carvão vegetal; $\mathrm{C} / \mathrm{O}=1,0 ;$ com cimento) ensaiada em forno de resistência a $1150{ }^{\circ} \mathrm{C}$. 


\subsection{Comparações dos Resultados}

Nesta seção do trabalho serão mostradas as comparações dos resultados obtidos nas experiências termogravimétricas, para todas as composições de pelotas auto-redutoras estudadas, com o forno de resistência e com o forno de microondas. Será apresentado então, em um mesmo gráfico, as curvas obtidas para a redução do minério de ferro sendo processada a $950{ }^{\circ} \mathrm{C}$ e $1150{ }^{\circ} \mathrm{C}$, em forno convencional de resistência elétrica, e a curva correspondente onde se utilizou a energia de microondas. Isto para todos os tipos de pelotas autoredutoras fabricadas, segundo a tabela 10. Lembrando que para os ensaios termogravimétricos em forno de resistência, a amostra era levada diretamente na temperatura já estabelecida previamente.

Percebe-se através dos gráficos comparativos apresentados a seguir (figuras 50 a 58) que os resultados obtidos em que se utilizou a energia de microondas, se encontram sempre em valores intermediários, ou seja, porcentagens de redução inferiores aos obtidos a $1150{ }^{\circ} \mathrm{C}$ e superiores aos encontrados a $950{ }^{\circ} \mathrm{C}$.

Também será mostrado nesta seção, na figura 59, um gráfico que compara os resultados termogravimétricos, em forno de microondas, para todas as composições de pelota auto-redutoras: de "A" a "F". 


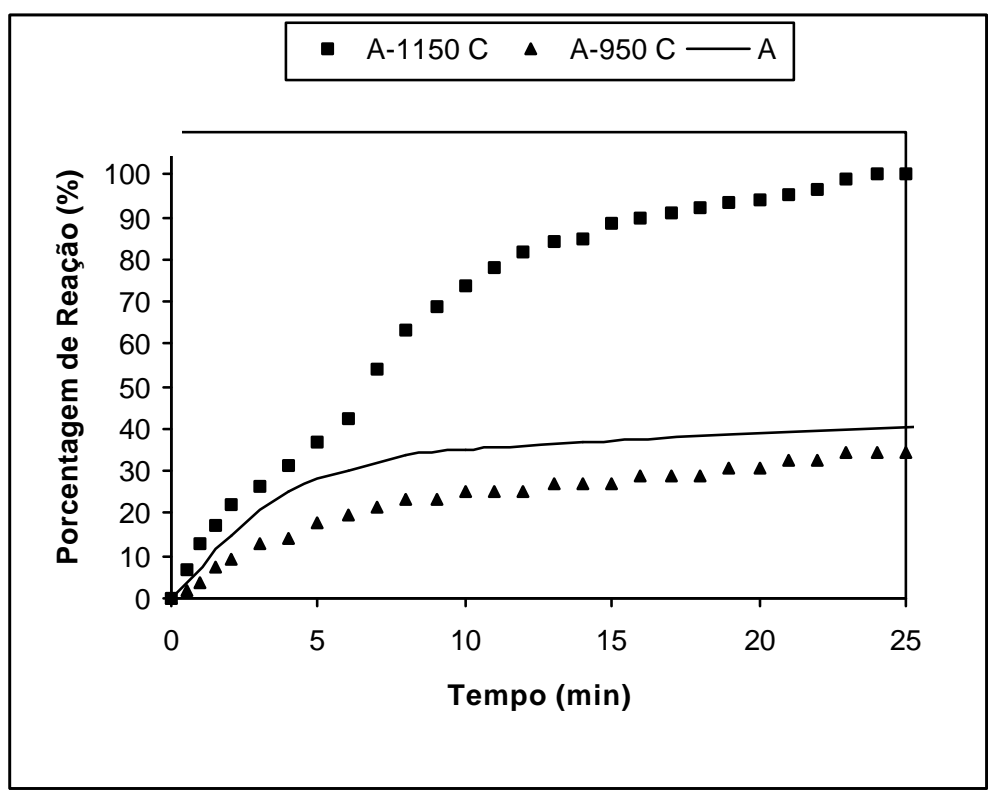

Figura 50: Ensaios termogravimétricos, porcentagem de reação $\mathrm{X}$ tempo (min), da pelota tipo A (coque; $\mathrm{C} / \mathrm{O}=1,0$; sem cimento), realizado em forno de resistência a $1150{ }^{\circ} \mathrm{C}, 950{ }^{\circ} \mathrm{C}$ e em forno de microondas.

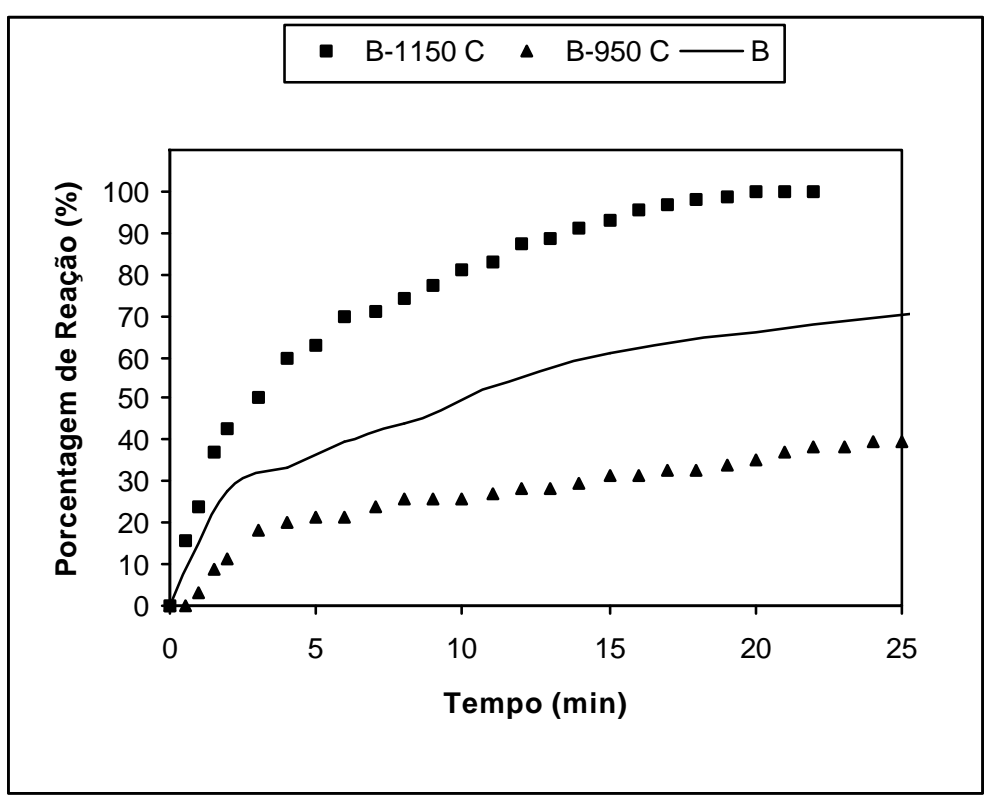

Figura 51: Ensaios termogravimétricos, porcentagem de reação $\mathrm{X}$ tempo ( $\mathrm{min}$ ), da pelota tipo $\mathrm{B}$ (coque; $\mathrm{C} / \mathrm{O}=1,0$; com cimento), realizado em forno de resistência a $1150{ }^{\circ} \mathrm{C}, 950{ }^{\circ} \mathrm{C}$ e em forno de microondas. 


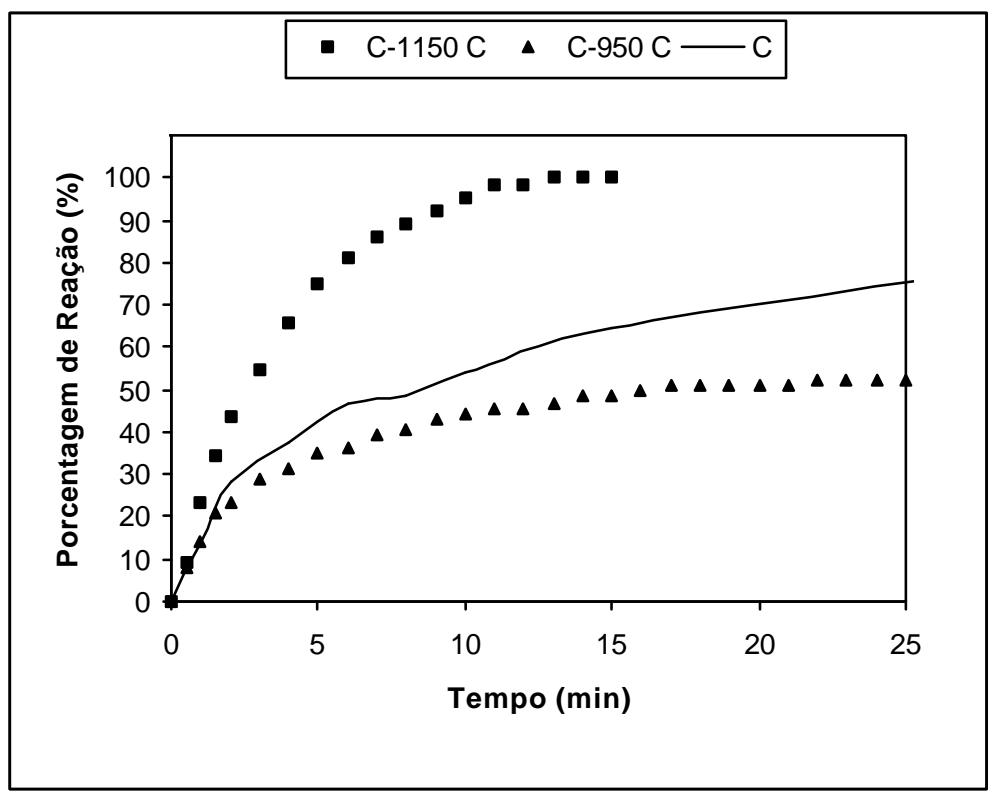

Figura 52: Ensaios termogravimétricos, porcentagem de reação $\mathrm{X}$ tempo ( $\mathrm{min}$ ), da pelota tipo $\mathrm{C}$ (coque; $\mathrm{C} / \mathrm{O}=1,33$; com cimento), realizado em forno de resistência a $1150{ }^{\circ} \mathrm{C}, 950{ }^{\circ} \mathrm{C}$ e em forno de microondas.

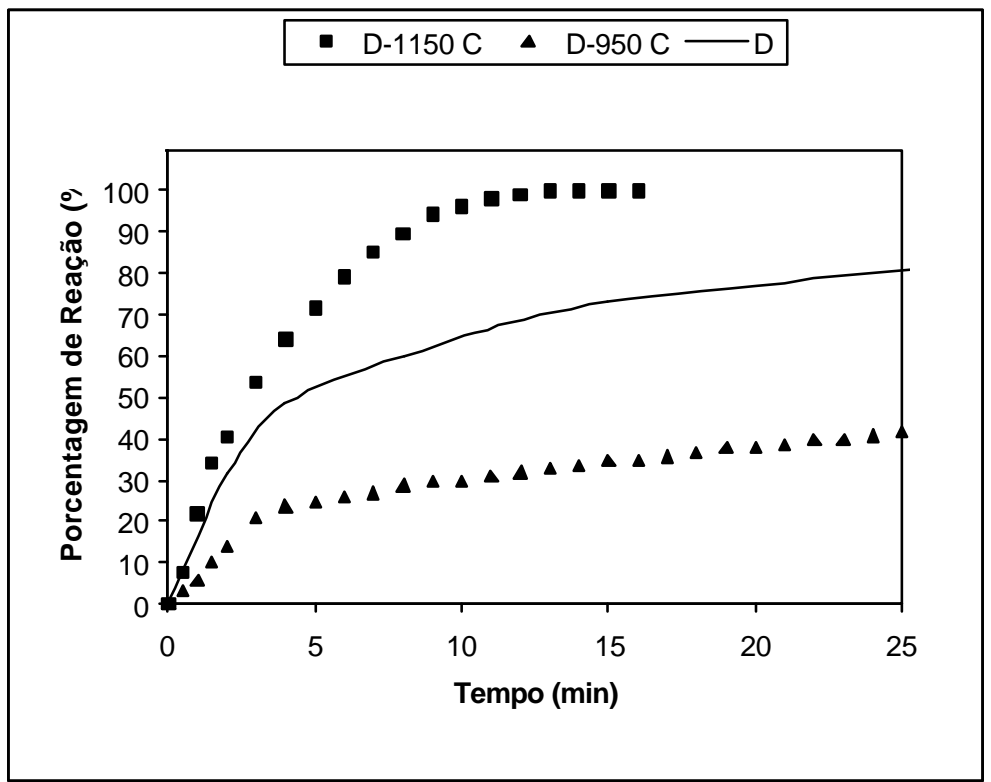

Figura 53: Ensaios termogravimétricos, porcentagem de reação $\mathrm{X}$ tempo ( $m i n$ ), da pelota tipo $\mathrm{D}$ (coque grosso; $\mathrm{C} / \mathrm{O}=1,0$; sem cimento), realizado em forno de resistência a $1150{ }^{\circ} \mathrm{C}, 950{ }^{\circ} \mathrm{C}$ e em forno de microondas. 


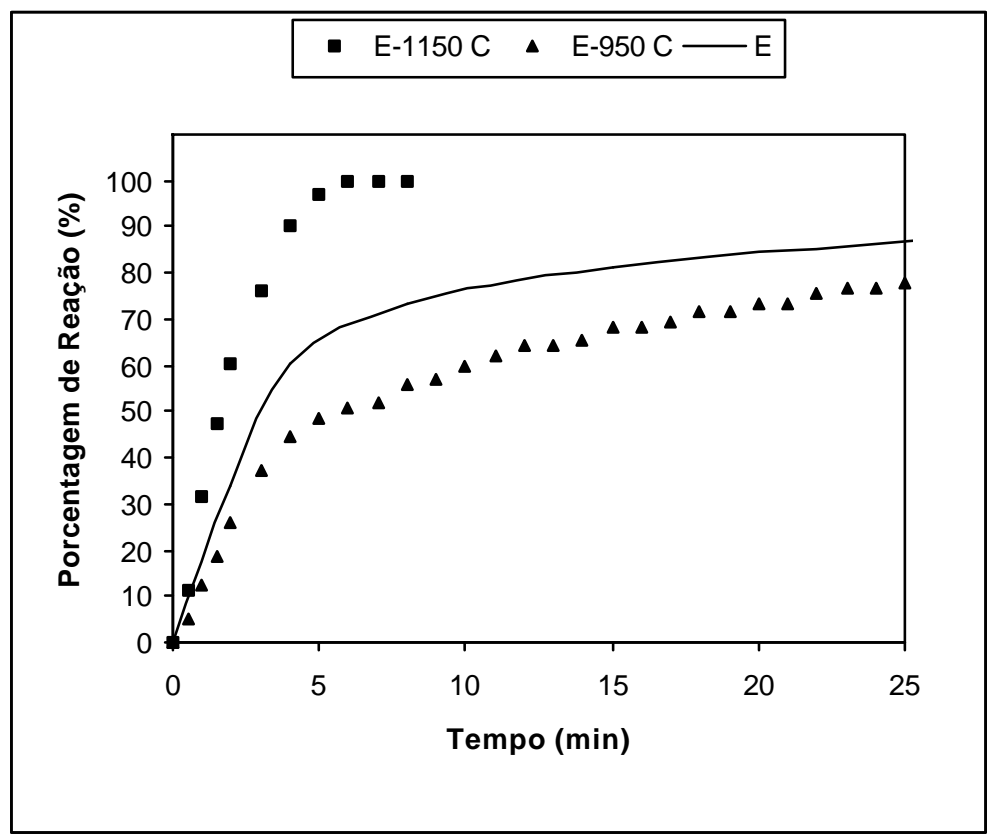

Figura 54: Ensaios termogravimétricos, porcentagem de reação $X$ tempo (min), da pelota tipo $\mathrm{E}$ (carvão vegetal; $\mathrm{C} / \mathrm{O}=1,0$; com cimento), realizado em forno de resistência a $1150{ }^{\circ} \mathrm{C}, 950{ }^{\circ} \mathrm{C}$ e em forno de microondas.

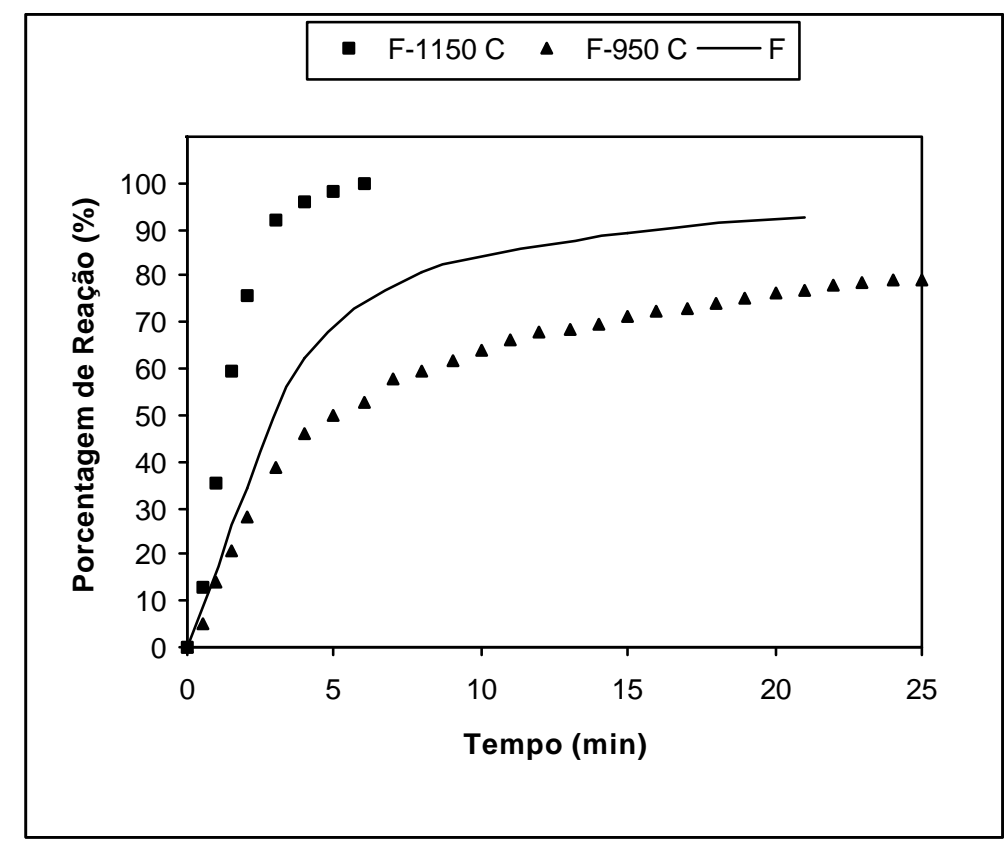

Figura 55: Ensaios termogravimétricos, porcentagem de reação $X$ tempo(min), da pelota tipo $\mathrm{F}$ (carvão vegetal; $\mathrm{C} / \mathrm{O}=1,33$; com cimento), realizado em forno de resistência a $1150{ }^{\circ} \mathrm{C}, 950{ }^{\circ} \mathrm{C}$ e em forno de microondas . 


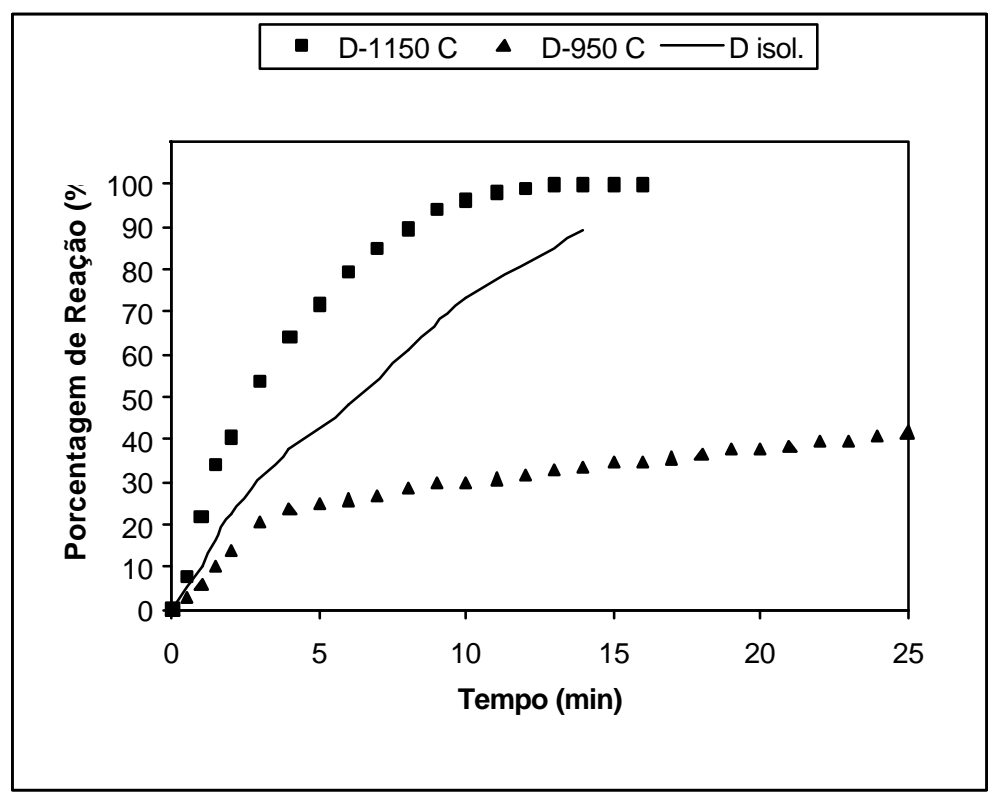

Figura 56: Ensaios termogravimétricos, porcentagem de reação $X$ tempo(min), da pelota tipo $\mathrm{D}$ isolada termicamente (coque grosso; $\mathrm{C} / \mathrm{O}=1,33$; com cimento), realizado em forno de resistência a $1150{ }^{\circ} \mathrm{C}, 950{ }^{\circ} \mathrm{C}$ e em forno de microondas.

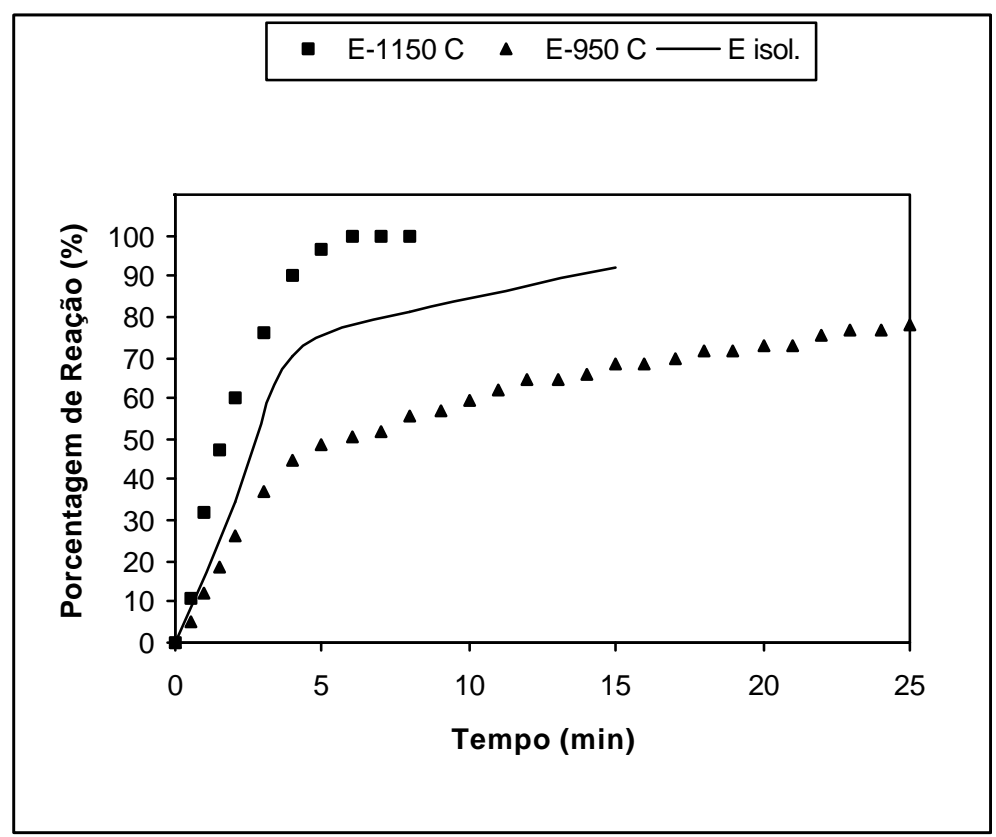

Figura 57: Ensaios termogravimétricos, porcentagem de reação $\mathrm{X}$ tempo(min), da pelota tipo $\mathrm{E}$ isolada termicamente (carvão vegetal; $\mathrm{C} / \mathrm{O}=1,0$; com cimento), realizado em forno de resistência a $1150{ }^{\circ} \mathrm{C}, 950{ }^{\circ} \mathrm{C}$ e em forno de microondas. 


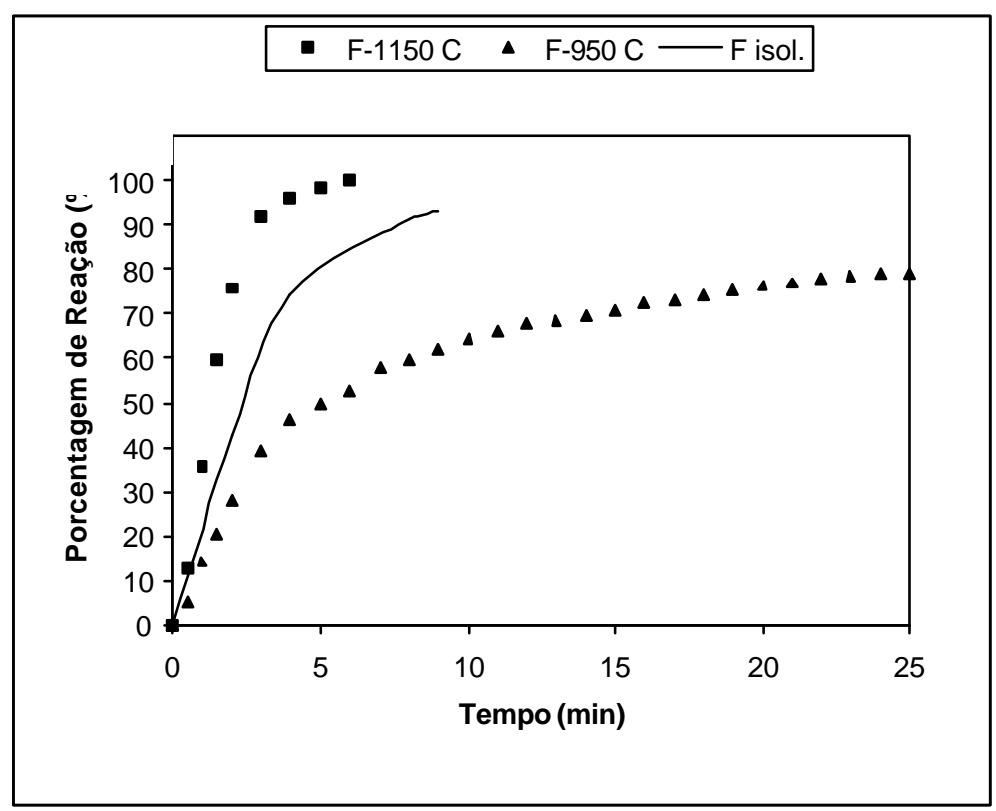

Figura 58: Ensaios termogravimétricos, porcentagem de reação $\mathrm{X}$ tempo(min), da pelota tipo $\mathrm{F}$ isolada termicamente (carvão vegetal; $\mathrm{C} / \mathrm{O}=1,33$; com cimento), realizado em forno de resistência a $1150{ }^{\circ} \mathrm{C}, 950{ }^{\circ} \mathrm{C}$ e em forno de microondas.

Observando os gráficos das figuras 50 e 51 que comparam os resultados termogravimétricos das pelotas A e B respectivamente, lembrando que a diferença entre essas pelotas está na presença de 6,5\% de cimento Portland ARI como aglomerante na pelota B. Percebe-se a influência da adição do cimento nos ensaios em forno de microondas e em forno de resistência. A $1150{ }^{\circ} \mathrm{C}$ a presença do cimento aumentou a velocidade de redução e comparando os resultados dos ensaios a $950{ }^{\circ} \mathrm{C}$ e em forno de microondas observa-se que o aumento na porcentagem de reação, após 25 minutos de experiência, foi mais pronunciado quando se utilizou a energia de microondas, indo de $40 \%$ a $71 \%$ de redução, ao passo que a $950{ }^{\circ} \mathrm{C}$, o aumento no grau de redução foi de $34 \%$ para $40 \%$; mostrando que a presença do cimento influencia mais quando se utiliza a energia de microondas na redução do minério de ferro. 
Analisando agora as figuras 51 e 52, das pelotas B e C, onde a diferença na composição dessas pelotas corresponde à maior quantidade de agente redutor - moinha de coque - para a pelota $C$. Verifica-se que o aumento na quantidade de coque foi mais favorável nos ensaios a $1150{ }^{\circ} \mathrm{C}$, atingindo-se o término da reação após 15 minutos, contra os 23 minutos para o caso da pelota $\mathrm{B}$. Houve também melhoras nas porcentagens finais de redução nos ensaios em forno de microondas e a $950{ }^{\circ} \mathrm{C}$ quando se aumentou a quantidade de coque.

Comparando-se as figuras 52 e 53, analisa-se a influência da granulometria do agente redutor - moinha de coque, pois as composições das pelotas $\mathrm{C}$ e D são as mesmas, mas a granulometria do coque na pelota $\mathrm{D}$ é maior. Os resultados mostram que o aumento do tamanho da partícula de carbono melhora o grau de redução, após 25 minutos de experiência, quando se emprega a energia de microondas: de $77 \%$ para $80 \%$ (seção 4.1.3), mas para os ensaios em forno de resistência ocorre o contrário, tanto a $950{ }^{\circ} \mathrm{C}$ como para $1150{ }^{\circ} \mathrm{C}$.

Nas figuras 56, 57 e 58 tem-se os resultados das pelotas D, E e F respectivamente, sendo que nas experiências em forno de microondas as amostras estavam isoladas termicamente por meio de uma manta isolante. Percebe-se um comportamento linear para essas pelotas isoladas e com valores de porcentagem de redução próximos aos encontrados a $1150{ }^{\circ} \mathrm{C}$ em forno de resistência. Para a pelota E que apresenta carvão vegetal como agente redutor, observa-se um comportamento linear até, aproximadamente, $70 \%$ de redução e a partir desse ponto uma queda na taxa de redução. Tal fato pode ser explicado, pela menor quantidade de carbono fixo do carvão vegetal em relação aos 
resultados da figura 55 (pelota $\mathrm{D}$ com moinha de coque). Isso fica evidente analisando o comportamento da pelota $\mathrm{F}$ isolada termicamente ,figura 58, que apresenta maior quantidade de carvão vegetal em relação à pelota $\mathrm{E}(\mathrm{C} / \mathrm{O}=1,0 \mathrm{e}$ $\mathrm{C} / \mathrm{O}=1,33$, respectivamente). Para esta pelota $\mathrm{F}_{\text {isol. }}$ a queda na taxa de redução, a partir de $70 \%$, não foi tão pronunciada quando comparada à pelota tipo $\mathrm{E}_{\text {isol. }}$

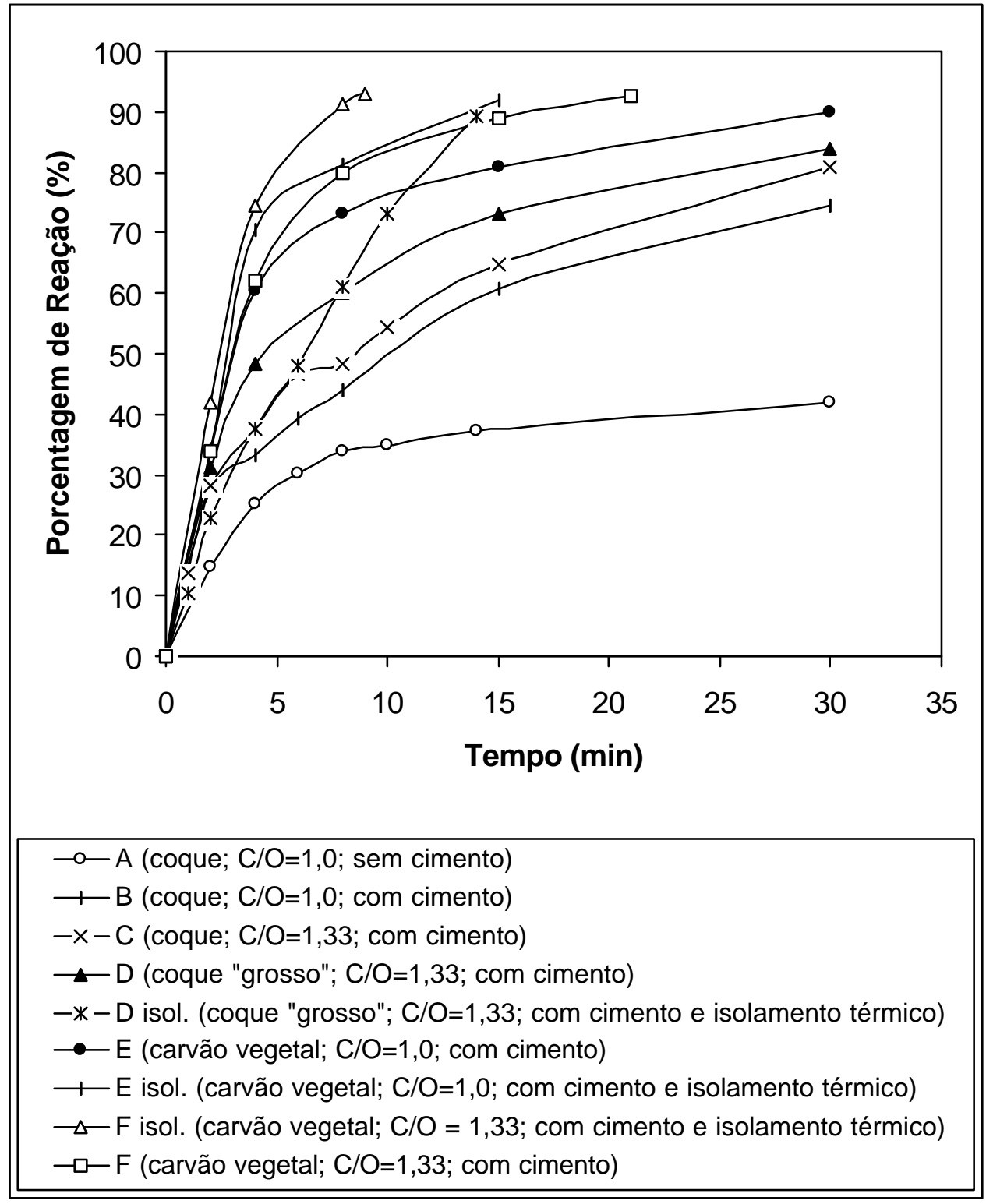

Figura 59: Ensaios termogravimétricos, porcentagem de reação $\mathrm{X}$ tempo(min), de todas as composições de pelota (segundo tabela 10), em forno de microondas. 


\subsection{Pré-tratamento do Minério de Ferro por Irradiação de Microondas.}

O minério de ferro hematítico, tipo Cauê, foi submetido à irradiação de microondas para posteriormente ser levado ao reator, misturado ao agente redutor - moinha de coque, num ensaio termogravimétrico. Duas experiências de termogravimetria foram efetuadas, uma com o minério de ferro sendo irradiado com microondas e outra sem irradiação, para assim analisar a influência da exposição do minério à microondas no processo de redução carbotérmica do minério de ferro ; semelhante ao trabalho de Standish e Pramusanto ${ }^{\mathbf{1 0}}$.

A composição da mistura foi a mesma da pelota tipo A ( $81,6 \%$ de minério de ferro e $18,4 \%$ de moinha de coque) sem cimento e com relação $\mathrm{C} / \mathrm{O}=$ 1,0. Nestes ensaios não se procedeu a pelotização, as misturas foram levadas a um cadinho (ligado por meio de fios a uma balança digital) que era colocado no interior de um forno de resistência a uma temperatura de $1000{ }^{\circ} \mathrm{C}$, e com fluxo de argônio. Portanto os ensaios foram isotérmicos para a mistura sem e com tratamento prévio. Esse tratamento prévio efetuado no minério de ferro foi realizado num forno de microondas $(2,45 \mathrm{GHz}-1100 \mathrm{~W})$ com tempo de exposição de 5 minutos. Posteriormente o minério era misturado com o coque e processava-se o ensaio termogravimétrico em forno de resistência. Na figura 60 tem-se os resultados desses ensaios: 


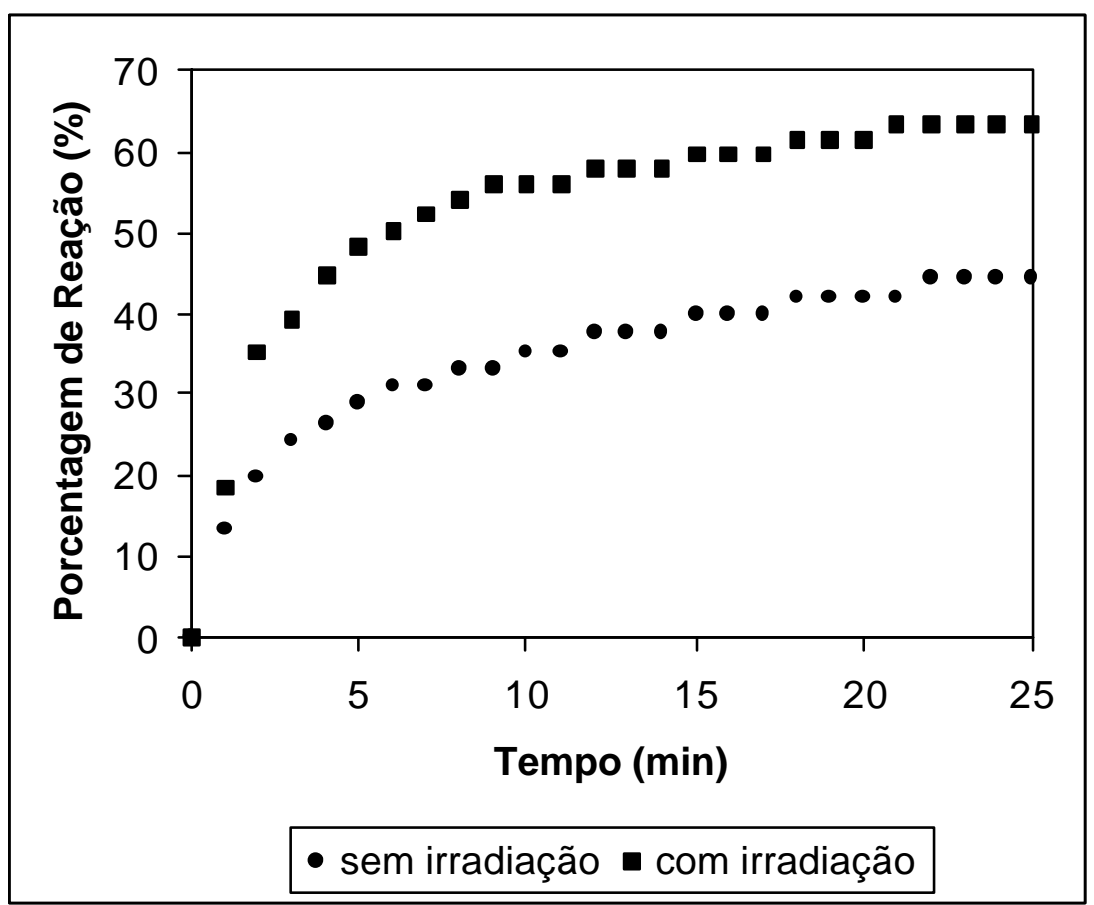

Figura 60: Ensaios termogravimétricos da mistura tipo A (coque; $\mathrm{C} / \mathrm{O}=1,0$; sem cimento) em forno de resistência $\left(1000{ }^{\circ} \mathrm{C}\right)$ na situação de pré-tratamento do minério de ferro por exposição à microondas e sem tratamento do minério.

Percebe-se, primeiramente que os resultados obtidos para a condição sem irradiação são semelhantes aos encontrados na figura 14 (seção 4.1) em que o grau máximo de redução (nos dois casos) foi de aproximadamente $44 \%$, mostrando a uniformidade dos resultados. A figura 60 mostra que as maiores porcentagens de redução foram obtidas na situação onde o pré-tratamento do minério de ferro foi efetuado (grau máximo de redução de 63\%), esse fato está de acordo com os resultados obtidos por Standish e Pramusanto ${ }^{\mathbf{1 0}}$, onde os autores dizem que essa melhora na redução ocorre devido à maior porosidade encontrada no minério de ferro exposto à microondas.

Outro estudo que utilizou a energia de microondas na forma de prétratamento de minério com sucesso, foi o trabalho de Fan ${ }^{36}$, et al, sendo que 
neste caso o objetivo era melhorar os resultados de flotação da ilmenita $\left(\mathrm{FeOTiO}_{2}\right)$, o que foi conseguido com aumento de $20 \%$ na recuperação da massa de ilmenita quando essa era tratada com exposição à microondas e as explicações que os autores colocam são mudanças na área específica da superfície do minério e observação de formação de novas fases.

Nesta experiência não foi analisado o porquê da melhoria na redução do minério de ferro quando esse era exposto anteriormente à irradiação de microondas, para se investigar tal fato deve-se proceder a mesma experiência com outras composições de mistura, além de outras variáveis metalúrgicas (como temperatura, tempo de exposição à microondas, granulometria do agente redutor, etc); tais procedimentos devem ser analisados em trabalhos futuros . 


\section{Conclusões}

1. A redução do minério de ferro hematítico por carbono na forma de pelotas auto-redutoras pode ser efetuada com a utilização da energia de microondas, 1100W - $2450 \mathrm{MHz}$, em atmosfera de gás argônio.

2. Nas experiências de redução em forno de microondas observou-se que todas as amostras sofreram o fenômeno de trincamento devido à liberação dos gases de reação no interior da pelota. A etapa de pelotização pode então ser eliminada em trabalhos futuros, neste estudo entretanto a pelotização se fez necessária para se poder comparar os resultados com as experiências em forno de resistência.

3. As variáveis de processo estudadas: presença de aglomerante, a quantidade, granulometria e tipo de agente redutor, o isolamento térmico da amostra; se mostraram de grande influência na cinética de redução do minério de ferro, e essa influência foi mais acentuada quando se utilizou a irradiação por microondas, comparada aos ensaios em forno de resistência.

4. Com relação à presença do aglomerante - cimento Portland ARI - foi verificado que sua presença favorecia a cinética de redução do minério de ferro e essa influência era mais pronunciada quando se empregava a energia de microondas.

5. Quando se variava a quantidade de agente redutor, moinha de coque e carvão vegetal, foi observado que seu aumento proporcionava melhores resultados de 
termogravimetria para os dois tipos de redutor, sendo mais marcante na situação onde se utilizou moinha de coque em forno de resistência à $950{ }^{\circ} \mathrm{C}$.

6. O parâmetro - granulometria do agente redutor moinha de coque - apresentou um comportamento diferente nos ensaios termogravimétricos em forno de resistência e forno de microondas: em forno de resistência o aumento do tamanho de partícula do coque diminuiu as porcentagens de redução do minério de ferro, entretanto, para forno de microondas, ocorreu exatamente o contrário.

7. Com relação à influência do tipo de agente redutor (moinha de coque ou carvão vegetal), observa-se que a cinética de redução do minério de ferro é favorecida quando se utiliza o carvão vegetal e isso ocorreu para os dois tipos de fornos empregados.

8. Nas experiências termogravimétricas em forno de microondas, investigou-se a influência de um isolamento térmico da amostra no grau de redução da mesma. Foi verificado, para todas as composições de pelotas estudadas, que o isolamento térmico melhorava as porcentagens de redução.

9. Foi observado, nas experiências termogravimétricas em forno de microondas, a ocorrência da abertura de arco elétrico no interior da pelota quando essa atingia, aproximadamente, 92 \% de redução, e quando tal fenômeno ocorria o ensaio era interrompido por medida de precaução.

10. Pela análise das curvas porcentagem de reação $X$ tempo, conclui-se que o grau de reação é diretamente proporcional à temperatura e essa observação é confirmada nos melhores resultados quando se utiliza o isolamento térmico. 
11. Os resultados dos ensaios termogravimétricos com o emprego da energia de microondas se adequaram a um modelo cinético do tipo parabólico de onde se obteve a constante cinética "k" $\left(\mathrm{min}^{-1}\right)$ utilizada para comparação dos resultados.

12. A análise microestrutural, por meio de um microscópico eletrônico de varredura (MEV), mostrou a formação da fase metálica do ferro de modo denso e facetado. Foi observado também o fenômeno de trincamento transgranular do minério de ferro em etapas intermediárias do processo de redução.

13. Comparando os melhores e piores resultados dos ensaios termogravimétricos em forno de microondas e forno de resistência, verifica-se que os piores valores, nos dois tipos de fornos, ocorreram para a pelota tipo A (coque, C/O $=1,0$, sem cimento), após 25 minutos de ensaio a porcentagem de redução atingiu 39\% para a amostra submetida à microondas, versus $32 \%$ para a amostra ensaiada em forno de resistência. Os melhores resultados foram obtidos para a pelota tipo $\mathrm{F}$ (carvão vegetal, $\mathrm{C} / \mathrm{O}=1,33$, com cimento), nos dois tipos de fornos, sendo que a experiência com microondas foi efetuada com isolamento térmico. Verifica-se que em forno de resistência o grau de redução atinge $100 \%$ após 7 minutos de ensaio a $1150{ }^{\circ} \mathrm{C}$ (isotérmico) e em forno de microondas, o grau de redução alcançou 93\% após 9 minutos com a temperatura atingindo $1152{ }^{\circ} \mathrm{C}$.

14. Foi verificado que um pré-tratamento do minério de ferro pela irradiação de microondas, para ser posteriormente reduzido por carbono em forno de resistência, melhorava os resultados de termogravimetria em até $19 \%$. 


\section{Referências Bibliográficas}

1. ZHONG, S; GOETZMAN, H.E. e BLEIFUSS, R.L. - Reduction of Iron Ore with Coal by Microwave Heating. Minerals and Metallurgical Processing, vol. $13, \mathrm{n}^{\circ} 4,1996$, pp. 174-178.

2. GHORESHY, M.; PICKLES, C.A. - Microwave Processing of Electric Arc Furnace Dust. Elect. Furn. Conf. Proc., 1994, pp. 187-196.

3. MOURÃO, M.B. - Análise do Processo de Redução de Minério de Ferro por Carbono na Forma de Pelotas Auto-redutoras. Tese Doutoramento EPUSP, São Pulo, 1988.

4. CONTRUCCI, M. A.; COSTA, P. H. C.; CAMARGO, L. M. A. et al. Produção de Ferro Gusa pelo Processo Tecnored. Metalurgia e Materiais ABM, vol. 49, n 417, 1993, pp. 360 - 368.

5. TAKANO, C. - Aspectos Fundamentais e Tecnológicos dos Efeitos dos Aglomerantes na Cura de Pelotas Auto-Redutoras. Tese de Livre Docência EPUSP, São Paulo, 1997.

6. SUTTON, W. H. - Microwave Processing of Ceramics - An Overview. Mat. Res. Soc. Symp. Proc., vol. 269, 1992, pp. 3-20, Materials Research Society.

7. Industrial Microwave Processing, Microdry Corp, 1987.

8. SENISE, J.T. - Escola de Engenharia Mauá, Comunicação Pessoal, 1998.

9. RAMBO,C.R. - Obtenção de Sílica e Carbeto de Silício a partir da Exposição de Palha de Arroz a Microondas e a Campos Eletromagnéticos na Faixa de R.F. Dissertação de Mestrado, IPEN, São Paulo, 1997.

10. STANDISH, N. e PRAMUSANTO - Reduction of Microwave Irradiated Iron Ore Particles in CO. ISIJ International, vol. 31, $n^{0}$ 1, 1991, pp. 11-16.

11. BALDWIN, B.G. - The Mechanism of the Reduction of Iron Oxide by Solid Coke. Jornal of Iron and Steel Institute, London, jan. 1955, pp. 30-36.

12. BOGDANDY, L. VON ; ENGELL, H.J. - The Reduction of Iron Ores. Berlin, Springer-Verlag, 1971. 
13. TRUSHENSKI, S. P.; Li, K. e PHILBROOK, W. O. - Non-topochemical reduction of iron oxides. Metallurgical Transactions, vol.5, pp. 1149-58, May 1974.

14. RAO, Y.K. - The kinetics of reduction of hematite by carbon, Metallurgical Transactions, 2, pp. 1439-1447, 1971.

15. FRUEHAN, R. J. - The rate of reduction of iron oxides by carbon, Metallurgical Transactions B, 8, pp. 279-286, 1977.

16. SRINIVASAN, N. S. e LAHIRI, A. K. - Studies on the reduction of hematite by carbon. Metallurgical Transactions B, vol. 8B, pp. 175178, Mar. 1977.

17. AJERSCH, F. - Chemical and physical characteristics affecting the reduction kinetics of iron oxide pellets with solid carbon. Canadian Metallurgical Quarterly, vol.26, nº 2, pp.137-144, 1987.

18. NASCIMENTO, R.C. - Uma Análise Microestrutural sobre Pelotas AutoRedutoras. Tese Doutoramento - EPUSP, São Paulo, 1994.

19. GHOSH, P. C. e TIWARI, S. N. Reduction of pellets of iron ore plus lignite coke. Journal of Iron and Steel Institute, vol. 208, nº 3, pp.255-257, Mar. 1970 .

20. MATTAR, C.H., TAKANO,C. e MOURÃO, M.B. - Cinética da Redução Não- Isotérmica de Minério de Ferro por Carbono. In. XXVIII Seminário de Redução de Minérios de Ferro-ABM. Vitória 1-3/12/97.

21. JAROSLAV S. - Microondas. São Paulo, Livros Ética Editora Ltda, 1987.

22. PERRY, R.H. e CHILTON, C.H. Manual de Engenharia Química. 5ª ed., Editora Guanabara,Cap.9, pp. 9.1-9.48, 1980.

23. SUTTON,W.H. - Microwave Processing of Ceramic Materials. Ceramic Bulletin, vol. 68, $\mathrm{n}^{\mathrm{o}}$ 2, pp. 376-386, 1989.

24. CLARK, D.E. e SUTTON, W.H. - Microwave Processing of Materials. Annu. Rev. Mater. Sci, pp. 299-331, 1996.

25. SENISE, J.T., A Utilização de Microondas em Processo de Aquecimento na Indústria Cerâmica. Cerâmica, 35 (234), pp. 95-99, julho, 1989.

26. METAXAS, C. e MEREDITH, R. J. - Industrial Microwave Heating. Peter Peregrinus, London, 357p., 1983. 
27. KOCAKUSAK,S. ; KÖROGLU,H.J. ; EKINCI,E. e TOLUN,R. - Boron Oxide Production by Microwave Heating. The Minerals, Metals \& Materials Society, pp. 455-465, 1994.

28. MORITA, K. e SANO, N. - New Iron and Steelmaking Process for Environmental Protection - New Roles of Steelmaking Slags, Global Symposium on Recycling, Waste Treatment and Clean Technology, vol. II , Rewas 1999.

29. HASSINE, N. A; BINNER, J.G.P. e CROSS,T.E. - Synthesis of Refractory Metal Carbide Powders via Microwave Carbothermal Reduction. Int. J. of Refractory Metals \& Hard Materials, vol. 13, pp. 353-358, 1995.

30. SEATON, C. E.; FOSTER, J. J.; VELASCO, J. - Reduction Kinetics of Hematite and Magnetite Pellets Containing Coal Char. Transactions ISIJ, Tokyo, 23, pp. 490-496, 1983.

31. ABRAHAM, M. C.; GHOSH, A. - Kinetics of Reduction of Iron Oxide by Carbon . Ironmaking \& Steelmaking, London, 6(1): 14-23, 1979.

32. MOURÃO, M.B. e CAPOCCHI, J.D.T. - Rate of Reduction of Iron Oxide in Carbon - Bearing Pellets . Trans. Instn. Min. Metall. (105) ,pp. 190-196, Sep - Dec, 1996.

33. Von KRUGER, F. L. - A Redução da Umidade de Minério de Ferro com o Emprego de Microondas. Dissertação de Mestrado - EPUSP, São Paulo, 1997.

34. MARCHESE, E. S. - Resistência Mecânica a Frio e Crepitação em Pelotas Auto-Redutoras. Dissertação de Mestrado - EPUSP, São Paulo,1994.

35. LORENSON,C. P.; PATTERSON, M.C.; RISTO,G.; KIMBER,R. - The Effect of Particle Size on Microwave Heated Carbon and the Subsequent Crystallite Growth. Mat. Res. Soc. Symp. Proc.; vol. 269, pp 129-135, 1992

36. FAN, X.; KELLY, R.M. and ROWSON, N.A. - Effect of Microwave Radiation on Ilmenite Flotation. Canadian Metallurgical Quarterly, vol. 39, $\mathrm{n}^{\mathrm{o}}$ 3, pp 247-254, 2000. 